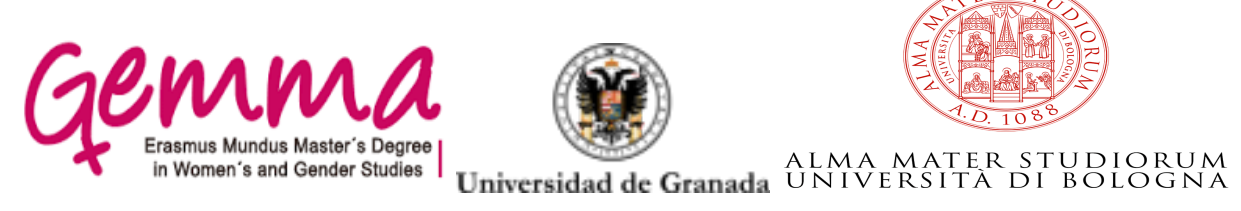

\title{
¿Construyendo libertades? Una aproximación etnográfica a los procesos de privación de libertad de las mujeres
}

\author{
TRABAJO FIN DE MASTER \\ 2015-2016
}

VALENZUELA VELA, LORENA

DIRECTORA: Alcázar Campos, Ana

Departamento de Trabajo Social y Servicios Sociales

Universidad de Granada

\author{
DIRECTORA DE APOYO: Franceschi, Zelda Alice \\ Dipartamento de Storia, Culture e Civiltà \\ Università di Bologna (Italia)
}









\section{Resumen}

$\mathrm{E}$ objetivo principal de este Trabajo Fin de Máster es conocer cuáles son las particularidades a las que hacen frente las mujeres que están en prisión, por el hecho de ser mujeres. Para explicarlo utilizo el símil metafórico de lo que podría ser el paso por prisión de cualquier mujer, compuesto por tres fases: antes, durante y después de la estancia en prisión. Un proceso complejo, cuyas fases se retroalimentan, pueden solaparse y modificarse continuamente.

Desde el enfoque del Trabajo Social, los Feminismos y las Teorías del Control y del Castigo, y la metodología etnográfica, reflexiva y evocadora, recupero y analizo información recogida, acontecimientos y encuentros vividos con mujeres privadas de libertad, desde mi primera vinculación al sistema penitenciario hasta el presente. Las investigaciones feministas en el sistema punitivo se tornan necesarias y urgentes pues las mujeres privadas de libertad tienen que hacer frente a una invisibilidad en el ámbito penitenciario que provoca que se planifique una política penal y penitenciaria desde la ausencia o negación (Aguilera, 2011). En un trabajo conjunto, desde las Teorías Feministas y el Trabajo Social tenemos que desarrollar referentes desde donde analizar, reflexionar y promover discusiones que repercutan en intervenciones más eficaces y integradoras de estas mujeres en el medio penitenciario.

\section{Riassunto}

L'obiettivo principale per cui ho deciso di sviluppare questa Tesi del Master è quello di mettere a conoscenza di tutti le situazioni particolari in cui si imbattono le donne in carcere, per il semplice fatto di essere donne. Perciò ho descritto l'esperienza in prigione delle detenute analizzandone la vita prima, durante, e dopo l'essere stata carcerate.

Basandomi sulle discipline dell'assistenza sociale, i Femminismi e le Teorie del Controllo e della Pena, sulla metodologia etnografica, riflessiva ed evocativa, ho recuperato ed analizzato, dall'inizio della mia esperienza fino ad oggi, informazioni e fatti, avvalendomi inoltre, per un ulteriore arricchimento del progetto, di incontri vissuti con donne prive della loro libertà. Da ciò ho dedotto che Le investigazioni femministe in ambito carcerario sono necessarie ed urgenti in quanto le donne private di libertà devono far fronte a una invisibilità in ambiente penitenziario provocata da una politica penale che non tiene in considerazione molte peculiarità proprie delle stesse.(Aguilera, 2011). In tutto ciò, il mio obiettivo, è quello di sviluppare un testo che possa fungere da punto di riferimento per la promozione di discussioni che portino ad interventi più efficaci ed integranti di queste donne all'interno delle prigioni. 


\section{El etnógrafo 1}

El caso me lo refirieron en Texas, pero había acontecido en otro estado.

Cuenta con un solo protagonista, salvo que en toda historia los protagonistas son miles, visibles e invisibles, vivos y muertos. Se llamaba, creo, Fred Murdock. Era alto a la manera americana, ni rubio ni moreno, de perfil de hacha, de muy pocas palabras. Nada singular había en él, ni siquiera esa fingida singularidad que es propia de los jóvenes. Naturalmente respetuoso, no descreía de los libros ni de quienes escriben los libros. Era suya esa edad en que el hombre no sabe aún quién es y está listo para entregarse a lo que le propone el azar: la mística del persa o el desconocido origen del húngaro, la aventuras de la guerra o del álgebra, el puritanismo o la orgía. En la universidad le aconsejaron el estudio de las lenguas indígenas. Hay ritos esotéricos que perduran en ciertas tribus del oeste; su profesor, un hombre entrado en años, le propuso que hiciera su habitación en una toldería, que observara los ritos y que descubriera el secreto que los brujos revelan al iniciado. A su vuelta, redactaría una tesis que las autoridades del instituto darían a la imprenta. Murdock aceptó con alacridad. Uno de sus mayores había muerto en las guerras de la frontera; esa antigua discordia de sus estirpes era un vínculo ahora. Previó, sin duda, las dificultades que lo aguardaban; tenía que lograr que los hombres rojos lo aceptaran como a uno de los suyos. Emprendió la larga aventura. Más de dos años habitó en la pradera, bajo toldos de cuero o a la intemperie. Se levantaba antes del alba, se acostaba al anochecer, llegó a soñar en un idioma que no era el de sus padres. Acostumbró su paladar a sabores ásperos, se cubrió con ropas extrañas, olvidó los amigos y la ciudad, llegó a pensar de una manera que su lógica rechazaba. Durante los primeros meses de aprendizaje tomaba notas sigilosas, que rompería después, acaso para no despertar la suspicacia de los otros, acaso porque ya no las precisaba. Al término de un plazo prefijado por ciertos ejercicios, de índole moral y de índole física, el sacerdote le ordenó que fuera recordando sus sueños y que se los confiara al clarear el día. Comprobó que en las noches de luna llena soñaba con bisontes. Confió estos sueños repetidos a su maestro; éste acabó por revelarle su doctrina secreta. Una mañana, sin haberse despedido de nadie, Murdock se fue.

En la ciudad, sintió la nostalgia de aquellas tardes iniciales de la pradera en que había sentido, hace tiempo, la nostalgia de la ciudad. Se encaminó al despacho del profesor y le dijo que sabía el secreto y que había resuelto no publicarlo.

-- ¿Lo ata su juramento? -- preguntó el otro.

-- No es ésa mi razón -- dijo Murdock --.En esas lejanías aprendí algo que no puedo decir.

-- ¿Acaso el idioma inglés es insuficiente? -- observaría el otro.

-- Nada de eso, señor. Ahora que poseo el secreto, podría enunciarlo de cien modos distintos y aun contradictorios. No sé muy bien cómo decirle que el secreto es precioso y que ahora la ciencia, nuestra ciencia, me parece una mera frivolidad.

Agregó al cabo de una pausa:

-- El secreto, por lo demás, no vale lo que valen los caminos que me condujeron a él. Esos caminos hay que andarlos.

El profesor le dijo con frialdad:

-- Comunicaré su decisión al Consejo. ¿Usted piensa vivir entre los indios?

Murdock le contestó:

-- No. Tal vez no vuelva a la pradera. Lo que me enseñaron sus hombres vale para cualquier lugar y para cualquier circunstancia.

Tal fue, en esencia, el diálogo.

Fred se casó, se divorció y es ahora uno de los bibliotecarios de Yale.

${ }^{1}$ Borges, Jorge Luis. “El etnógrafo” en: Borges, Jorge Luis. Elogio de la sombra. (pp. 57-61) Buenos Aires/Barcelona: Emecé. 1969. 


\section{GRAZIE MILLE}

Per ogni giorno, ogni istante, ogni attimo che mi è stato dato...

A Bologna por todo lo que me has dado, por ser y significar tantas cosas a la vez, fuente de estrés, de aprendizaje, de felicidad, por alimentarme el alma con cada cornetto y cappuccino. Por contagiarme de tu vida y de tu color más rojo y reivindicativo. Por las historias en cada uno de tus pórticos y por tus siete secretos que resultaron ser más y mejor. Por esa ventana con margaritas que me regalabas en cada uno de mis trayectos a Vía Cartoleria. Por todas las personas que pusiste en mi camino.

A Ana por ser la única capaz de dejarme sin palabras en este punto, el gracias más sincero y la admiración más grande. Por los minutos, horas y momentos, que no vuelven, que me has dedicado. Por darme la oportunidad de embarcarnos juntas en lo que está por venir. Por iniciarme, enseñarme y cuidarme en este proceso, por tu capacidad de lucha y su contagio. Por creer en mi.

A Zelda, por su acompañamiento en este proceso.

A Mami y Ju, lo cotidiano también es político y este proyecto está impregnado de la fuerza que me esperaba todos los días al abrir la puerta de casa. Por enseñarme que hay que levantarse en cada tropiezo. Por regalarme Bologna, Copenhague, el Feminismo y el Trabajo Social. Por ser mis heroínas más grandes. A Papi, por tu huella, por estar siempre con nosotras. A mi abuelo y abuelas, por ser expertos en querer. A la artista más bonita de la familia, por hacerme la prima más orgullosa del mundo y el regalo más especial, la portada.

A las que habéis leído una y otra vez estas páginas durante su elaboración buscando de la manera más cariñosa los errores, Albi. A mis amigas, a mis Ts`s.

A todas las joyas que me ha dado el GEMMA, por ser mi tesoro feminista. Por las conversaciones, las recomendaciones y el ambiente de cuidado que hemos construido durante este proceso. Isa y Tere, gracias por todo lo que solo nuestros cuerpos saben que hemos vivido. Lau y Sheila, por ser y estar siempre de esa forma tan especial. Elena, Tan, Dresda, Clau.

Al grupo de investigación Otras. Perspectivas feministas por dejarme estar en vuestro espacio y compartir vuestros saberes, un regalo. Al GEMMA, por esta oportunidad, por llenar mi desconocimiento de tantos feminismos. Por enseñarme que las luchas contra el patriarcado solo pueden ser radicales.

A todas y todos las/los profesionales que me habéis atendido y dedicado vuestro tiempo, audios, e-mails... Antonio, Victoria, Betty, Juan, Clotilde, Virginia, y a todas con las que he mantenido alguna conversación.

A todas las mujeres que han querido compartir sus vidas y sus experiencias para crear este documento. Por ser fuente de inspiración y de lucha incansable, por cambiarme tanto. Por enseñarme que la libertad está en el interior de cada una y darme la opción de creer que el poder no empapa todos los rincones de una celda, y la esperanza siempre se abre espacio. Por mostrarme vuestros sueños, ilusiones y metas. Por regalarme la imagen de vuestros rostros mientras me enseñabais esa foto que tanto significa. Por hacerme reír tanto y tan fuerte. 


\section{Tabla de contenido}

Resumen

El etnógrafo

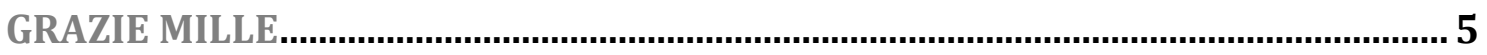

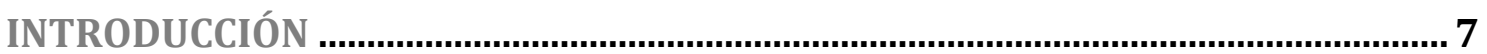

1. MARCO TEÓRICO .............................................................................................10

1.1. PODER - CONTROL - CASTIGO, ¿qué construye a qué? ......................................11

a) Del Estado del Bienestar al Estado Encarcelador: The Prisonfare .................................. 14

b) ¿Criminalización de una pobreza feminizada? ................................................................... 18

1.2. MUJERES, DESIGUALDADES Y PRISIÓN ….......................................................20

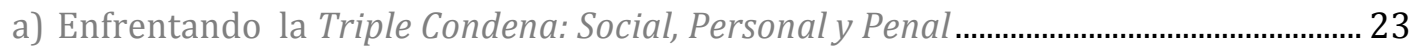

b) Exclusión Social, Estigma \& Poderío ……………….................................................................. 26

c) Reinserción, Resiliencia y Agencia ........................................................................................ 29

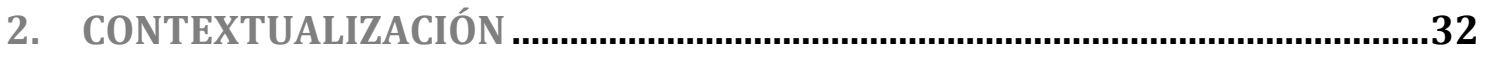

3. INGREDIENTES METODOLÓGICOS...............................................................39

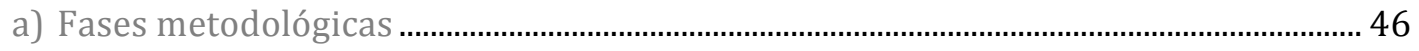

4. ATRAVESANDO LA PRISIÓN............................................................................49

4.1. El cuerpo del delito: "trazos de una indefinición necesaria" ............................52

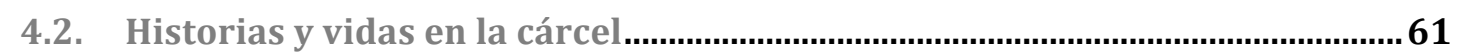

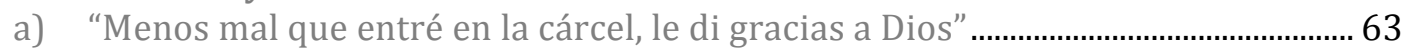

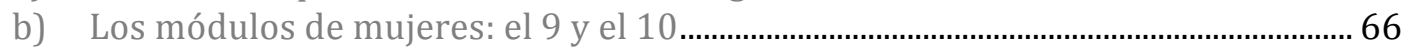

c) ¿Permisos y Beneficios Penitenciarios? …………......................................................... 73

d) Anestesiando los dolores: medicinas y drogas............................................................. 81

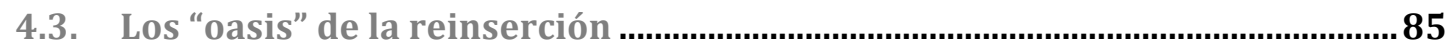

a) El acceso a través de las y los profesionales ................................................................. 87

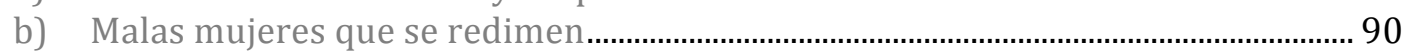

c) Donde lo colectivo está atravesado por el estigma.........................................................93

5. EL ENCIERRO NO SE PUEDE CERRAR Y OTRAS FORMAS DE CONCLUIR ....95

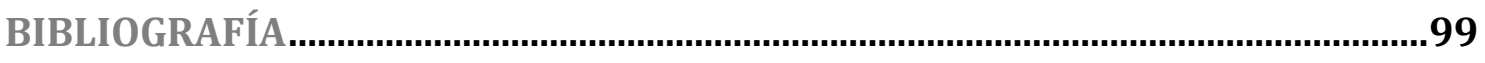

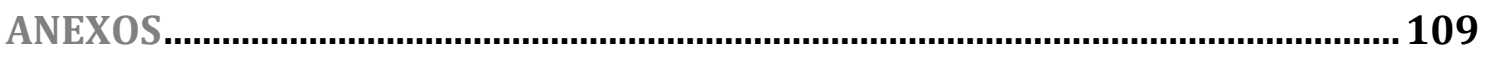





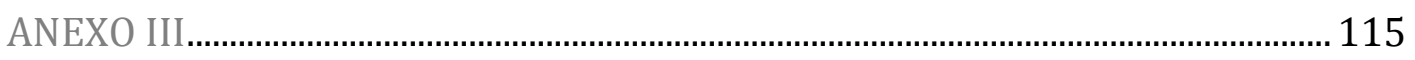




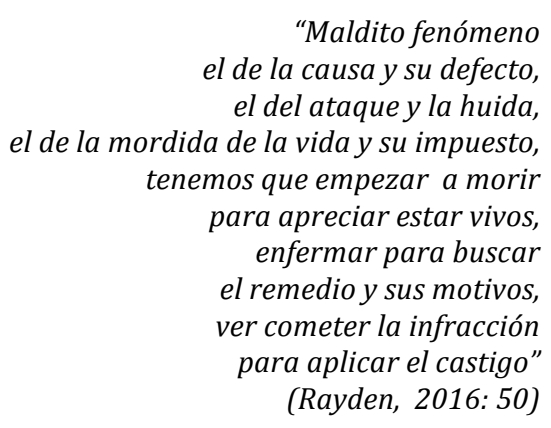

"Llaves que abran candados: los de los pesados cerrojos de las celdas y los de las adormecidas conciencias de esta sociedad de cerrazón cada vez más peligrosa y galopante"

(Segovia, 2005: 189)

Tras muchas modificaciones y variaciones en estas páginas recojo y desarrollo mi tema de investigación: aproximación al sistema penitenciario y reconocimiento de las particularidades a las que tienen que hacer frente las mujeres que están en prisión, por el hecho de serlo.

Este documento condensa todos los cambios que mis intereses de estudio han experimentado, inclusive durante el propio proceso de escritura. Las condiciones de la investigación y las mías propias y personales - creo que unas y otras son indivisibles y se construyen a la vez - impusieron unos ritmos diferentes a los imaginados y, definitivamente, me llevaron a dejar atrás algunos matices y aspectos de la realidad penitenciaria de las mujeres que me habían interesado desde los inicios, y que afortunadamente tendré la oportunidad de recuperar en mi tesis doctoral.

Privilegié, en un primer momento, la resiliencia y capacidad de agencia que desarrollan las mujeres que han pasado por prisión. Sin embargo, con el tiempo fui consciente de que había obviado un paso previo de análisis esencial y que, finalmente se impuso como objetivo de esta investigación: reconocer las particularidades y singularidades de género que tiene para estas mujeres el paso por la cárcel. No obstante, ha permanecido siempre mi creencia firme en su capacidad de lucha y resistencias diarias, privadas y cotidianas, a un poder al que también se resiste y se desplaza. Un enfoque que permite estudiar este poder no solo "en su efectividad y en su intención, sino en su desvarío, en su irritación y en sus deslices" (Parrini, 2007: 21). Hay un cambio en el ángulo de estudio, que 
desarrollaré en mi tesis doctoral, que consiste en reconocer aquellos aspectos del poder y el control que no solo que vigila y castiga, sino que "incita a deseos y ordena proyectos de vida. Una óptica que nos incita a buscarlo no solo en sus certezas y designios, también en sus grietas (Parrini, 2007: 21).

Dicen que "que hay historias que invitan a pensar sobre ellas e historias que invitan a pensar con ellas" (Poó, 2009: 3). Espero que estas historias de mujeres nos hagan pensar, compartir y comprender un poco más la realidad penitenciaria y la visión de "un mundo que se volvió invisible o al menos opaco para la mayoría de nosotros" (Fassin, 2016: 16).

Este proyecto es, en definitiva, una obra colectiva en la que hemos participado tantas personas como he conocido a lo largo de 6 años de vinculación con el sistema penitenciario. Siendo, claramente, las mujeres privadas de libertad sus protagonistas, ya que con su tiempo y confianza han contribuido a la elaboración del documento con cada uno de los relatos, experiencias e historias, que de todas las maneras posibles compartieron conmigo. Y es solo gracias a ellas que la cárcel y sus vidas inundan estas páginas, a pesar de que cuesta mucho pensar en las prisiones y en general en aquello que no forma parte de nuestra cotidianidad (Segovia, 2005).

Durante todo este tiempo - más allá del proyecto fin de master- han sucedido infinidad de cosas. Cuando nombro al tiempo lo hago situándome en 2010, con el nacimiento de mis intereses en el ámbito penitenciario, y en segundo lugar, en lo que es mi primera experiencia en prisiones en el año 2013 con las prácticas de Trabajo Social. Si tengo que elegir una palabra que recogiera las emociones, sensaciones y experiencias que han formado parte de todos estos años esta sería APRENDIZAJE, como proceso educativo, social, emocional, experiencial y existencial. Un aprendizaje que en los últimos tiempos ha derivado en su rama más radical. Entendiendo radical como aquello perteneciente o relativo a la raíz, es decir, preocupándome por el origen, la causa, la base o el soporte de la realidad penitenciaria de las mujeres.

Es por ello, que este Trabajo Fin de Master tiene como objetivo conocer cuáles son las particularidades a las que hacen frente las mujeres que están en 
prisión, por el hecho de ser mujeres. Para explicarlo utilizo el símil metafórico de lo que podría ser el paso por prisión de cualquier mujer, compuesto por tres fases: antes, durante y después de la estancia en prisión. Un proceso complejo, cuyas fases se retroalimentan, pueden solaparse y modificarse continuamente.

La etnografía y la autoetnografía han sido las herramientas metodológicas principales. En ellas he encontrado el poder y la energía, que reconoce la antropóloga Ruth Behar, para “crear vínculos entre desconocidos, para sanar las heridas, para cruzar las fronteras, para transformar el desespero en esperanza, para encantar al desencantado" (Behar, 2009: 34). He optado por una metodología cualitativa que me permitiera posicionarme más allá de los datos estadísticos, conocer y comprender, en mayor medida, a las mujeres presas: "las estadísticas y los perfiles sirven para aproximarnos a sus rasgos principales, pero no bastan para entender su realidad ni sus sentidos" (Almeda 2003: 65). Se trata de que tomen la palabra, nos cuenten sus historias, sus experiencias y sus reflexiones, es decir, situarlas como punto de partida y centro del trabajo. No podemos olvidar que las mujeres desarrollamos matrices específicas de creencias sobre nosotras mismas, sobre nuestro poder y sobre la legitimidad del orden patriarcal, por lo tanto: "para poder comprender la criminalidad femenina es importante ver cómo se definen las mujeres a sí mismas, cómo definen sus situaciones y cómo experimentan cada una, subjetivamente, la opresión" (Romero, 2003: 34).

Ejercicio de investigación sobre sistema punitivo español desde la perspectiva feminista que se torna necesario y urgente, pues las mujeres privadas de libertad tienen que hacer frente a una invisibilidad en el ámbito penitenciario que provoca que se planifique una política penal y penitenciaria desde la ausencia o negación (Aguilera, 2011).

Desde el Trabajo Social y los Feminismos tenemos que desarrollar conjuntamente referentes desde donde analizar, reflexionar y promover discusiones que repercutan en intervenciones más eficaces e integradoras de las mujeres en el medio penitenciario, teniendo en cuenta siempre "la complejidad del conocimiento y de las realidades en un espacio punitivo, estigmatizado y de una gran complejidad social" (Añaños, 2012). Por ello, tenemos que buscar métodos, intervenciones e investigaciones que escuchen sus voces y reconozcan que existen 
prácticas y estrategias - de oposición, de disputa, de negociación, de recreación y de integración - mediante las cuales ellas logran reformular el encierro carcelario y "crear espacios de relaciones solidarias, asumir compromisos afectivos y proteger su identidad" (Nari, 2000: 24). Los profesionales e investigadores tenemos que situarnos en condiciones óptimas para responder a los requerimientos de esta situación.

Este trabajo parte de la existencia de variedad de identidades y de que su combinación puede exponer a las mujeres que han estado privadas de libertad a diferentes tipos de discriminación. Es decir, en este punto, no podemos obviar las formas en que etnicidad, género, clase social y otros sistemas de opresión crean desigualdades y condicionan la posición de estas mujeres, es decir, las cárceles forman parte de los procesos de reproducción de la desigualdad social, económica y de género, como instancia de control y dominación (Manzanos, 1992).

Partiendo de esta realidad, a continuación desarrollo la producción teórica que sustenta mi trabajo. En un segundo apartado, realizo la contextualización legislativa y cuantitativa de este entorno. Seguidamente, expongo los métodos y las formas en que me he acercado a la realidad penitenciaria y he construido este documento. En cuarto lugar, elaboro el análisis de parte de la información recogida durante este proceso. Finalmente, cierro el documento con unas conclusiones.

\section{MARCO TEÓRICO}

Comienzo este trabajo de investigación sobre mujeres y prisión con la síntesis del desarrollo teórico existente respecto al tema. Soy consciente de que mi objetivo aquí es dar una idea muy breve de la profundidad y complejidad histórica con la que esta realidad debe y merece ser tratada, y que ello realmente supera a las posibilidades de este proyecto (Azaola, 2005).

Siguiendo a Mercedes Gallizo (2013: 12) afirmo que "el mundo de las prisiones es un observatorio privilegiado de los males de la sociedad en la que vivimos". Residiendo aquí la complejidad de adentrarse y trabajar con esta realidad. Para ello abordaré, en un primer eje teórico, la producción de conocimiento desarrollada hasta ahora desde las denominadas teorías del control y el castigo 
(punishment en su acepción inglesa). A continuación, en un segundo eje teórico expondré que se ha dicho acerca de las consecuencias y especificidades que tiene para las mujeres el paso por prisión.

\subsection{PODER - CONTROL - CASTIGO, ¿qué construye a qué?}

En estos últimos meses he desarrollado una afinidad especial con la perspectiva teórico política del control y del castigo, es por ello que asumí el reto en este proyecto de pensar la cárcel no como un espacio autorrefencial, sino como un escenario conectado con procesos más amplios y globales, en relación al neoliberalismo, la criminalización de la pobreza y "la selectividad penal de los dispositivos judiciales y policivos" (Wacquant, 2010 en Bello, 2013: 2).

Emergen en este momento tres preguntas vertebradoras del apartado y que desde el inicio motivaron su creación: ¿quién castiga? ¿por qué? \& ¿a quién? (Fassin, 2016) ${ }^{2}$, y sin las cuales me resulta imposible entender las dinámicas y la realidad de todas y cada una de las mujeres que han vivido y están vivendo la realidad penitenciaria.

La producción teórica en torno a estas preguntas es extensa e imposible de incorporar en su totalidad en este trabajo. Una decisión consciente me lleva a pensar que en este punto se torna esencial comenzar por la figura del filósofo Michel Foucault para entender que la privación de libertad y la coerción ininterrumpida que ello conlleva constituye uno de los principales mecanismos de disciplinamiento del Estado (Nari, 2000).

En su trabajo - Vigilar y Castigar (1975) - Foucault nos da algunas claves para comprender qué significa el espacio carcelario, cómo se constituye el modelo disciplinario y las consecuencias que esto tiene en la vida de las personas y en el proceso de reinserción. Foucault lo define como un espacio cerrado y vigilado en todos sus puntos, en el que las personas ocupan lugares fijos, todos sus

\footnotetext{
2 Seminario impartido por Didier Fassin en la Universidad de California, Berkeley, 2016: http://tannerlectures.berkeley.edu/2015-2016-lecture-fassin/
} 
movimientos se encuentran controlados y todos los acontecimientos se registran, donde el poder se ejerce por entero de acuerdo con una figura jerárquica continua, "en el que cada individuo está constantemente localizado, examinado y distribuido" (Foucault, 1975: 201).

Aunque muchos de los planteamientos de Foucault han sido problematizados por los feminismos, además de por otros pensadores contemporáneos, tales como Loïc Wacquant. Sin embargo, no podemos obviar la importancia de sus escritos sobre el sistema penitenciario y su legado debe servirnos de inspiración y punto de partida, ya que abre un espacio conceptual importante y fecundo.

En su obra Vigiliar y Castigar (1975) expone la forma en que el sistema carcelario moderno se ha creado y se pregunta de dónde viene la práctica de encerrar para corregir. Defiende que se trata de una nueva tecnología puesta en práctica entre los siglos XVI y XIX, mediante el desarrollo de un conjunto de procedimientos destinados a "dividir, controlar, encauzar a los individuos y hacerlos a la vez dóciles y útiles"3. Todo ello lo hace a través de lo que sería un aparato disciplinario perfecto, conocido como panóptico (arquitectura carcelaria desarrollada por Jeremy Bentham, en su obra Le Panoptique, 1780). Este se caracteriza por permitir en "una sola mirada verlo todo permanentemente, en silencio" (Samayoa, 2014: 348). Aparece como una forma de perfeccionamiento del uso del poder y su efecto es inducir en las personas privadas de libertad o detenidas un "estado inconsciente y permanente de visibilidad que garantiza el funcionamiento automático del poder" (Samayoa, 2014: 348). Por lo tanto, la prisión "lugar de ejecución de la pena, es a la vez lugar de observación de los individuos castigados" (Samayoa, 2014:349). El panóptico encuentra en el sistema penitenciario su lugar de realización más privilegiado, siendo a la vez "vigilancia y observación, seguridad y saber, individualización y totalización, aislamiento y transparencia" (Samayoa, 2014:349).

Así, Foucault defiende que el efecto más importante del sistema carcelario es que logra naturalizar y legitimar el poder de castigar, y "rebajar al menos el umbral de tolerancia de la penalidad" (Samayoa, 2014: 350). Es decir, nos encontramos

\footnotetext{
${ }^{3}$ Así es definido el trabajo teórico de Michel Foucault en la contraportada de la edición en castellano de su obra "Vigilar y Castigar. Nacimiento de la prisión" (1975) Madrid: Siglo XXI
} 
con profesionales del sistema educativo, la medicina y lo social, que a la vez ejercen el papel de jueces y juezas, esto es que "todos hacen reinar la universalidad de lo normativo" (Samayoa, 2014: 350).

Foucault (1975) establece que entre los principios y/o agentes que rigen el funcionamiento de la prisión destacan: el aislamiento, el trabajo, la prisión como lugar de ejercución o modulación de la pena. El aislamiento garantiza "que se puede ejercer sobre ellos, con el máximo de intensidad, un poder que no será constrarrestado por ninguna otra influencia; la soledad es la condición primera de la sumisión total" (pag.240). Así como asegura el fortalecimiento de la culpa y el remordimiento. En este sentido, la pena no solo debe ser individual, también indiviualizante, es decir, procurar el aislamiento con el exterior y a la vez entre las propias personas que se encuentran denidas. En cuanto a la utilidad del trabajo penal, defiende que no se trata de "un provecho, ni aun la formación de una habilidad útil; sino la constitución de una relación de poder, de una forma económica vacía, de un esquema de la sumisión individual y de su ajuste a un aparato de producción" (pág. 246). En lo relativo a la prisión entendida como instrumento de modulación de la pena y como lugar de observación de las personas castigadas, esto es así en dos sentidos, como vigilancia y como "conocimiento de cada detenido, de su conducta, de sus disposiciones profundas, de su progresiva enmienda" (pág.252).

Finalmente, las personas que están privadas de libertad son al mismo tiempo producto de la institución, es decir, aunque la prisión sanciona la delincuencia, defiende que ésta se fabrica en y por un encarcelamiento que la prisión prolonga a su vez.

Este autor nos da las claves para entender qué significa el espacio carcelario, cómo se constituye el modelo disciplinario y las consecuencias que esto tiene en la vida de las personas y en el proceso de reinserción como espacio cerrado y vigilado en todos sus puntos, en el que las personas ocupan lugares fijos, todos sus movimientos se encuentran controlados y todos los acontecimientos se registran, donde el poder se ejerce por entero de acuerdo con una figura jerárquica continua, "en el que cada individuo está constantemente localizado, examinado y distribuido" (1975:201). 
Sin embargo, no podemos olvidar que las aproximaciones clásicas al fenómeno carcelario han padecido de un sesgo androcéntrico. La ausencia de las mujeres y de la perspectiva feminista ha llevado a elaborar conclusiones parciales acerca de las prisiones. En su análisis sobre la evolución de las políticas de encierro Almeda $(2002,2006)$ pone de manifiesto que "esta transición del control de los cuerpos a un mayor énfasis en el control moral que Foucault describe, fue propio únicamente del encierro masculino" (De Miguel, 2012 :24).

Los trabajos desde los feminismos en esta área ponen en relieve el vínculo entre las tecnologías disciplinarias y las tecnologías de género (De Lauretis, 2004). Estas investigaciones señalan, de un modo en que Foucault no lo hizo, que: "las disciplinas carcelarias no sólo fabrican sujetos dóciles y cuerpos domesticados para la producción capitalista, sino que imponen subjetividades femeninas y masculinas, que son constantemente resistidas por las personas presas (Dirsuweit, 1999; Moran, Pallot y Piacentini, 2009; Parrini, 2007; Pemberton, 2013; PontónCevallos, 2008; Vartabedian, 2001)" (Bello, 2013: 3).

La forma de castigar ha sido y es diferente para hombres y para mujeres. En algunos de los aspectos nos detendremos más adelante.

\section{a) Del Estado del Bienestar al Estado Encarcelador ${ }^{4}$ : The Prisonfare}

No podemos entender las teorías del control y del castigo sin los aportes teóricos del sociólogo Loïc Wacquant (2010), quien defiende que en la sociedad actual los Estados han pasado de la regulación de la "asistencia social" a la administración penal de los "excluidos" de la sociedad de mercado, existiendo una "estrategia de los gobiernos hacia la penalización de la pobreza" (2010: 9). Existe una tendencia macrosocial "hacia la desigualdad, la fragmentación de la mano de obra asalariada, el achicamiento del Estado de bienestar y la concentración y estigmatización espacial de la pobreza" (Wacquant, 2010: 10).

Wacquant coincide con Foucault en afirmar que "la penalidad es una fuerza versátil y eminentemente fértil a la que se debe dar un lugar de privilegio en el

${ }^{4}$ Juliano, 2011: 43. 
estudio del poder contemporáneo" (Wacquant, 2010: 417). Sin embargo, añade que "el agresivo despliegue del Estado penal ha engendrado nuevas categorías y discursos, nuevos cuerpos administrativos y políticas gubernamentales, tipos sociales renovados y formas asociadas de conocimientos en los ámbitos del delito y de la asistencia social" (Wacquant, 2010: 417).

Para Loïc Wacquant (2010b) el sistema penal actúa como herramienta de control de la inseguridad ciudadana y de contención de los trastornos que pudieran ocasionar las políticas de desregulación económica y retraimiento social de los Estados en el contexto de crisis global en el que nos encontramos, afirmando: “¿Cómo contener la marea creciente de familias indigentes, personas que viven en las calles, jóvenes sin empleo alienados y la desesperación y violencia que se intensifican y acumulan en los barrios relegados de las grandes ciudades?" (2010b: 100).

En el contexto de crisis mundial, la penalización ha sido, en muchas ocasiones, utilizada por los Estados como una técnica de invisibilización de los problemas sociales, "la cárcel actúa como un contenedor judicial donde se arrojan los desechos humanos de la sociedad de mercado" (Wacquant, 2010: 26). En este sentido, se ha instaurado un gobierno de la inseguridad social, que vincula las políticas asistenciales y las políticas penales, las cuales "trabajan conjuntamente para omitir a la población con problemas, forzándola a salir de la ayuda pública, por un lado, y manteniéndola encerrada, por otro, con objeto de empujarla, al final, hacia los sectores periféricos del creciente mercado laboral secundario" (Wacquant, 2010: 408).

Así, en la actualidad, no es posible entender el bienestar y la política social sin tener en cuenta la política penal y viceversa, ya que, las políticas sociales marcan las opciones vitales de "las poblaciones más susceptibles al crimen callejero (tanto perpetradores como víctimas)" (Wacquant, 2012: 195).

Es decir, este autor defiende la existencia de una analogía entre el bienestar social (welfare) y el sistema penal, que nombra como prisonfare, refiriéndose al "conjunto de políticas que responden a los problemas sociales con medidas punitivas que involucran a la policía, los tribunales, las cárceles y sus extensiones" 
(Wacquant, 2012: 205). La consecuencia de ello es el aumento generalizado de las poblaciones carcelarias como instrumento estatal para el control de la inseguridad y la implantación de la doctrina de "tolerancia cero" (Wacquant, 2010b: 17).

De esta forma, los Estados de las sociedades avanzadas del Occidente capitalista están pasando de lo que sería la regulación de la asistencia social a la administración penal de los excluidos de la sociedad de mercado, existiendo una tendencia hacia la penalización de la pobreza y la asimilación del subproletariado. Esta realidad es fruto de la combinación de cuatro lógicas estructurales: tendencia macrosocial hacia la desigualdad, fragmentación de la mano de obra asalariada (mutaciones del empleo y al vaivén de la relación de fuerzas entre clases y grupos que luchan por su control), la reducción del Estado de Bienestar y la concentración y estigmatización espacial de la pobreza (Wacquant, 2010b). Podría resumirse en la siguiente fórmula:

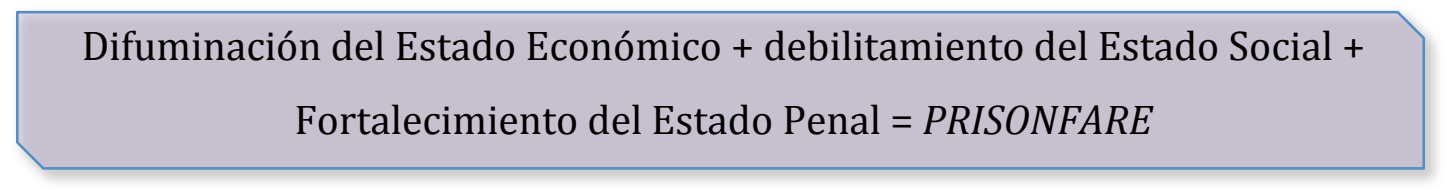

La amenaza a la seguridad ciudadana siempre suele venir representada como proveniente del exterior, a pesar, irónicamente, de la pandemia de violencia doméstica y machista que estamos sufriendo. El preso, concebido como asesino y violador, es percibido como la gran amenaza social. Sin embargo, la mayoría de las personas privadas de libertad no han sido condenadas por crímenes violentos, siendo concebidas, sin embargo, como la encarnación suprema del enemigo. El Estado persigue con esto que la gente se sienta mejor, desviando así su atención de aquellas amenazas reales a la seguridad que "provienen del ejército, de la policía, de las empresas y, a veces, de sus propias parejas" (Davis, 2016: 132).

Tal y como afirma la antropóloga Dolores Juliano (2011) "El intervencionismo estatal es crecientemente disciplinario. Esto se relaciona con el deterioro económico y los recortes de las políticas que fundamentaron el "Estado de Bienestar" (2011: 45). Mediante el incremento de las funciones de control, el Estado maquilla el retroceso de lo que podría ser su papel social. Todo ello se lleva a cabo, como señala Garland (2002) priorizando la prisión frente a cualquier otro tipo de medida o herramienta preventiva. 
Esta tendencia comienza a perfilarse en Estados Unidos en los años 80 con la extensión del conocido lema "tolerancia cero" en relación a la pequeña delincuencia, que va acompañado de un endurecimiento de las penas. Esta tendencia de penalización de la marginalidad urbana se está extendiendo también por Europa, aunque con un retraso de dos décadas y a menor escala. Sin embargo, y desde una perspectiva macro-política más amplia, existe una tendencia similar, en el sentido en que se está produciendo "una reforma punitiva de las políticas públicas que enlaza la "mano invisible" del mercado al "puño de hierro" del Estado penal" (Wacquant, 2012: 190). No obstante, cabe señalar que los países europeos "no siguen ciegamente el criterio estadounidense de hiperencarcelamiento: el camino de Europa hacia el estado penal implica la intensificación conjunta del tratamiento tanto social como penal de la pobreza y la activación de las funciones de vigilancia por parte de la asistencia social, que conducen a una forma de “panóptico social” (Wacquant, 2010b: 17).

Esta tendencia de tolerancia cero se ve enriquecida y sustentanda por el peso mediático y el discurso altamente politizado que, en la actualidad, tienen muchas de las cuestiones del control del delito, es lo que Garland (2005) denomina politización del control del delito, de modo que "cada decisión se adopta con gran publicidad y en el marco de la lucha política y cada error se convierte en un escándalo" (Garland, 2005: 49).

El antropólogo francés Didier Fassin (2016) nos habla también de este mismo modelo y, además, defiende que esta represión ejercida sobre los sectores más vulnerables tiene que hacernos reflexionar sobre el modelo contemporáneo cada vez más desigual, internacional y socialmente hablando. En una sociedad en la que las inequidades se están profundizando la respuesta política ha sido el despliegue del Estado punitivo, del que venimos hablando, consagrado a las áreas más segregadas y carenciadas, "aun cuando no tienen las tasas de criminalidad más altas, y a los grupos étnicos y raciales minoritarios, que componen la empobrecida clase obrera" (pág. 15).

Varias teóricas feministas han llevado a cabo un análisis paralelo de la evolución de los castigos, revelando el papel del sexo y el género en los procesos de transformación penal, las implicaciones sociales del incremento del 
encarcelamiento de mujeres (Sudbury 2005; Schaffner 2005; Haney 2004), así como el "mayor control que se ejerce a nivel cultural sobre las vidas y los cuerpos de las mujeres por medio de un miedo al crimen, generizado y ubicuo (Madriz 1997; Wood 2005)" (Bernstein, 2014: 281).

Por otro lado, y no menos importante, estas teóricas también han profundizado en las diversas formas en las que los propios feminismos y/o activismos feministas (sobre todo en su presentación hegemónica estadounidense) han contribuido a facilitar el aumento del brazo carcelario del Estado neoliberal. Es lo que se conoce como carceral Feminism y que designa: "those varieties of feminist theory and praxis that seek to address women's issues through juridical means and (the threat of) incarceration" (Sandbeck, 2012: 2). Algunas especialistas (Gottschalk 2006; Bumiller 2008; Coker 2001; Guber 2007; Halley 2008a, 2008b) han descrito cómo las propias campañas feministas contra la violencia sexual, han contribuido en la evolución de la justicia penal como aparato de control (Bernstein, 2014). Lo cual no quiere decir que todos los feminismos y todas las feministas estemos comprometidas con esta política carcelaria.

\section{b) ¿Criminalización de una pobreza feminizada?}

Seguiendo a Chandra Talpe Mohanty (2008) en el siglo XXI las mujeres y las niñas de todo el mundo continuamos siendo el $70 \%$ de la población pobre del mundo y la mayoría de las refugiadas. Constituimos alrededor del $80 \%$ de las personas desplazadas del Tercer Mundo/Sur en África, Asia y América Latina. Realizamos dos terceras partes del trabajo del mundo y recibimos menos de una décima parte de sus ganancias. Somos propietarias de menos de una centésima parte de las propiedades del mundo y somos las más afectadas por las consecuencias de la guerra, la violencia doméstica y las persecución religiosa.

Como establece la antropóloga Dolores Juliano (2009) todo esto se debe a la desvalorización que existe de las tareas de cuidados tradicionalmente femeninas y a la discriminación salarial, precariedad laboral y desempleo. El desarrollo de políticas de ajuste estructural en todo el mundo ha llevado a la reprivatización del trabajo de las mujeres al desplazarlo de nuevo del Estado al hogar. Todo ello, junto 
con el aumento del fundamentalismo religioso y los nacionalismos de tipo conservador, han conducido "a la vigilancia de corte policial de los cuerpos de las mujeres en las calles y en los lugares de trabajo" (Mohanty, 2008: 450).

Por lo tanto, debemos tener en cuenta que no solo existe una criminalización de los sectores sociales más vulnerables sino que también esta criminalización tiene género. La penalización de las mujeres se inscribe dentro del castigo a los sectores "incómodos" de la población, y la tendencia social de cambiar la libertad por la seguridad (Juliano, 2011). En este punto España tiene una posición destacada debido a que cuenta con la proporción más alta de mujeres dentro de la población penitenciaria: "8\% frente al 3,8\%de Francia, 4,3\% de Italia (...) y 6,2\% en Inglaterra (Cruells e Igareda: 2005 en Juliano, 2009: 8).

No podemos olvidar lo que afirman Angela Davis y Gina Dent (2001) y es que la economía política de las prisiones (nacida en Estados Unidos y extendida después a Europa) y la industria del gasto en el Occidente/Norte, requiere ser analizada bajo el foco de la intersección entre género, raza, colonialismo y capitalismo. En palabras de Mohanty (2008):

las fábricas y los lugares de trabajo de las corporaciones globales buscan y disciplinan el trabajo de mujeres pobres del Tercer Mundo/Sur, inmigrantes/emigrantes, de la misma manera las cárceles de Europa y de los Estados Unidos aprisionan a números desproporcionadamente altos de mujeres de color, inmigrantes y no ciudadanas, de ascendencia africana, asiática y latinoamericana (2008: 451).

Por lo tanto, raza, género y clase entran en sinergia para "atomizar y singularizar el cuerpo que debe ser regimentado y disciplinado" (Mendieta, 2016: 18). Las prisiones se convierten en interruptores de retransmisión en el contrato psíquico-social- racial, es decir, parte de este contrato en el cual "la aparente estabilidad del sistema social está segurada por la amenaza continua del castigo severo, un castigo que, desde un principio, recaerá sobre aquellos que han sido racializados" (Mendieta, 2016: 20). Así como también es un dispositivo para la producción del género que castra a la vez que hipersexualiza, es decir, "la prisión es un lugar donde la teconología política de los cuerpos es más explicitamente productora del género y la raza. Es también donde la simultánea producción del género y la raza aparecen en sus formas más violentas. La violencia sexual cotidiana perpretada contra presos masculinos y femeninos es, sin embargo, la 
amplificación de la violencia por la que los sujetos, que han sido racializados y marcados con un género hipersexualizado, sufren continuamente la suspensión de su participación cívica” (Mendieta, 2016: 20).

Sexualización y racialización de la violencia, tanto en prisión como fuera, son las dos caras de una misma moneda (Davis, 2016). En este sentido, la estructura penitenciaria se convierte en una herramienta y mecanismo social más en la construcción de las identidades de género (Bodelón, 2011).

\subsection{MUJERES, DESIGUALDADES Y PRISIÓN}

“Ellas son mujeres malas, cautivas y presas" (Lagarde, 2011: 681)

El segundo eje teórico de este proyecto me permite desarrollar lo que significa y trae consigo el delito en femenino y la forma en que el sistema patriarcal se entreteje estratégicamente en ello.

La perspectiva $\mathrm{y}$ los estudios feministas han hecho importantes contribuciones epistemológicas en el plano criminológico (Romero, 2003). Han permitido entender que el sexismo, el sistema patriarcal, los privilegios y la subordinación e invisibilidad de las mujeres forman parte de la cultura y de la sociedad, por lo tanto, permean también "la criminología, los procesos criminales y de criminalización y la forma en la que hombres y mujeres confrontan la ley" (Romero, 2003: 35).

El espacio de la transgresión social continúa siendo un lugar privilegiado para el estudio de las normas y de la vida social en general. En el caso de las mujeres, genéricamente definidas bajo conceptos de obediencia, la transgresión se torna doblemente significativa: "define los hechos de poder que socialmente traspasan las mujeres y permite evaluarlos en torno a la construcción de su autonomía " (Lagarde, 2011: 79). 
Como defiende Angela Davis (2014) ${ }^{5}$ el feminismo nos ha hecho repensar sobre la cuestión del encarcelamiento y el complejo carcelario industrial dentro de un contexto más amplio. Así podemos ver las conexiones entre lo personal, lo político, lo institucional y lo doméstico, en definitiva, entre lo público y lo privado: "las mujeres constituyen la población de mayor crecimiento en las cárceles". Sin embargo, continúan siendo una minoría dentro del total de personas que se encuentran privadas de libertad, esto se debe a que existen otras maneras de castigar a las mujeres en la sociedad en general. Es decir, no podemos minimizar (como se describe en literatura en general) la relevancia de las experiencias de vida de las mujeres delincuentes (Romero, 2003), ya que las mujeres trasgresoras pueden ser en igual medida víctimas y victimarias "puesto que la violencia es una característica común en su trayectoria de vida" (Romero, 2003: 38).

Debemos reconocer que las conductas de las mujeres en relación con la transgresión y los delitos necesitan de un análisis especial, en primer lugar porque no encajan de ninguna manera en las estrategias explicativas utilizadas para los hombres (Juliano, 2009). En segundo lugar, por el hecho de que, tradicionalmente ha existido una tendencia a considerar las conductas de mujeres que cometen delitos como significativamente más aberrantes y peligrosas para la sociedad que las conductas de sus homólogos varones (Davis, 2016).

Así mismo, cuando se habla de formas de castigo diferentes se hace referencia a que mientras que la prisión nace y se desarrolla como la principal herramienta de castigo público, las mujeres han seguido estando vinculadas a rutinas de castigo que no han estado en el ámbito público. Es decir, han sido encarceladas en mayor proporción en instituciones psiquiátricas, entendidas como locas, mientras los hombres eran considerados delincuentes. Las consecuencias de esta asunción no pertenecen al pasado, continúan conformando las cárceles de mujeres, como se puedever en el hecho de que "las drogas psiquiátricas" se sigan distribuyendo de forma más habitual en estos entornos (Davis, 2016), aspecto en el que me detendré en mayor medida en el análisis.

\footnotetext{
${ }^{5}$ Angela Y. Davis (2014) En

http://www.democracynow.org/es/2014/3/6/angela_davis_habla_de_la_abolicion
} 
En este sentido, si la categoría de "enfermo mental" se aplica a las mujeres comprobamos que queda fuertemente sexualizada y que se prefiere frente a la categoría de "delincuente". Y, si tenemos en cuenta el impacto de la clase y la raza sobre estas categorías de "delincuencia" y "enfermedad mental", podemos ver que en las mujeres blancas y ricas tiende a aplicarse la segunda, la enfermedad mental, sin embargo, las mujeres negras y pobres tienden a ser vistas más bien bajo la categoría de delincuentes (Davis, 2016: 77).

Partiendo de lo anterior, podemos afirmar que los feminismos nos dan las claves para entender la complejidad de las experiencias de las mujeres privadas de libertad, siendo necesario también tener en cuenta la interseccionalidad como paradigma que aborda las conexiones entre las múltiples dimensiones y modalidades de las relaciones sociales y la formación de los sujetos, más allá de sumar categorías de diferenciación social (McCall, 2005: 1773). Ninguna de las categorías se posiciona en el centro o con mayor poder frente a las otras. No se pueden entender los procesos ni las vidas de las personas analizando categorías aisladas sin tener en cuenta el dinamismo y la interrelación continua de todas ellas (Collins, 1998).

Como defiende Mohanty (2008: 434) se torna necesario y esencial conocer los efectos reales y concretos "de la reestructuración global de los cuerpos de las mujeres bajo criterios raciales, de clase, nacionales, sexuales, en el medio académico, en el centro de trabajo, en la calle, en la casa, en el ciberespacio, en los barrios, en las prisiones y en los movimientos sociales".

En el caso de las mujeres privadas de libertad, no se pueden obviar las peligrosas interacciones que se producen entre racismos, dominación masculina y las estrategias estatales de represión política (Davis, 2016). Existiendo en muchas ocasiones un racial profiling, es decir, "la inclusión de determinadas características raciales o étnicas en la consideración de una persona como sospechosa de cometer algún tipo de delito" (Davis, 2016: 72). Es llamativo cómo las mujeres blancas etiquetadas como "delincuentes" tienden a "ser asociadas en mayor medida con "lo negro" que sus homólogas “normales"” (Davis, 2016: 77).

Angela Y. Davis afirma que "es fundamental reconocer el vínculo existente 
entre el racismo estructural y el complejo industrial penitenciario, entre el castigo y la economía capitalista" (Citado en Villaverde, 2016, sin página). Si tenemos en cuenta que el objetivo de la prisión es privar de las libertades y de los derechos, estos derechos y libertades tienen que ser reconocidos antes de que nos los puedan quitar. En el caso de las mujeres en el contexto estadounidense no entraban en esta definición, porque, en sus inicios no eran consideradas personas de pleno derecho (Villaverde, 2016).

\section{a) Enfrentando la Triple Condena: Social, Personal y Penal}

Las definiciones estereotipadas a las que todas las mujeres tenemos que hacer frente conforman círculos particulares de vida para nosotras, y estas mismas definiciones son, de acuerdo con Marcela Lagarde (2011), también nuestros cautiverios como madresposas, putas, monjas, presas y locas. Sin embargo, en lo que respecta a las mujeres presas, estas concretan en una misma persona, además de la realidad penitenciaria, las prisiones y subordinaciones a las que todas nosotras tenemos que hacer frente, tanto material como subjetivamente hablando, es decir:

la casa es presidio, encierro, privación de libertad para las mujeres en su propio espacio vital. El extremo del encierro cautivo es vivido por las presas, objetivamente reaprisionadas por las instituciones del poder. Sus delitos son atentados que tienen una impronta genérica específica; su prisión es ejemplar y pedagógica para las demás (Lagarde, 2011: 69).

En los últimos años los estudios feministas destacan la necesidad de especificar la complejidad de las exclusiones para el caso de las prisiones de mujeres, ya que el encarcelamiento de las mujeres se ha leído tradicionalmente como una nota a pie de página respecto al eje central del castigo masculino. Al abrigo de normativas políticamente correctas y formalmente igualitarias, las prisiones continúan siendo un instrumento sexista y discriminatorio (Mapelli, 2013).

Dicha afirmación cobra sentido si tenemos en cuenta que: los espacios físicos que ocupan estas mujeres son, por lo general, espacios residuales dentro de las macro-prisiones masculinas; la existencia de control por medio de la homogeneización y sobre-medicalización; los programas de tratamiento a los que 
tienen derecho están creados a partir del imaginario del recluso tipo varón, es decir, "no en la consideración de los riesgos que específicamente conducen a la mujer a delinquir (Mapelli, 2013: 71); las prisiones no se encuentran adaptadas para acoger $\mathrm{y}$ entender las complejidades y contradicciones inherentes a la experiencia del embarazo o la maternidad en prisión; las oportunidades de trabajo en prisión para las mujeres son desiguales, escasas y sesgadas por preconcepciones de género (actividades de hostelería, puericultura o corte y confección), existe una reproducción penitenciaria de los roles dependientes y domésticos tradicionalmente asignados a las mujeres; y finalmente, la existencia de sobre-representación de mujeres inmigrantes y gitanas relacionada con la alianza del sistema penal y de factores raciales y clasistas de discriminación (Mapelli, 2013). Denunciando "la forma en que los procesos de criminalización femenina se nutren de los colectivos de mujeres económica, social y culturalmente más fragilizadas (Carlen, 1998; Almeda, 2003; Nicolás y Bodelón, 2009)” (Bodelón, 2011: 10).

En este punto también sería necesario tener en cuenta que la mujer privada de libertad representa para el imaginario social a la "anti-mujer", a aquella que "rompió con el pacto social y sexual; la que traicionó ese mandato social de género que la naturaliza como buena, abnegada, sumisa y altruista" (Nari, 2000: 24). Estas mujeres se alejan del ideal femenino para ocupar un ámbito no elaborado ni incorporado simbólicamente para ellas como una forma adecuada de vida femenina. Es en este momento en que sus contradicciones se agudizan debido "a su escasa posibilidad de comprensión sobre el acontecer, a la imposibilidad de interpretación racional y afectiva en términos nuevos que les permitan asumir, en lo posible, su propia vida" (Lagarde, 2011: 357)

Desde una sociedad androcéntrica y jerárquica la mujer que delinque estaría haciendo uso de atributos, habilidades y estrategias masculinas, participando así del universo simbólico masculino, es decir, ser mujer y estar en prisión es mucho más que ser tachada de criminal:

a woman in prison is acting against her responsability as wife and mother, submissive, dependent and docile (...) femenine crimes start with subjective changes: women abandon their passivity to become more attentive and aggressive or as the result of greater access to 
the labor market and publish space, where crime take places (Silva-Segovia, 2016: 100).

Distintas investigaciones - tanto en EE.UU como en Europa - sobre delincuencia y género confirman que "las mujeres difieren significativamente de los varones respecto a sus historias personales, en cómo se inician, en el tipo de delitos y en la trayectoria posterior" (Fontanil, 2013: 23). Ello les lleva a responder de forma distinta a los tratamientos a unas y otros, iguales programas no significa que las mujeres necesiten los mismos tratamientos que los hombres (Mallicoat, 2011).

Resulta esencial entender que la situación de las mujeres en el ámbito penitenciario está contextualizada en una estructura carcelaria gestionada por y para los hombres y donde estas ocupan una posición subsidiaria debido, por un lado, a su menor entidad numérica, y por otro lado, a lo que podría denominarse una menor conflictividad. Las graves consecuencias de todo ello se han traducido en la perpetuación histórica de factores de discriminación en relación a la precariedad de los espacios, peores condiciones en el alojamiento, lejanía del entorno social y familiar, mezcla de lo que se conoce como "perfiles criminales" y la falta de conocimiento sobre sus necesidades específicas (Yagüe, 2007).

Aspectos todos ellos que llaman aún más la atención cuando nos acercamos a la realidad española, al constatar una tendencia al alza en el número de mujeres presas desde los años 80 (Pascual, s.f.). Sin embargo ello no significa que el problema de la delincuencia esté aumentando, sino que se relaciona con una mayor penalización de delitos menores (Wolf, 2006). La representación de la mujer privada de libertad en España es la más alta de los países europeos (García, 2012). A pesar de ello, la realidad es que el número de mujeres encarceladas continua siendo mucho menor que el de los varones, actualmente "nueve de cada diez internos siguen siendo hombres" (Pascual, s.f.: 5).

En resumen y recuperando el título del apartado, hacer mención al concepto de triple condena (Aguilera, 2011) para la estancia en prisión de las mujeres implica reconocer:

i) El aspecto social, por la ruptura con el rol social que se nos encomienda. La tradicional idea de que las mujeres debemos ser naturalmente 
virtuosas hace que nuestras transgresiones se evalúen desde una perspectiva moralista en mayor medida que las de los hombres. Los delitos femeninos tienden a verse implícitamente como "pecado" y se transforman fácilmente en culpa" (Juliano, 2009).

ii) El elemento personal, en relación a que la mujer presa va a sufrir un terrible desarraigo familiar con su ingreso en prisión, ya que, en la mayoría de las ocasiones, su pérdida de libertad va a implicar la desintegración de la familia, puesto que eran ellas las que sostenían la unidad familiar. Esto último no siempre sucede si es el hombre el que entra en prisión pues son ellas las que mantienen el rol de "cuidadoras".

iii) En tercer lugar, una condena propiamente penitenciaria, en la que la mujer va a tener unas condiciones de cumplimiento más duras que el hombre por el simple hecho de serlo, ya que, mayoritariamente cumplen condena en cárceles de hombres (Aguilera, 2011: 118).

En base a lo anterior, podemos afirmar que es necesario reflexionar y entender cuáles podrían ser las alternativas que contribuyesen a generar menores vulnerabilidades a las mujeres antes, durante y después de su estancia en prisión. Se torna urgente marcar como prioridad social la atención íntegra a estas mujeres tanto en el entorno carcelario como mediante soluciones no prisionales (Mapelli, 2013).

\section{b) Exclusión Social, Estigma \& Poderío}

Son tres las categorías de análisis que orientan esta investigación. Como he desarrollado a lo largo de estas páginas la experiencia penitenciaria trae consigo un elemento de estigma concreto para el caso de las mujeres. En este apartado me propongo desarrollar de manera muy breve la categoría exclusión social a la que hago referencia. A ello añado el concepto de poderío, teniendo como objetivo buscar un punto de análisis que me permita situarme más allá de las vulnerabilidades y situarme en la capacidad de agencia que estas mujeres desarrollan. 
Analizar la exclusión social de las mujeres privadas de libertad exige pensar dicha categoría de exclusión social en términos interactivos y relacionales, siendo conscientes de la complejidad de la realidad a la que la aplicamos, y como categoría que reside en prácticas sociales y en la acción humana, como defiende Joaquín García Roca (2009).

La categoría exclusión social hace referencia a un fenómeno multidimensional, en la medida en que se refiere a la compleja y variable combinación tanto de aspectos laborales como formativos, ocupacionales, espaciales, institucionales o de género. Además de a un proceso dinámico, del que continuamente se puede entrar, salir o permanecer, en una "suerte de frontera o vulnerabilidad, aunque para muchas personas es el lugar permanente de existencia" (De Miguel, 2012: 13). Es un fenómeno construido, no es natural e inevitable sino fruto de la correlación de fuerzas y la organización social desequilibrada (Calvo et al., 2006:19, en: De Miguel, 2012: 43).

Pensar en exclusión social es pensar en la condición humana y el sistema social:

En ella se muestran tanto las capacidades de lo humano como el límite de la sociedad, de modo que desvela la verdad escondida y silenciada, perturba el orden social fundado sobre la discriminación, confunde la lógica perversa implícita en la cohesión social y subvierte ciertas prácticas que se consideran naturales en la producción y persistencia de la exclusión social (García, 2009: 25, en: Vidal, 2009).

Siguiendo este planteamiento, la solución a la salida de la exclusión no es la integración ni la re-inclusión sino la recreación. Este concepto parte del empoderamiento de las personas en situación de exclusión y de la reconciliación social, supone fortalecer las "reglas del juego que dictaron la exclusión" (Vidal, 2009: 45). En este sentido, yo elijo hablar de poderío en lugar de empoderamiento. Término acuñado por la antropóloga mexicana Marcela Lagarde (2011), entendido como clave feminista relativa al poder vital, que es a su vez camino hacia la libertad y fundamento de cualquier aspiración de igualdad. Hablar de poderío es hacerlo de poderes de emancipación como "resultado del fortalecimiento del conocimiento y la conciencia de sí y del mundo, de la autoafirmación, la independencia y la autonomía" (Lagarde, 2011: 40). Este concepto acentúa y pone en el centro los poderes vitales positivos de las mujeres, poderes no opresivos, que 
pueden ser usados a favor de una misma y a favor de tu entorno. Nos conduce a la transformación de maneras de ser, de pensar y actuar, de los modos de vida con sus actividades, prácticas y relaciones sociales. Tiene como sentido último la libertad, y la genera ${ }^{6}$.

Retomando el tema que aquí me ocupa, en prisión las mujeres sufren los efectos de la institucionalización, de la violencia estructural y todas las dificultades psicológicas que supone una pena privativa de libertad. Además, cuando estas mujeres salen de la cárcel tienen que hacer frente al estigma de presa, de acuerdo a estereotipos, prejuicios y discriminaciones, añadiendo a todo eso las violencias culturales (Galtung, 1990) y las violencias simbólicas (Bourdieu, 1988). Por lo tanto, podría decirse que "son los estigmas, el rechazo a las minorías y la construcción de los parias de la tierra lo que constituye a este colectivo" (Goffman, 1970; Bauman, 2005 y Appadurai, 2007)” (Jiménez, 2013: 87).

De acuerdo con el antropólogo Francisco Jiménez Bautista (2013), las mujeres presas la mayoría son doblemente víctimas de la violencia estructural: en la calle son víctimas de la exclusión social y marginación con la creciente criminalización de conductas relacionadas con la pobreza. Y en prisión, "son víctimas del olvido y negligencia de las autoridades públicas" (Jiménez, 2013: 87).

El estigma es definido como la inhabilitación para una plena aceptación social (Goffman, 1998:7), es una desacreditación global como consecuencia de una falta atribuida (De Miguel, 2012). La estigmatización "puede interpretarse como un distorsionador ideológico que impide captar la imagen real de la persona estigmatizada, en tanto que persona, y que la coloca bajo un rótulo uniformizador en el que sus características más rechazadas socialmente ocupan la totalidad del campo identitario asignado" (Juliano, 2006:150).

En el contexto de prisión, las mujeres tienden a verse como malas, culpables de su situación y la de su entorno:

sentimientos de culpa por haber "abandonado" a los suyos, preocupación por su suerte y

\footnotetext{
${ }^{6}$ Sin embargo, en este proyecto de investigación, el planteamiento de la categoría poderío se queda en ello, condición teórica, perspectiva que yo asimilo y uso en el momento de vincularme y relacionarme con estas mujeres pero que no puedo desarrollar en el análisis, será uno de los aspectos a desarrollar en la tesis doctoral.
} 
vergüenza por la publicidad inevitable de su estigma de presas, son todos elementos que aparecen en las cárceles de mujeres con mayor fuerza y frecuencia que en las cárceles para hombres (Juliano, 2009: 17).

El principal estigma con el que se encuentran es el del incumplimiento de la norma, que no se juzga socialmente de la misma manera para hombres que para mujeres. Mientras que para los hombres existen modelos socialmente aceptados de transgresión, para las mujeres esta transgresión transmuta socialmente en estigma y rechazo: "esto hace que los hombres puedan hacer compatible el delito con sus roles sociales y familiares, mientras que en parecidas circunstancias ellas pierdan irreversiblemente su tejido familiar y su reconocimiento social" (Juliano, 2009: 17).

Este estigma genera la separación entre las mujeres buenas y las malas. De acuerdo con Dolores Juliano (2006), "la sociedad no sólo ha construido las categorías estigmatizadas con el objetivo de dirigir su mensaje de repulsa a quienes no cumplen las normas, sino que se extiende como un meta-mensaje al conjunto de la sociedad" (De Miguel, 2012: 46).

En definitiva, es importante reflexionar no tanto sobre por qué las mujeres no cumplen las normas, más bien sobre por qué la sociedad tolera de manera más cómplice las infracciones masculinas, sancionando y desvalorizando las femeninas (Juliano, 2006).

\section{c) Reinserción, Resiliencia y Agencia}

El artículo 25.2 de la Constitución española de 1978 establece que: "las penas privativas de libertad y las medidas de seguridad estarán orientadas hacia la reeducación y reinserción social y no podrán consistir en trabajos forzados".

Sin embargo, se puede afirmar que las penas privativas de libertad han fracasado en este espíritu resocializador (Segovia, 2005). Como defiende Angela Y. Davis (2016) debemos reconocer el carácter profundamente generalizado del castigo.

Paradójica y realmente la cárcel es un medio desocializador, es decir, la 
separación de las personas de la sociedad y su reclusión conlleva la progresiva ruptura de los lazos con el exterior que, a su vez, "va asumiendo determinados códigos y valores propios de la cárcel, provocando su prisionización"7 (Daunis, 2016: 2).

En lo que respecta a la reinserción de las mujeres privadas de libertad, una investigación realizada por el Observatorio de la Delincuencia, en el año 2012, informa de la limitación de las Instituciones Penitenciarias españolas para alcanzar el éxito de la reinserción, entre otros factores debido a que no tienen en cuenta la compenetración con otras políticas sociales.

Como revela la investigación de Ma Jesús Miranda (2002) la cárcel no rehabilita - los índices de reincidencia son superiores al 50\% en todos los estudios conocidos- ni disuade. Además de que existe una "absoluta discrepancia entre las aspiraciones de las presas (cambiar las condiciones de vida que tenían antes del ingreso en prisión, y que fueron las que les condujeron al delito) y la oferta institucional" (Miranda, 2002: 379). Así como una presupuesta salida "ideal" de prisión, vinculada al peso que tiene la familia en el éxito final del proceso, haciendo que cuanto menos se ajuste a este ideal más complejo sea el éxito de la reinserción. Muchas de estas mujeres tienen que volver a los mismos entornos que previamente habitaban, donde tienen que enfrentarse a los mismos problemas, sin recursos suficientes, volviendo en muchas ocasiones también a los mismos estilos de vida (Mallicoat, 2011).

Si analizamos las medidas que se llevan a cabo por la mayoría de las prisiones europeas podemos ver que son inadecuadas. Esto es así por diversos motivos. En primer lugar, porque las oportunidades de trabajo que se ofrecen dentro de prisión no proporcionan a las presas las competencias profesionales útiles en el mercado de trabajo. En segundo lugar, las oportunidades de formación y educación dentro de prisión no contribuyen suficientemente a la adquisición de formación necesaria tras la salida de prisión. En tercer lugar, las mujeres no reciben suficiente preparación y apoyo para regresar a sus familias y a la

\footnotetext{
7 El término prisionización hace referencia a la adopción de lo que podría denorminarse subcultura carcelaria, y comporta la aceptación del rol de preso/a "(socialmente desvalorizado), la acumulación de información sobre el funcionamiento de la cárcel, la modificación de los modos de comer, vestir, dormir y trabajar, el uso del argot carcelario, el reconocimiento de no estar en deuda con la institución por satisfacer sus necesidades básicas, y el deseo de un buen trabajo en el establecimiento" (García-Bores, 2003: 3).
} 
comunidad sin problemas. Y, por último, los programas que se ofrecen en prisión presentan importantes diferencias de género, lo que muchas veces refleja y refuerza los roles tradicionales de género (De Miguel, 2012: 34-35).

A pesar de que las investigaciones apuntan que: "Close ties to families during incarceration are crucial in maintaining connections in the community ...for women returning to the community, the assistance of family is crucial to succes" (Mallicoat, 2011: 508). Uno de los factores comunes al que tienen que hacer frente las mujeres, tanto dentro como una vez fuera de prisión, es la disrrupción que sufre la comunicación entre ellas y sus vínculos familiares y sociales durante el proceso de privación de libertad. Siguiendo lo que establece Mallicoat (2011), más de la mitad de las mujeres afirman haber perdido el contacto con sus familias:

this makes for greater adjustment problems in reintegrating into the community (...) For women without family support, being released from prision appears to be even more frightening. In these circumstances, women on parole have to become their own support system. Yet, success in the community is very much dependent on the belief that they will be accepted in society (Mallicoat, 2011: 509).

Sin embargo, si descentramos la mirada de las estructuras normativas de la institución carcelaria "emergen a la superficie territorios menores, en los que silenciosamente las mujeres presas resisten y se oponen al poder y a la opresión del sistema carcelario" (Makowski, 1997: 68). Apareciendo así las formas en que las mujeres intentan de alguna forma reconstruir su cotidianeidad a través de prácticas y estrategias, tanto individuales como colectivas, "indispensables para sobrevivir, para adaptarse y resistir en el encierro carcelario" (Nari, 2000: 11). Entretejen relaciones sociales con otras mujeres, en ocasiones recrean relaciones de parentesco o "simil-familias", de amistad y de amor. Todo ello les permite crear vínculos afectivos y construirse un espacio propio y privado, de intimidad, y reconstruirse como sujetos sociales. A veces acuden a oficios religiosos, a actividades educativas como estrategia para reformular el tiempo y los espacios del encierro (Nari, 2000). Incluso aparece la queja como forma metafórica de resistencia y como recurso de canalización del malestar, es decir, se convierte en un elemento perturbador del sistema carcelario que no está preparado y solo sabe hacer frente únicamente a formas masculinas de resistencia. Por otra parte, la queja puede dar lugar “a la emergencia del juicio crítico y, desde ahí, a la movilización de formas distintas de acción y resistencia que pueden trascender el 
ámbito individual " (Makowski, 1997: 70).

Como muestra el trabajo de Nari (2000), a pesar de la brutalidad opresiva y cosificación que para las mujeres significa el Sistema Penitenciario, estas siempre buscan formas de desarrollar prácticas cotidianas que les permitan sobrevivir como personas. Siendo esencial centrarnos en los inesperados e impredecibles sitios de resistencia de las mujeres privadas de libertad frente a los frecuentemente devastadores efectos presentados que la reestructuración global acarrea para las mujeres (Mohanty, 2008).

Cuando todos estos movimientos se producen en la forma en que miramos la realidad las investigadoras aparece un entramado de "visibilidad que permite divisar, desde los oscuros pasillos de la prisión, los movimientos de resistencia, rebeldía y acción colectiva de las mujeres presas" (Makowski, 1997: 69).

Finalmente, la solución principal a todas las complejas y diversas cuestiones planteadas en este capítulo reside en que "las prisiones solo pueden ser superadas antes y fuera de las prisiones" (Segovia, 2005: 28).

Angela Y. Davis (2016) defiende que abolir las prisiones exige, en primer lugar, reconocer la necesidad radical de transformación del actual orden social y su amplio espectro de problemas. En segundo lugar, comprender las conexiones que existen entre todo un conjunto de instituciones que tradicionalmente se han prseentado como dispares y desconectadas. Por último, reconocer que el encarcelamiento excesivo de nuestra época es consecuencia de la disminución de oportunidades educativas:

que a su vez se ven reducidas por el uso del encarcelamiento como una falsa solución a una educación pública pobre. La persistencia de la pobreza en el seno del capitalismo global conduce a que haya cada vez más población encarcelada, lo que a su vez refuerza las condiciones que reproducen la pobreza (Davis, 2016: 152).

\section{CONTEXTUALIZACIÓN}


Tres son los ejes de contexto que introduzco en este documento en relación a las mujeres y el sistema penitenciario español. El primero, el marco normativo en el que se sustenta. El segundo, la estructura de dicho sistema. Y finalmente, una aproximación cuantitativa a las mujeres que se encuentran cumpliendo condena, desde el marco mundial hasta la Comunidad Autónoma de Andalucía.

Contextualizar la realidad penitenciaria de las mujeres exige en primer lugar reconocer la complejidad que ello supone, así en este trabajo no puedo incorporar todos los matices, las realidades y situaciones diversas que existen cuando te aproximas al ámbito penitenciario. Es decir, como defiende Garland (2005), nos encontramos en un campo que se caracteriza por la variedad de políticas y prácticas, muchas de ellas contradictorias, así como por la multiplicidad de prácticas y discursos. Además de por la dificultad de acceso a la información. Aunque hay multitud de estadísticas y documentos presentados anualmente por la Secretaría General de Instituciones Penitenciarias, las estadísticas públicas no exponen de manera clara y detallada toda la información. Es decir, si te trata de número de personas privadas de libertad según sexo, edad y lugar de procedencia hay un fácil acceso, al igual que para conocer la tipología de centros penitenciarios de nuestro sistema penal. Sin embargo, para conocer de qué forma se distribuyen internamente hombres y mujeres en cada uno de los establecimientos, el movimiento resulta casi imposible.

Respecto al eje normativo, podemos establecer que el Centro Penitenciario está sometido, siguiendo la estructura jerárquica de las leyes en nuestro país, en primer lugar, a la Constitución española de 1978, BOE de 29 de diciembre de 1978 (C.E., art.17, 25 y 149), a la Ley Orgánica 1/1979, de 26 de septiembre, General Penitenciaria (L.O.G.P.), la Ley Orgánica 10/1995, de 23 de noviembre, del Código Penal (C.P.) y la Ley Orgánica 5/2010, de 22 de junio, por la que se modifica la Ley Orgánica 10/1995, de 23 de noviembre, del Código Penal. Con menor rango está la Ley Orgánica 7/2003, de 30 de junio, de medidas de reforma para el cumplimiento íntegro y efectivo de las penas; Real Decreto 190/1996, de 9 de febrero, por el que se aprueba el Reglamento General Penitenciario (R.P.), y a efectos solo de trabajo de los órganos inferiores se podrán emitir circulares, instrucciones y órdenes de servicio (art. 3.5 del R.P.): Instrucción 12/2006 sobre Programación, Evaluación e Incentivación de actividades y programas de tratamiento y la Instrucción 4/2009 
que modifica la anterior. Además toda la legislación penitenciaria recoge las recomendaciones establecidas en las Normas Penitenciarias Europeas.

Nos encontramos en un ámbito profundamente limitado por la acción del derecho y las leyes, además cuyas competencias no están descentralizadas, según el artículo 149 de la Constitución Española: "el Estado tiene competencia exclusiva sobre las siguientes materias: "nacionalidad, inmigración, relaciones internaciones, Administración de Justicia...”. Estado Español tiene las competencias exclusivas en materia de Instituciones Penitenciarias, junto con inmigración.

Las competencias en materia penitenciaria las asume el Ministerio del Interior con la Secretaría General de Instituciones Penitenciarias (SGIP) a excepción de Cataluña que tiene transferidas las competencias en esta materia.

Si profundizamos en la manera en que las mujeres son tomadas en consideración por la legislación penitenciaria nacional, encontraremos que parece centrarse únicamente en las dificultades y preocupaciones de las mujeres privadas de libertad-madres "en buena medida que éstas no son sino un subgrupo de la total desatención de las necesidades generalizadas de la mujer excluida como mujer" (Mapelli, 2013: 93).

Diversas investigaciones, coinciden en afirmar que la Ley Orgánica General Penitenciaria (Mapelli, 2013; López 2015; Olmos, 2002) carece de una visión profunda y específica hacia la cuestión femenina" (López, 2015: 99). Esto es constatable en los escasos seis artículos en que se hace referencia (8.3, 9.1, 16.a, 29.1.e, 38.1, 2,3, 43.3). En su mayoría trata aspectos sobre segregación por sexo dentro de los Centros Penitenciarios, exención de la obligación de trabajar en periodos pre y post-parto, necesidad de departamento con material de obstetricia, la previsión de recursos materiales para el parto de las reclusas, exención de la aplicación de la sanción de aislamiento a embarazadas, tras el parto y a las que tuvieran consigo los hijos (Olmos, 2002) y la permanencia de sus hijos en prisión, permitiendo la convivencia de estos con sus madres hasta los tres años (inicialmente era hasta los seis, pero esto se transforma con Ley 13/95 que modifica la Ley Orgánica General Penitenciaria de 1979). 
Como defiende López (2015) en la última veintena numerosas investigaciones han denunciado la falta de atención al género, en tanto que las prisiones femeninas conviven en una estructura espacial inadecuada, elaboradas en muchos casos para población reclusa masculina, con precaria dotación de recursos económicos, personal poco preparado y una oferta muy reducida de programas rehabilitadores que refuerzan el papel tradicional de las mujeres en la sociedad (Garrido, 1988; Vega Fuente y García Mas, 1989; Lorenzo Modelo, 1997; Almeda, 2003, 2007; Sáez Carreras, 2010; Mapelli, Herrera y Sordi, 2013; Vila Merino y Martín Solbes, 2013).

Es necesaria también la reflexión sobre el Código Penal español como causa de la alta tasa de población femenina reclusa. Es decir, en España han sido especialmente castigados los delitos contra la salud pública, estos cuentan con una mayor participación femenina, siendo esta una de las causas de que existan en España las mayores cotas de mujeres en prisión, en comparación con el resto de países europeos. Sin embargo, estos tipos de delitos femeninos cuentan con una mayor aceptación social que otros relacionados con el ejercicio de la prostitución (Jimenez, 2013) como también defiende Juliano (2009).

En relación al segundo eje, la estructura del Sistema penitenciario español, de acuerdo a la Secretaría General de Instituciones Penitenciarias en España existen 161 establecimientos penitenciarios, de los cuales 68 son centros penitenciarios de cumplimiento de penas ordinarias (Andalucía cuenta con uno en cada provincia); 2 Centros Psiquiátricos Penitenciarios (Alicante y Sevilla); 13 Centros de Inserción Social con plena autonomía organizativa y funcional y 19 dependientes, de los cuales 7 se encuentran en Andalucía (Granada, Córdoba, Sevilla, Málaga, Huelva, Cádiz y Algeciras), sin embargo, Jaén y Almería carecen de ellos, aunque sí tienen Servicios de Gestión de Penas y Medidas Alternativas (de los cuales hay un total de 55 servicios en toda España); 3 unidades de madres (Sevilla, Palma de Mallorca y Madrid), más otra que se encuentra en Cataluña; y 43 unidades de custodia hospitalaria.

En este proyecto hago mención a dos de estas tipologías, definidas por la Secretaría General de Instituciones Penitenciarias como:

- Centros Ordinarios: son los centros tipo, y responden arquitectónicamente 
a una estructura modular, respondiendo a la función de custodia y rehabilitación, garantizando la seguridad y el cumplimiento de las penas.

- Centros de Inserción Social: destinados al cumplimiento de penas privativas de libertad en régimen abierto, así como al seguimiento de cuantas penas no privativas de libertad se establezcan en la legislación penal.

De los 68 Centros Penitenciarios Ordinarios, tan solo 4 están destinados a albergar a la población femenina, el resto de mujeres privadas de libertad se ubican en 49 módulos femeninos dentro de prisiones para hombres.

Finalmente, en el estado español existen tres grados de privación de libertad y libertad condicional: a) Primer grado: es aquel que se cumple en régimen cerrado con unas condiciones muy limitadas y rígidas (Jiménez, 2013); b) Segundo grado o Régimen Ordinario: es el grado en que son clasificadas la mayoría de las personas condenadas c)Tercer grado: régimen abierto semi-abierto de semi-libertad.

Además, como establece teóricamente la Secretaría General de Instituciones Penitenciarias se debe dar el "cumplimiento de la condena allí donde el preso tenga arraigo social". Sin embargo, en la práctica, este principio es de difícil cumplimiento sobre todo para el caso de las mujeres con hijos, ya que únicamente existen 3 unidades de madres en toda España, con lo cual el arraigo social queda puesto a un lado. Al igual sucede en aquellos casos en que ambos miembros de la pareja se encuentran encarcelados y quieran convivir con sus hijos menores de 3 años, la unidad familiar con estas características tan solo la alberga el Centro Penitenciario de Madrid VI.

Este modelo organizativo de las prisiones hace que el Defensor del Pueblo Andaluz, ya desde los años 90, venga reclamando la reforma de las prisiones para mujeres y su readaptación a las políticas de igualdad y reinserción (Pascual, s.f.). Esto le llevará en 2006 a denunciar que:

las mujeres se encontraban impedidas de disfrutar de determinadas zonas, que en algunos centros no hay espacio en las enfermerías para las mujeres, no se les permite acceder al módulo terapéutico, etc. Además de la imposibilidad de introducir criterios de separación y clasificación teniendo en cuenta su personalidad e historial delictivo (Mapelli, 2013: 66). 
En este sentido, también se han puesto en marcha algunas medidas, tanto a nivel internacional como nacional. En el marco europeo, tanto las Reglas de las Naciones Unidas para el tratamiento de las reclusas y medidas no privativas de libertad para las mujeres delincuentes, dictadas por la ONU en 1977; como las Reglas Penitenciarias Europeas por el Consejo Europeo en su tercera versión (2006); y el Informe de la Comisión de Derechos de la Mujer e Igualdad de Género (2007/2116, INI) del Parlamento Europeo de 15 de febrero de 2008, sobre la situación especial de las mujeres en los centros penitenciarios y las repercusiones de la encarcelación de los padres sobre la vida social y familiar (2007/2116 (INI), han venido a denunciar la situación penitenciaria de las mujeres, incidiendo en las situaciones discriminatorias a las que estas tienen que hacer frente. Entre las principales recomendaciones del Parlamento Europeo en esta materia están:

la necesidad de adaptación a las necesidades específicas de las mujeres recluidas que promuevan la igualdad y tengan en cuenta las circunstancias específicas de las mujeres embarazadas; el promover la conservación de los lazos familiares sobre todo reduciendo el impacto del encarcelamiento en los menores; y, la preparación para el futuro (educación, formación, empleo e integración social) (García-Vita, 2015: 116).

A nivel nacional, la Secretaría General de Instituciones Penitenciarias ha tomado algunas medidas y ha puesto en marcha ciertos programas para el fomento de la igualdad entre mujeres y hombres en el ámbito penitenciario. Entre las más importantes está el Plan Estratégico de Igualdad de Oportunidades entre Mujeres y Hombres 2008-2011. Sin embargo, todavía nos enfrentamos a la existencia de numerosos problemas, tanto sociales como económicos, que impiden que estas normas pasen de ser meras declaraciones de intenciones a convertirse en acciones concretas (Pascual, s.f.: 3).

Finalmente, respecto al elemento cuantitativo, el Institute for Criminal Policy Reserach en su investigación mas reciente afirma que más de 10,35 millones de personas en el mundo se encuentran en situación de privación de libertad (Wamsley, 2016). De las cuales más de 700,000 mil son mujeres y niñas.

Desde el año 2000 la población mundial total privada de libertad se ha incrementado en torno al 20\%. Los datos indican que los niveles de población femenina en esta situación han crecido más rápido que los niveles de hombres, 
esto es, en torno al $15 \%$ en los últimos 15 años según "The World Female Imprisionent List" (Walmsley, 2015). De acuerdo con esta investigación América sería el continente con mayor número de mujeres privadas de libertad, 297.663 (Estados Unidos, 205.000; Brasil, 37.380; México, 13.000), seguido de Asia, 264.626 y Europa, 103.250. En el continente europeo el primer lugar lo ocupa España con 4.982 mujeres, seguida de Inglaterra con 3.922, Alemania con 3.753, Italia con 2.122 y Francia con 2.032 (Wamsley, 2015).

Como se puede ver, España ocupa el primer lugar. Según la Secretaría General de Instituciones Penitenciaras, en su estadística de mayo (2016), la distribución de la población reclusa según el sexo era de un 92,44\% hombres (56.977) frente al 7,56\% de mujeres (4.657). Siendo tanto para mujeres como para hombres la franja de edad más representada la que oscila entre los 41 y los 60 años, seguida de aquellas personas que tienen entre 31 y 40 años. Del total de población, 16.187 hombres y 1.317 de mujeres son extranjeras.

El porcentaje de mujeres en España cumpliendo pena privativa de libertad es mínimo en comparación con el de hombres. En cambio, los porcentajes varían si, en vez de referirnos al total de personas penadas en prisión, los hallamos en relación con las personas reclusas con motivo de condenas por delitos relativos a drogas. Alrededor de un 27-26\% de los/as internos/as en centros penitenciarios son personas que están cumpliendo condena por delitos contra la salud pública; dentro de este colectivo alrededor de un $87 \%$ de las personas condenadas por estas infracciones, son hombres, y las mujeres representan aproximadamente el 13\%. Si analizamos la importancia de las condenas por tráfico de drogas en cada sexo, obtenemos que en el colectivo de varones, alrededor de un $25 \%$ de los penados en prisión está cumpliendo pena privativa de libertad por estos delitos, mientras que en las mujeres el porcentaje se mueve aproximadamente entre el 4448\%, según los años, incluso llegando al 50\% en 2009 (Secretaría General de Instituciones Penitenciarias).

Conjuntamente con el fenómeno de la inmigración y de las mujeres extranjeras en prisión, también hay que tener en cuenta, que una gran parte de la población femenina española que se encuentra privada de libertad es de etnia gitana, 
alrededor del 35\% (Yagüe, 2007), lo que "supone que el factor multicultural determina comportamientos, hábitos, tradiciones, cultos, lenguas, etc., de manera fundamental en el medio penitenciario"(Jiménez, 2015: 109).

\section{Ingredientes metodológicos}

"El valor de lo que hacemos: gente real que se encuentra con otra gente real en un lugar real y en un momento en el tiempo"

(Gimeno, 2011: 155)

¿Cómo pensar la cárcel y el género? ¿de qué forma atraviesa la realidad penitenciaria a las mujeres? ¿cuáles son las particularidades a las que tienen que hacer frente las mujeres en este contexto? Son las preguntas principales que vertebran esta investigación.

Para buscar las posibles y parciales respuestas a ellas, he utilizado el enfoque etnográfico y la autoetnografía. Por un lado, he llevado a cabo entrevistas con mujeres que de diversas formas han experimentado la realidad penitenciaria, así como con profesionales. Por otro lado, mediante un ejercicio de memoria y evocación he trabajado y recuperado acontecimientos, situaciones e información recogida durante mi estancia en el Centro Penitenciario de Albolote. Finalmente, durante este proceso de iniciación a la etnografía, llevo a cabo un análisis de lo que supone acceder al trabajo de campo durante los procesos de adaptación a la vida en libertad de estas mujeres y los primeros contactos en el mismo.

Mi objetivo de investigación es reconocer y analizar las particularidades de género en las experiencias de las mujeres presas durante todo el proceso, desde la entrada en prisión hasta la puesta en libertad.

El enfoque epistemológico de esta investigación es finito y parcial. Dentro del campo de las prisiones me sitúo políticamente desde un enfoque abolicionista y feminista. Opto por una metodología interseccional como elemento que me ha sido útil para comprender las experiencias de criminalización, castigo, luchas y resistencias de estas mujeres. Reconociendo que "las violencias interseccionales de 
género, raza, clase y sexualidad, son la condición de posibilidad para la perpetuación de la cárcel como herramienta fundamental para controlar a los indeseables del capitalismo global (Crenshaw, 1994; Curiel, 2007; Davis, 2003; Lugones, 2008; Viveros, 2002)" (Bello, 2013: 11).

Soy consciente de que en muchas ocasiones los formatos académicos obligan a excluir de la redacción final, en gran medida, las reflexiones y las experiencias vividas por la investigadora durante el trabajo de campo. No obstante considero que este no es el caso, en todo momento he tenido la oportunidad y la intención de incorporar mi persona como un elemento más a lo largo de toda la investigación, y asumo que hay decisiones y dilemas que, efectivamente, han influido en la producción de conocimiento y en el resultado final de este trabajo. He escogido este enfoque que incorpora la autoetnografía por el valor emancipatorio que presenta, al conceder voz a quienes en ocasiones no se les otorga en un proceso de investigación, es decir, a la propia investigadora y, por otro lado, al romper con los constreñimientos positivistas de metodologías que se rigen por criterios de fiabilidad, cientificidad, objetividad, potenciando las capacidades creativas de las y los investigadores (Guerrero, 2014).

Un trabajo de campo inacabado o en producción, puesto que me encuentro en el inicio de mi tesis doctoral, que me ha permitido ser consciente de que este proceso es una suma de numerosos acontecimientos, no todos controlados por la investigadora, en este caso por mí. Por lo tanto, no poder controlar estos acontecimientos se ha vuelto una característica básica de mi trabajo, tomando conciencia de que se trata de entablar relaciones con las personas, y que tanto las personas como las relaciones son imprevisibles (Cerri, 2011: 362).

Finalmente, he decidido que este documento no podía ser una labor de limpieza absoluta del rastro que mis subjetividades, sentimientos y sensaciones estaban dejando en el mismo, como si tuviera que desecharlos para llegar a ser profesional. Todo ello - yo - ha llevado hasta el último momento a modificaciones constantes del plan de trabajo y los objetivos de la investigación, circunstancias personales que llegan y que me han hecho comprender que afrontarlas y adaptarte también forman parte de este trabajo. Por ello parto de la imposibilidad de la neutralidad de mi persona como investigadora (Gregorio, 2006). 
Igualmente, acceder a todos mis recuerdos, tomar consciencia de que recogían saberes múltiples, importantes y centrales, y reconocerlo como tal, ha sido para mí la forma más honesta de plantearme mi trabajo como investigadora recién iniciada, no soy más que, como reconocía Ruth Behar, esa mujer que "ha llegado a conocer a otros conociéndose a sí misma y que ha llegado a conocerse conociendo a otros" (Behar, 1996: 33). Este trabajo está escrito desde la tranquilidad, motivación y comodidad que la autoetnografía me ha permitido al enseñarme que "permanentemente debemos preguntarnos sobre lo que hemos aprendido del encuentro con los otros y, también, sobre lo que ello nos ha permitido aprender acerca de nosotros" (Azaola, 2005: 12).

La práctica de recuperar los relatos de las vidas de estas mujeres que había recogido hace dos años, así como las entrevistas mantenidas estos últimos meses, como herramienta metodológica, me han permitido reconocer que por algún motivo "es importante conocer y considerar la vida de alguien" (Piña, 1986: 1). Siguiendo a la antropóloga Ruth Behar (2009: 39):

no podemos vivir sin historias. Nuestra necesidad de ellas es tan grande, tan intensa, tan esencial, que perderíamos nuestra condición de humanos si dejáramos de contar historias sobre lo que creemos que somos. Más importante aún: si dejáramos de querer escuchar las historias de cada uno. Hace diez años creía que si cada mujer pudiera contar su historia y ser escuchada, podríamos cambiar el mundo.

Realizar trabajo de campo en la actualidad implica reconocer que existe una variedad muy amplia de procesos "en los que lo personal e impersonal, local, nacional y global se entrelazan de maneras complejas y le dan un contenido peculiar, tanto a la observación como a la participación" (Jimeno, 2012: 8).

Por otro lado, la etnografía feminista me lleva a preguntarme acerca de cuáles son las implicaciones de mi figura investigadora "como conocedora generizada" (Gregorio, 2006: 30). Es decir, me ha permitido reflexionar y plantearme cuestiones en relación a una posible "disolución entre sujeto -conocedor- y objeto - de conocimiento-, entre el yo y el otro para tomar un camino dialógico e intersubjetivo desde posiciones políticas situadas" (Gregorio, 2006: 30).

Esta metodología, es a la vez un posicionamiento ético, una concienciación crítica que exige reflexionar acerca de cómo me sitúo dentro de las categorías socialmente construidas que crean o borran el poder y el privilegio: raza, etnicidad, religión, género, preferencia sexual, lenguaje... (Tilley, 2014: 273). 
Esta investigación toma como punto de partida la categoría de "conocimientos situados" acuñada por Donna Haraway (1995), es decir, frente a la producción de conocimiento científico tradicional, postindustrial, racista, masculinicista y militarizado, se propone un conocimiento parcial, localizado, crítico y paradójico, encarnado en una visión, que presenta el SELF de la investigadora como dividido y contradictorio, es decir, el yo que conoce es siempre parcial en todas sus facetas. Por un lado, este yo que conoce es responsable de sus prácticas y de la forma en que mira y es sensible al poder. Se trata de una visión desde un cuerpo complejo, contradictorio, estructurante y estructurado, frente a la visión tradicional científica desde arriba y desde la simpleza. Por otro lado, entiende que los "objetos de conocimiento" son un "aparato de producción corporal", es decir, eje activo y generador de conocimiento, actores a la vez que agentes de la investigación (Haraway, 1995: 339).

Los conocimientos situados y de la gente permiten trabajar desde un reconocimiento del derecho a la palabra y al discurso, lo que Marcela Lagarde (2011) denomina equifonía, "frente al silenciamiento de las mujeres y la sordera a la voz y los saberes de las mujeres ... el presupuesto para el diálogo y la posibilidad de la pluralidad y la empatía" (Lagarde, 2011: 45). Desmontando violencias, despotismo y autoritarismo.

El proyecto parte, simultáneamente, de posiciones personales, sociales, culturales, históricas, múltiples, contextuales y colectivas, es decir, defiendo que "desde nuestras trayectorias concretas y cotidianas podemos explicar cómo los significados dominantes del mundo son encarnados por las personas" (Poó, 2009: 3), y en este sentido nuestros deseos, sentimientos, experiencias, opresiones toman sentido. En este momento, y siguiendo a Carmen Gregorio (2006: 36) lo personal no solo es y debe ser político, también es teórico, lo privado da un salto a lo público.

Las investigaciones feministas tienen que poner atención a las "micropolíticas de contexto, subjetividad y lucha, así como a la macropolítica de los sistemas y procesos políticos y económicos globales" (Mohanty, 2008: 411). Así podremos ver cómo "lo particular a menudo tiene un significado universal - sin que lo particular 
se borre por el uso de lo universal y sin plantear una brecha infranqueable entre ambos términos" (Mohanty, 2008: 411).

En cuanto a las mujeres que han colaborado con sus historias, relatos y experiencias de vida personales, subjetivas y únicas, todas ellas comparten la experiencia de haberse relacionado con el sistema penitenciario. Edad, tipo de delito, procedencia, formación... entre otras categorías, no son categorías que hayan guiado mi proceso de contacto y de relación con las mujeres que colaboran en este trabajo. El interés ha residido en dos cuestiones, por un lado, en que de cualquiera de las formas posibles estas personas se identificaran con la categoría mujer, sea cual fuese la manera de hacerlo. Y, por otro lado, se hubieran relacionado con el sistema penitenciario.

Antes de continuar avanzando, quisiera detenerme en un aspecto que ha ocupado mi tiempo y mi mente ampliamente durante este proceso. Deviniendo uno de los principales dilemas éticos de esta investigación: entender y decidir sobre cómo equilibrar las necesidades de la investigación y las necesidades de mis sujetas de investigación en todo lo relativo a los delitos. Esto es, el delito cometido es culpa y etiqueta que persigue a todas las mujeres que han estado privadas de libertad y, en cierto moto, también me ha acompañado a mí. La cotidianeidad con la que me he visto obligada a justificarme del por qué no pongo mi foco de interés en el tipo de delito cometido y por qué no es necesario hacerlo para mí, me obliga a dedicar un espacio a ello. El delito para ellas viene acompañado de culpa y estigmas; para la mente curiosa que desea conocerlo, de morbo y desconocimiento; para mí de impotencia, por ser consciente de que una vez enunciado tu trabajo, de forma habitual la única resonancia en el receptor era esto mismo, el delito. Todas nosotras desaparecíamos y las sabias personas interpeladoras comenzaban a dar sus magistrales lecciones acerca de qué se debe condenar, por qué y a quién; pero acaso ¿no está ya lo suficientemente presente el delito en la cotidianeidad y pensamientos de estas mujeres?

Me detuve a pensar en el morbo y en el para qué de este trabajo, sobre si reflexionar y profundizar en el delito lo enriquecía. Finalmente, he decidido rotundamente que no, no es necesario para esta investigación nutrir la curiosidad de los demás en este aspecto, no entra dentro de los objetivos planteados. Sin 
embargo, sí considero central, reconocer el estigma que podía crear con este proyecto si centralizaba este aspecto del delito cometido. Solo ha sido en este momento, en el que he asumido el ejercicio de ficción que supone narrar. Soy consciente de que con esta elección he tenido que renunciar a ciertos aspectos, sin embargo, considero que me ha permitido acceder a otros saberes. Reconozco que en esta investigación existen muchos puntos muertos que o no he alcanzado a ver, o no se han sacado a la luz o no he querido incorporar. Siempre que nos proponemos narrar un hecho, una vida, una experiencia debemos tener en cuenta que habrá algo que no veamos, que no contemos y de lo que no seamos conscientes.

Mi objetivo no ha sido escoger a mujeres con perfiles que se adaptaran a la investigación. Es decir, he evitado la creación de estos perfiles o categorías fijas e inmutables asignadas, ya que, se entiende "el propio acto de categorizar como una expresión de poder" (Gregorio, 2006: 30). Por lo tanto, no ha sido la búsqueda de un objetivo previamente establecido lo que ha guiado el trabajo, sino el análisis de los saberes de estas mujeres que me han llegado. No quería buscar saberes que se adaptaran a la investigación, he preferido adaptar la investigación a los saberes que estas mujeres han querido compartir:

Cuando alguien busca -dijo Siddhartha-, suele ocurrir que sus ojos sólo ven aquello que anda buscando, y ya no logra encontrar nada ni se vuelve receptivo a nada porque sólo piensa en lo que busca, porque tiene un objetivo y se halla poseído por él (Hesse, 1981: 174).

Durante todo el proceso he reflexionado sobre la necesidad o no de elaborar estadísticas sobre estas mujeres. No es casual que no estén aquí desarrolladas, ni se vaya a hacer en las siguientes páginas. Sin embargo, con ello no quiero desechar la perspectiva cuantitativa y lo importante de los datos para nombrar numéricamente las realidades. No obstante, la naturaleza de esta investigación no residía en este punto, y sentí que hacerlo podía crear realidad, además de simplificar todas y cada una de las características de estas mujeres aún más de lo que el propio sistema lo hace. Siento que dejaría al margen a tantas de ellas a las que pongo cara y nombre y que no se sentirían incluidas, que decido no hacerlo. Los números nos perjudican, es decir, el menor porcentaje de mujeres frente a hombres que se encuentran en las prisiones siempre es la excusa suficiente para 
centrar investigaciones, recursos y servicios en ellos. Si descentramos la mirada de este punto, descubrimos las peculiaridades que el paso por prisión tiene para las mujeres y que se escapan de los números.

Desde el inicio de este proceso de investigación continuamente me ha asaltado la pregunta sobre ¿qué sentido tiene lo que estoy haciendo? El hecho de hacerme esta pregunta me llenaba de inseguridad. La respuesta para obtener el título del master no era suficiente y me preocupaba la posición de parálisis en la que me posicionaba ante mi trabajo cada vez que salía a la luz este interrogante. Finalmente fui consciente que esta pregunta sobre el sentido, era una pregunta de orientación, buscando situarme en algún plano para tomar una dirección. Una parte de mí ansiaba encontrar las palabas clave, justas, únicas y bien cifradas o esas "frases perfectamente encadenadas que, razonadamente, nos proporcionen una significación inconfundible y nada ambigua al respecto" (Martínez, 2006: 79). Leyendo a esta autora entendí que el sentido proviene también de la incompletud más radical que existe entre la palabra y la vida y que debía darle la posibilidad de ser horizonte. Pensando en ello, esta búsqueda de sentido que continuamente ansiaba devino en una pregunta en la que me encontraba más cómoda ¿para qué lo estoy haciendo? Dejó de preocuparme no tanto el hallazgo de una respuesta clara como el planteamiento y el reconocimiento de los claroscuros de mi problema de investigación, con un contorno y dirección siempre en movimiento (Martínez, 2006).

Finalmente - antes de describir brevemente las distintas fases de la investigación- uno de los últimos aspectos y dilemas que me han asaltado en este proceso ha sido la decisión sobre cómo nombrar a todas las personas cuyos testimonios, de una forma u otra quedan recogidos en estas páginas. Aquellas mujeres y profesionales a las que he tenido oportunidad de preguntar sobre la forma en que les gustaría ser llamadas lo he hecho, pues las entrevistas y encuentros los he mantenido a lo largo de estos últimos meses y, efectivamente, se ha dado la posibilidad. Sin embargo, existen otras mujeres con las que tuve los encuentros años atrás, en concreto dos entrevistas extensas que realicé para mi trabajo fin de grado y que ahora recupero, y los muchísimos encuentros con otras mujeres en el espacio del Centro Penitenciario de Albolote durante mis prácticas. A 
estas últimas asumo que directamente las he lanzado al anonimato, es la única forma que he tenido de "protegerlas" en el sentido en que tampoco ellas decidieron de forma consciente sobre su participación en esta investigación, aunque sí en mi Trabajo Fin de Grado. Plasmarlo en estas páginas y reconocer lo problemático de toda esta situación es la opción más honesta y sensible que he encontrado. Asumiendo que ello no justifica ni elimina el uso que he hecho de una información privilegiada en una relación de poder.

\section{a) Fases metodológicas}

La elaboración de este Trabajo Fin de Master se ha llevado a cabo en cuatro fases durante un periodo de seis meses, aunque se podría decir que no se han dado de forma lineal ni en una única dirección, en muchas ocasiones se han solapado, y ha sido un constante venir y devenir unas sobre otras.

Un primer momento exploratorio, de búsqueda bibliográfica y diseño del trabajo, esta actividad se ha mantenido en el tiempo y la lectura y análisis de textos, artículos, libros, películas, ha sido una tónica constante durante todo el proceso.

Un segundo momento, que me ha ocupado mucho más del tiempo previsto, ha sido el acceso al campo, negociación, contactos con asociaciones, con profesionales, permisos de acceso al Centro de Inserción Social Matilde Cantos de Granada. Siendo esta una de las razones por las que, en mitad del proceso, los objetivos de la investigación son modificados (aspecto que desarrollo en mayor medida en el último apartado del análisis). Las negociaciones de acceso han sido difíciles especialmente por tres razones. Por un lado, la escasez de recursos en la provincia de Granada destinados de forma específica a estas mujeres. Por otro lado, a causa de la diversidad de trayectorias que toman las mujeres tras finalizar su estancia en los Centros Penitenciarios Ordinarios que hace que seguirles la pista sea difícil. Y, finalmente, y muy relacionado con la escasez de recursos, me he encontrado con la complejidad en las relaciones con los y las profesionales. La dificultad planteada de acceso al campo por la existencia de una especie de red (informal) de profesionales que podría ser vista - metafóricamente - como la máxima extensión del sistema panóptico carcelario, es decir, el hermetismo y 
control que caracterizan a la estructura de prisiones llega hasta los y las profesionales que se encuentran totalmente ajenos, geográficamente hablando, a dicha realidad. Digo geográficamente, porque no se encuentra físicamente dentro de la prisión o de la Administración Penitenciaria, pero por su trabajo reproduciendo la consideración de que no son sujetas con capacidad de decisión y ejerciendo actividades de control. En cualquier momento recurren y hacen uso de la sensibilidad y complejidad del tema antes de dar, incluso, la posibilidad de plantearles a las mujeres su participación. He sentido firmemente, que para poder llegar a mis compañeras, previamente debía pasar por profesionales que dieran su "visto bueno" a mi trabajo, una evaluación informal con la que no contaba durante el diseño de la investigación pero que definitivamente ha condicionado en exceso el trabajo de campo, un trabajo que en un principio no iría destinado a ellos, y que definitivamente, he tenido que amoldar. Elegí mujeres que estuvieran ya en libertad - una libertad física, porque, como se ha podido ver, los brazos del sistema se extienden bastante más lejos de lo que nunca hubiera pensado - para evitar las limitaciones que el propio sistema penitenciario incorpora y que pueden ralentizar considerablemente los plazos de una investigación. Es decir, solicitud de permisos de acceso al campo, análisis y evaluación del proyecto de investigación, presentación de guiones de entrevistas que también deben ser evaluados y, finalmente, devolución de la información recogida. Si tenemos en cuenta la razón que justifica mi elección de dichas mujeres, la facilidad de acceso a ellas y opción de evitar que se establecieran limitaciones y requisitos por parte de la institución queda totalmente puesta en tela de juicio. El acceso al campo ha sido y sigue siendo difícil, la extensión de los brazos del sistema llega hasta el control que los profesionales que intervienen fuera de la prisión llevan a cabo sobre las personas que pueden o no pueden aproximarse a estas mujeres, en gran medida son ellos los que deciden qué personas son aptas o no para vincularse a las mujeres y no ellas mismas. Paradójicamente, se las sigue considerando personas sin agencia ni capacidad suficiente para decidir sobre sus acciones y su día a día, en concreto, sobre su participación o no en este trabajo. Esto me lleva a reflexionar que durante el proceso investigativo no solo es suficiente con pensar y trabajar sobre cómo quería situarme yo ante las mujeres con las que quería colaborar y qué podía hacer por mi parte para evitar que estas relaciones de poder tan fuertes se establecieran, 
este ejercicio carece de sentido si no tengo en cuenta algo que, como he dicho anteriormente, no había tenido: las relaciones de poder que ejercen estos profesionales sobre las mujeres y las relaciones de poder que estos también han ejercido sobre mí como investigadora. Frases tales como: "no quiero que se sientan como un escaparate" o "necesitaría una carta que acredite tu investigación por la Universidad de Granada", entiendo que no vienen cargadas de inocencia, sino de control y, de cierta forma, como método que sigue reproduciendo etiquetas y una carga de estigma sobre este colectivo y extendiendo los brazos del castigo.

Creo especialmente relevante desarrollar y evidenciar este aspecto de mi investigación porque ha sido una limitación considerable de la misma y me ha obligado a permanecer sin poder acceder directamente a ellas durante dos meses y que, por tanto, ha modificado, informado y nutrido mis preguntas de investigación. Es decir, es un aspecto sobre el que continuaré trabajando y profundizando para mi proyecto doctoral que previamente no había considerado.

Por otro lado, ha habido un cambio a lo largo de todo el proceso y toma de conciencia de lo que consideraba y considero actualmente "mi trabajo de campo", es decir, como trabajo de campo, al inicio, únicamente nombraba al hecho de poder estar en el recurso de piso de acogida con estas mujeres - era mi idea inicial - sin embargo, al final del proceso, he acabado entendiendo que mi trabajo de campo comenzó mucho antes, está compuesto por todo el recorrido, desde el contacto por teléfono con el primer profesional, hasta la planificación de las entrevistas, reuniones, diálogos con mi tutora, asistencia a seminarios, congresos, e incluso conversaciones con mi familia y amistades.

$\mathrm{Al}$ inicio, mis preocupaciones se centraron en las expectativas, el rechazo o las suspicacias que pudiera generar yo como una extraña, etiquetas y categorías que me había auto-fijado de forma totalmente aleatoria. Tras un seminario sobre autoetnografía entendí que superar estas etiquetas únicamente pasaba por mí y por autorizarme a mí misma, no dar poder a los demás para juzgarme y no verme como una persona ajena (crearme yo misma como una "otra") que, con la única excusa de la formación académica, me tomo el derecho de profundizar sobre un tema delicado y que marca la vida de estas mujeres. 
En tercer lugar, en paralelo a esta fase, he venido realizando mi trabajo de campo y las entrevistas con las mujeres y los/as profesionales que finalmente han accedido a ello. Un paso previo a ello ha sido la elaboración de un documento de consentimiento informado. Lo elaboré en mitad de todas las dificultades anteriormente descritas, y ha sido una herramienta con la que he buscado superar todas estas barreras que interrumpían nuestro contacto directo. Intenté mostrarme de forma honesta, clara y sencilla en estas páginas, para que su lectura fuera amena y rápida para las mujeres que estuvieran interesadas en participar y no supusiera una dificultad añadida. ${ }^{8}$

Finalmente, en último lugar, he llevado a cabo la escucha, transcripción y lectura de la información y saberes recogidos, así como el análisis y elaboración del documento final, que hoy es presentado.

\section{ATRAVESANDO LA PRISIÓN}

$$
\begin{array}{r}
\text { "En estas páginas podrán ustedes encontrar mucho coraje: } \\
\text { el coraje de ser mujer, el coraje que da la antropología, } \\
\text { el coraje que da la política (...) parte de este coraje } \\
\text { pertenece a mi comadre, parte proviene de mí, } \\
\text { y parte nos embarga parejamente" } \\
\text { (Behar, 2009: 43) }
\end{array}
$$

Para el análisis del proceso de investigación llevado a cabo acudo al símil metafórico de lo que podría ser el paso por prisión - de cualquier mujer que haya podido vivir esta realidad. Con ello no solo me refiero a personas cuya experiencia haya estado atravesada por la privación directa y en primera persona de la libertad física, también todas aquellas que indirectamente pudieran sufrirla, familiares, amigos y amigas, profesionales... o incluso a quienes sin haber conocido el sistema penitenciario, sea cual sea el ángulo en el que nos situemos, sistema educativo, hospitales, centros de internamiento de inmigrantes, servicios sociales, universidad... hayamos sentido las prisiones de nuestras vidas, el peso de las rejas sobre nuestros cuerpos por salirnos de roles y acciones que la sociedad espera de nosotros, por creer y luchar por identidades diversas u ocupar espacios que determinadas personas consideran aptos o no para unos y otras.

\footnotetext{
8 Este modelo se encuentra en el anexo III.
} 
Cuando me refiero al paso por prisión soy consciente de la diversidad de trayectorias, historias y subjetividades que engloba, de la linealidad o no de los procesos que cada una de estas mujeres experimenta. En este caso concreto, identifico este proceso - mi proceso - con un círculo compuesto por diversas fases, y que vuelve al punto de partida, cargado de interrogantes, al tratarse de una trayectoria de investigación que no encuentra su fin en este proyecto fin de master, sino que se trata del inicio del proceso de tesis doctoral.

Es decir, la forma en que estructuro este paso metafórico por prisión se corresponde con el antes, durante y después de la experiencia carcelaria, consciente siempre de que es un "juego" simbólico y figurado, con el fin de recoger la inmensidad y complejidad del sistema carcelario, y cuyas etapas en la vida de estas mujeres pueden no ser tan claras y diferenciadas.

En primer lugar, narro el proceso por el cual defino mi problema de investigación. Cómo llego a la realidad penitenciaria y cómo afronto todas las complejidades y contradicciones generadas durante este tiempo. En la realidad, el paso previo a la entrada en prisión es la comisión de un delito, y la existencia de una sentencia firme que así lo ratifique o la situación preventiva a la espera de dicha sentencia. Es decir, mi entrada al sistema carcelario no sigue este proceso. En primer lugar, mi vinculación llega como práctica de Trabajo Social y más tarde como voluntaria e investigadora. A diferencia de las mujeres presas yo no he sido acusada de cometer un delito, no estoy privada de libertad. Mi estancia en prisión y la investigación fueron una elección personal, así mis propios intereses e interrogantes fueron los que generaron este acercamiento. Todo ello me lleva a pensar que, aunque no sea una decisión consciente, esta posición implica que no existe una igualdad entre nosotras debido a los diferentes roles que llevamos a cabo unas y otra.

A continuación, hago referencia geográficamente al Centro Penitenciario de Albolote y mi estancia en el mismo durante ocho meses como estudiante de prácticas de grado en Trabajo Social de la Universidad de Granada. Aquí recupero toda la información recogida acerca de lo que el sistema penitenciario nos dice sobre lo que implica ser mujer privada de libertad, cómo actúa el género en un sistema creado por y para hombres. 
El último apartado se corresponde con la puesta en libertad, que puede deberse a la finalización de la condena o al cumplimiento en tercer grado o semi libertad. En este punto recojo mi proceso de acceso y trabajo de campo en la actualidad, ¿qué he aprendido sobre el propio sistema carcelario a raíz de querer investigar sobre reinserción de mujeres? Es la pregunta principal que rige este apartado.

Por otro lado, cuando hago mención a de cualquier mujer, elijo la categoría mujer - siendo consciente de las dificultades y los dilemas que ha generado en mí durante todo el proceso elegir cómo nombrar - porque en este ámbito funciona de manera rígida el binomio hombre-mujer, u ocupas un espacio u ocupas otro, el sistema te identifica con una de las dos formas, sin dar opción a otros sentires. Esto no significa que identidades y cuerpos que no se sienten representados por este binomio hombre-mujer no ocupen los espacios carcelarios, algo a lo que volveré más adelante.

Sin embargo, y de forma contradictoria, durante todo el proyecto de investigación entiendo esta categoría mujer como una realidad subjetiva y única de cualquier persona que se defina en torno a ella o que a lo largo de su proceso vital en algún momento se haya definido de esta forma. Como concepto atravesado por la interseccionalidad, abierto, dinámico, cambiante y performativo, que es y deja de ser al mismo tiempo, en construcción constante y con las contradicciones y/o certezas que ello pudiera generar. Finalmente, en relación a esta forma de identificar la categoría mujer, también me permite definir mi yo, como sujeta investigadora, cuerpo que ha sentido la experiencia de prisión y como mujer, blanca, heterosexual, joven, europea, estudiante, feminista, trabajadora social, viajera $\ldots$

Este trabajo es un ejercicio experimental, un intento de abordar, explorar y desplegar la cantidad de información y saberes múltiples recogidos desde el inicio de mi relación con el sistema penitenciario en 2013 hasta la actualidad. Saberes algunos generados desde los márgenes, otros desde los centros neurálgicos del poder. En una búsqueda por reconocer todo lo que las presencias y ausencias durante este tiempo me han dicho y nos dicen sobre el sistema penitenciario y la forma en que define y encarcela a las mujeres. Una manera de encontrar sentido a este proceso vivencial - que dura ya tres años - que me ha permitido no reducirlo, 
ni sobrestimarlo, al contrario, ponerlo en valor. Ha cobrado poder y sentido precisamente al hacerlo desde todas las contradicciones, confusiones, de volver tres años atrás, y de las desorientaciones y ambigüedades del estar y el vivir este proceso también en el presente. Cuando me refiero a sentido, lo hago siguiendo la definición que la doctora en psicología social Luz Ma Martínez (2006: 77) presenta:

El sentido es a la vez acto de apertura y situación ante lo "real", ante el mundo, por lo cual no debe querer limitar, sino más bien al contrario, debe gestarse y ponerse en marcha para avanzar sobre límites. De este modo, el sentido quedará expuesto como una búsqueda de inteligibilidad en acción, como pensamiento crítico.

El apartado que a continuación desarrollo, cómo llego hasta la prisión, es para mí, personalmente, el que me ha alumbrado en la búsqueda de este sentido. El ejercicio de memoria y recuerdo llevado a cabo ha sacado a relucir aspectos de mi proceso que mi mente había desechado, bisagras clave para unir todos los hechos que tantas veces, por separado, me habían hecho dudar de mi trabajo. Me ha hecho consciente de que en muchas ocasiones tenemos la mala costumbre de usar el descuido tan a diario, olvidando que en los pequeños detalles reside una gran importancia, y que con ellos podemos construir grandes caminos.

\subsection{El cuerpo del delito: "trazos de una indefinición necesaria"9}

Este primer punto, como he dicho anteriormente, se correspondería metafóricamente con el paso previo de la entrada en prisión, la comisión de un delito. El Código Penal español ${ }^{10}$ (1995: 5) tipifica como delito todas aquellas "acciones y omisiones dolosas o imprudentes penadas por la ley".

Sin embargo, quisiera dejar claro que, en este caso, se trata de un juego de palabras, una especie de performance de lo que ha sido la definición de mi objeto de estudio - que se extiende desde 2010, pasando por el presente y proyectándose en el proceso de tesis doctoral -, un símil metafórico de todos los pasos y decisiones que he ido tomando y que me han llevado a vincularme a las prisiones y al sistema penitenciario, en mi caso bajo el rol de mujer pero no privada de libertad "física", sino como estudiante, práctica de Trabajo Social (en un principio)

\footnotetext{
9 Martínez, 2006: 77

10 Cuya última modificación data del abril de 2015
} 
y graduada en Trabajo Social (después) e investigadora.

En este punto quiero hablar de mi yo investigador, que apenas se inicia en este mundo, que realmente ni he podido ni he querido separar de mi yo más personal y subjetivo, ese que me construye social, política y culturalmente hablando.

Deseo honestamente situarme en esta investigación, y que esta narración permita a todas las lectoras comprender cómo y por qué he llegado hasta donde estoy y formarse opiniones propias al respecto. Porque yo, personalmente, prefiero y elijo saber de qué se me está queriendo contagiar, para poder valorar desde una posición más igualitaria como lectora (Poó, 2009).

Opto por explicar brevemente cómo llego hasta aquí no porque personalmente quiera situarme en el centro del trabajo, sino porque considero que hablar de ello lo enriquece y nos acerca al nosotras que juntas hemos construido y seguimos construyendo, pues no se trata en ninguno de los casos de un proceso acabado, tan solo del inicio del mismo.

Puesto que la vida nos atraviesa, forma parte también de nuestra escritura y de lo que decidimos trabajar o no. Es un ejercicio de honestidad y posicionamiento que todas las personas que leáis estas páginas sepáis desde dónde me situó, siendo consciente que todo ello no elimina las posibles relaciones de poder que, aún queriéndolas evitar, se han podido dar y se han dado.

Si cualquier persona me preguntase cuándo comienza mi experiencia penitenciaria, la primera respuesta sería el 15 de diciembre de 2013 en el Centro Penitenciario de Albolote, en el marco de mis prácticas de grado. Sin embargo, el ejercicio de memoria que he realizado para este apartado me lleva aún atrás en el tiempo, 2010 y el inicio de mis estudios de Grado en Trabajo Social en la Universidad de Granada , y se extiende hasta hoy.

Como establece la antropóloga Teresa del Valle (2006), el recuerdo y le evocación forman parte de la cara de una misma moneda que es la memoria, por tanto, conviven necesariamente con el olvido. Quisiera traer aquí las dificultades encontradas para la elaboración de este documento, cargado de emocionalidad, de momentos que no dejo de recordar, de otros que me llevan a la evocación y los 
olvidos involuntarios, pero también los voluntarios, de lo no contado conscientemente.

Toda la experiencia acumulada hasta hoy, y de manera significativa mis prácticas en prisión, supone para mí uno de los hitos más importantes de mi vida académica, profesional, pero también personal, me cambió y modificó mi forma de posicionarme en el mundo: "Nunca podemos escribir sobre lo que realmente pasó, ni dos segundos, ni diez años después; pero sí podemos escribir sobre lo que significa para nosotras y lo que estos significados nos permiten ser y hacer en el mundo" (Poó, 2009: 3).

Tres años después, tras la experiencia en el Máster GEMMA, asumo que mis reflexiones ahora quedan lejos de las que pude realizar en ese tiempo de inicio y que mi posicionamiento frente a la realidad con la que conviví es muy diferente. Es por ello que, a lo largo de todo el documento, no pretendo generar una verdad absoluta, ni tan siquiera reproducir fielmente aquello que viví y que vivo ahora. Aquí están volcadas todas las subjetividades, reflexiones y sensaciones de lo que experimenté y que sigo sintiendo, recordando, y de nuevo viviendo, en un punto completamente distinto al que estaba, donde el tiempo ha asentado ideas, ha permitido que trabaje otras muchas y me ha dado la posibilidad de que me siga construyendo.

Continuamente, durante este proceso, me ha asaltado la pregunta acerca de lo que supone volver y trabajar sobre procesos vividos con anterioridad y con otra finalidad. Es decir, continuamente han emergido a la superficie sensaciones de preocupación sobre el qué pensarían algunas de las mujeres presas con las que compartí años atrás momentos, historias y conversaciones, y que ahora, sin saberlo, llegan a formar parte de esta investigación, creándola y haciéndola posible. ¿Me he podido aprovechar de ellas? ¿es ético? Me impone y me asalta el miedo de pensar en estas mujeres, que tantísimo me ayudaron, se pudieran sentir atacadas, ofendidas o intimidadas. No he encontrado una respuesta o solución para esta sensación incómoda, a pesar de ello he construido este trabajo. Narrar este dilema y hacerlo explícito en el texto ha sido una de las opciones que he elegido, e intentar tratar las intimidades, cotidianeidades y experiencias vertidas de la forma 
más respetuosa y con el mayor de los reconocimientos y admiración por hacerme partícipes. Es irremediable pensar en cómo sus historias, tan llenas de agencia en muchas ocasiones y sin que ellas realmente hayan podido llegar a conocer la existencia de trabajo, han llegado a conformar este documento. Sin embargo, soy consciente de que ello no elimina esta dificultad y no me deja libre de generar malestares. Finalmente, he sentido lo que sus historias generan más allá de ellas, es decir, sin quererlo han formado parte también de mi recorrido, lo conforman, y no traerlas aquí sería como eliminar a su vez una parte de mí, y ello tampoco era el objetivo de este trabajo.

La reflexividad que en este apartado incorporo, o mi yo investigador y a la vez persona que hago central, no es sin más una confesión sincera de las motivaciones, de los supuestos personales...la reflexividad de la que hago uso me ha supuesto pensarme en la cárcel en términos de posiciones sociales, de las relaciones que he establecido, y continuo haciendo con las personas, y supone también que "el conocimiento producido de esta forma es un conocimiento posicionado, desde localizaciones particulares en el campo" (Gayane, 2007: 7).

Mis intereses, como he dicho al inicio del apartado - que no mi vinculación, esta vendrá después -, por el ámbito penitenciario nacen en los primeros meses de mi Grado en Trabajo Social en 2010. Seis años después sigo recordando la conversación/debate con una compañera - hoy una gran amiga - sobre cárcel, castigo y la función que debe cumplir la pena de privación de libertad. Traigo aquí este momento, como el primer hito importante dentro de mi proceso de formulación de mis intereses de investigación. Entiendo hito, siguiendo la definición de Teresa del Valle (1995:185) en relación a "aquellas decisiones, vivencias, que al recordarlas se constituyen en una referencia significativa (...) que se destacan con nitidez en el recuerdo".

En este momento vital, sin apenas haber leído y con una "conciencia crítica" respecto al tema formada únicamente por los medios de comunicación, me posicionaba y defendía rotundamente la dureza de los castigos y de la pena de privación de libertad sin medida para todas aquellas personas que habían ocasionado un mal a la sociedad. En este momento, los delitos casi quedaban reducidos para mí al asesinato y los abusos sexuales y desde este sentir defendía profundamente mi postura, haciendo enfadar y molestar profundamente a la 
persona que tenía enfrente, que intentaba por todos sus medios y herramientas de razonamiento explicarme otra forma de entender la prisión, y reflexionar sobre el fin de reinserción que establece la Constitución Española. En ese momento no sentí que este discurso permeara en mí de forma directa, sin embargo, caló hasta lo más profundo, tanto que sigo recordando la situación y las sensaciones hasta día de hoy, y fue el punto de inflexión, inicio e impulso que me ha llevado a mi interés actual de investigación.

En el siguiente curso doy un paso más allá y realizo un trabajo en grupo al que titulamos Mujer en el ámbito penitenciario. Releer este trabajo me ha emocionado porque los argumentos y contenidos que desarrollamos se nutren de posturas más alejadas de este primer discurso al que he hecho mención anteriormente: hay muchos estudios sobre el funcionamiento de las cárceles, respecto a los hombres, pero es bastante difícil encontrar investigaciones o trabajos sobre la situación de las mujeres en estos centros (pág. 2). Planteando como objetivos identificar y describir los recursos del sistema penitenciario para mujeres privadas de libertad, centrados en el Centro Penitenciario de Albolote y el Centro de Inserción Social Matilde Cantos de Granada; y, por otro lado, conocer el funcionamiento, composición y normativa vigente del Sistema Penitenciario español. Es emocionante de nuevo descubrir los juegos de la memoria y los olvidos que habían hecho que pasara por alto este aspecto, sin recordar que fue mi primer contacto con una profesional y una mujer que en ese momento se encontraba privada de libertad, por suerte recuperado en este esfuerzo por recoger $y$ reflexionar sobre lo que hoy ocupa el centro de mi vida académica y personal. Sin aún formación, sin perspectiva de género, ni mucho menos teorías feministas, comienza a vislumbrarse en mí un interés en ese campo, así como personalmente a generarse intuiciones respecto a lo que significaba esta dificultad para acceder a información e investigaciones sobre mujeres privadas de libertad y cómo existía una desigualdad en cuanto a recursos destinados a ellas frente a los destinados a hombres.

Seguidamente, durante mi estancia con la Beca Erasmus en la Metropolitan University College de Copenhague (Dinamarca) en 2013, como alumna del curso de International Social Work, que tenía como objetivos acercarnos y presentarnos al 
sistema de bienestar danés - escandinavo, conocimos a un chico, joven, danés de ascendencia musulmana que había estado en prisión y que, finalmente, había cumplido totalmente su condena, acontecimiento que desarrollaré en el último apartado por lo significativo del modelo de reinserción estándar al que aspiran en su mayoría los Sistemas Penitenciarios europeos de varón, joven, nacional y con un perfil que ellos llamarían "normalizado".

En diciembre de 2013 comienzan mis prácticas en el Centro Penitenciario de Albolote. Unas semanas antes acudo a un curso en la Facultad de Ciencias de la Educación sobre la realidad penitenciaria que lleva a cabo la Asociación Pides, con la que actualmente estoy realizando trabajo de campo. Ellos realizan sus intervenciones socio-educativas en esta prisión con un enfoque que difiere significativamente del que usa la institución, y atendiendo en muchas de las ocasiones el aspecto más humano y afectivo de estas mujeres y hombres que se encuentran cumpliendo condena en este lugar.

Todo lo anterior me lleva a solicitar y comenzar mis prácticas en el Centro Penitenciario de Albolote y a vincular mi Trabajo Fin de Grado a la realidad penitenciaria, y a las diversas formas de relacionarse con la droga que sentía que las mujeres privadas de libertad llevaban a cabo, es decir, entendiendo esta relación no solo como consumo directo, sino también en los delitos cometidos por las mujeres privadas de libertad.

Las condiciones carcelarias para llevar a cabo una investigación etnográfica son difíciles. No me refiero específicamente a las características materiales del lugar, lo hago pensado en lo que significa investigar el encierro y el castigo. Hago referencia al miedo a caer en el relativismo más severo cuando te ves envuelta a diario en historias de vida y problemáticas tan complejas, con una experiencia casi inexistente y con realidades muy fuertes que allí conviven. Con ello no quiero desmerecer otras vidas, historias y experiencias en otros contextos, busco reconocer que en determinados momentos hubo situaciones que me sobrepasaron, preocupaciones que no he sido capaz a día de hoy de dejar atrás y problemas que me conmovieron profundamente.

En paralelo, también he tomado consciencia de que con el paso de los días me fui acostumbrando e incluso naturalizando muchas de las dinámicas e 
historias que allí se daban, las diversas formas de ingreso, la entrega diaria de mi documento de identidad y los minutos de espera que le seguían, los registros del bolso, los objetos que no era posible introducir, las explicaciones para que en algunas ocasiones me lo permitiesen, el día que tienes que dejar atrás tu bolso. Al final todo ello también fue un proceso de aprendizaje, que en ocasiones crees que controlar y en otras muchas te llega a superar.

Hubo algo a lo que nunca llegué a acostumbrarme: el ruido de las puertas al abrirse y cerrarse continuamente. Este me generaba malestar y escalofríos y lo sigue haciendo. Así mismo, las sensaciones que me invadían al dejar atrás todos los días a las dos de la tarde esas instalaciones nunca cambiaron, por más rutina que ello suponía. Lo que implicaba dejar atrás, al otro lado del muro, a tantísimas personas me afectaba. Comparto y me identifico con las palabras de Julieta Vartabedian (2001: 8) sobre su experiencia etnográfica en prisión: “jamás me pude acostumbrar a esa sensación de 'abandono' que se producía con mi despedida diaria, jamás pude encontrarle el sentido a esta forma de castigar tan devastadora y cruel que aísla, denigra y modifica a las personas que transitan por una prisión". Antes no había sido capaz de nombrar estas sensaciones, ello ha sido uno de los aspectos que este trabajo fin de master me ha hecho recuperar, reconocer $y$ redactar.

Finalizadas mis prácticas, mi vinculación con las mujeres en prisión no cambiará con mi inicio del master Gemma, sin embargo, mi forma de aproximarme y entender la realidad lo hará drásticamente. Estos dos años comenzaron siendo de deconstrucción, cuestionamiento y descubrimiento de nuevas claves para entender la sociedad y de entenderme, conocerme a mí misma, de respetar y respetarme; y acaban con un compromiso personal, social, político, moral de lucha pacífica contra la crueldad del sistema patriarcal; y una defensa de los cuerpos, las identidades y las libertades de las mujeres.

Este proyecto me ha permitido repensar todo lo vivido y tomar conciencia de que había creado en mi mente, como forma de autocuidarme de aquello que me dolía, estructuras para relativizar y quitar importancia a todo lo vivido con estas mujeres en prisión. Sin embargo, siguiendo a Teresa del Valle (1995), ahora entiendo que: 
Hay cosas que solo el paso del tiempo puede esclarecerlas. Se trata de encontrar claves, en la mirada al pasado, que desvelan acontecimientos que se han vivido anteriormente pero cuyo significado aparece con otra claridad (...) hay momentos que se han vivido de manera independiente y que en el recuerdo aparecen concatenados como si de repente se hubiera descubierto la clave secreta que nos muestra un sentido hasta entonces escondido (pág.184).

Finalmente, el objetivo final de esta investigación no puede entenderse sin enmarcarlo en un acontecimiento que sucedió previo al Trabajo Fin de Master, como es mi matriculación en el Programa de Doctorado de Estudios de las Mujeres, Discursos y Prácticas de Género de la Universidad de Granada. Y la elaboración de mi plan de investigación, que marcó el inicio de mi trabajo.

Mis objetivos de investigación, en este proyecto más amplio, giran en torno a la reinserción de mujeres que han estado privadas de libertad, y las resiliencias y agencias que estas desarrollan durante este proceso. Es por ello que, en primer lugar, elijo una aproximación al tema para mi TFM mediante la construcción de historias de vida del proceso en prisión de las mujeres. El contacto con las diversas asociaciones e instituciones penitenciarias comienza en marzo. Durante dos meses presento mi proyecto a diversos agentes y todo empieza a funcionar como una especie de bola de nieve, unos me llevan a otros. Sin embargo, en estas semanas no tengo acceso a ninguna de las mujeres que a mí me interesan.

Hay instituciones más accesibles, otras menos, pero el contacto con las mujeres se torna especialmente difícil.

Finalmente, comienzo mi trabajo de campo en un Centro de Reducción del Daño ${ }^{11}$, al ser la institución que más rápido me recibe y permite mi incorporación, sin embargo, las problemáticas a las que atiende son múltiples y debo ser paciente hasta coincidir con dos de las mujeres que finalmente muestran interés por mi trabajo, Acuario y Leo. Sus características son particulares, pues es un lugar de personas con consumos activos de drogas, donde las idas y venidas son muy frecuentes, con las que la paciencia y las relaciones pausadas se imponen.

Durante el verano recibo el permiso de acceso para hacer investigación en el Centro de Inserción Social Matilde Cantos de Granada, previo contacto con una

11 Es un centro de atención a personas en situación de drogodependencia que busca "prevenir las enfermedades infectocontagiosas, favorecer la accesibilidad a la red asistencial para las drogodependencias y a los dispositivos de salud, y mejorar la calidad de vida. En definitiva, lo que se pretende es dar prioridad a aquellos objetivos que permitan disminuir los efectos contraproducentes del uso de drogas. Si se desea consumir drogas que sea con la mayor seguridad posible. Se trata de ofrecer planteamientos más pragmáticos y menos sujetos a moralismos alejados de la realidad" (Observatorio Vasco de Drogodependencias, 2000: 17). 
profesional del mismo e inicio de los múltiples trámites para conseguir dicho permiso.

A la vez que llevo a cabo todo esto, comienzo a involucrarme como voluntaria en dos asociaciones. Por un lado, la Asociación PIDES, que realiza sus intervenciones en el Centro Penitenciario de Albolote, la cual ha iniciado todos sus trámites para que en septiembre se permita mi acceso, y donde trabaja uno de los profesionales que más se ha interesado por la investigación y facilitado el contacto. Por otro lado, inicio los contactos para acudir como voluntaria a un piso de acogida de permisos y terceros grados para mujeres que están o han estado en prisión. Este se encuentra entre los servicios que desarrolla la Pastoral Penitenciaria, y es el primero de la provincia de Granada destinado en exclusiva a mujeres y fue inaugurado en noviembre de 2015. De nuevo la ayuda y el interés por el proyecto que estoy desarrollando es grande, la capellana se muestra muy receptiva y quedo a la espera de que se inicie una nueva acogida para involucrarme en el proceso. Es necesario saber que el piso cuenta con siete plazas, las cuales no suelen llenarse, y que hasta ahora tan solo han acogido a mujeres que se encuentran en el Centro Penitenciario de Albolote y en el Centro de Inserción Social Matilde Cantos. Esta característica es importante conocerla para comprender que las acogidas en este recurso son muy discontinuas en el tiempo, con una duración de entre tres y seis días, y que las mujeres pueden disfrutar de un total de 36 días al año de permisos penitenciarios. Es por ello que todavía no se han iniciado nuevas recepciones a las que yo pueda vincularme.

Todas estas dificultades de acceso al campo y a las mujeres me llevan a situarme en otro punto y a pensar sobre lo que significa e implica hacer trabajo de campo. Y la necesidad que yo empiezo a sentir de no querer forzar todos los vínculos que se estaban dando, pensando en la riqueza de las relaciones que podía generar a largo plazo y la importancia que tenía para mí establecer relaciones pausadas y vínculos progresivos.

Finalmente, es en este punto en el que nace mi proyecto Fin de Master, repensando en todas las claves que mi proceso de acceso al campo y mi experiencia en prisión me estaban dando para conocer qué significa y qué implicaciones tiene para las mujeres el paso por prisión. Me refiero a tiempos muy amplios de acceso a la institución, permisos que se extienden, trabas burocráticas y 
trabas para llegar a estas mujeres, construcción de relaciones y negociaciones muy pausadas con los agentes y asociaciones del tercer sector. Además, al igual que pueda ocurrir en otros ámbitos, la entrada del verano supone la paralización de muchas actividades tanto en el interior de los centros penitenciarios en relación a intervenciones con las mujeres como en el estudio y concesión de acceso a estos espacios.

Por otro lado, y muy vinculados a la investigación, han estado aspectos y circunstancias personales, que de alguna forma y en mayor medida de lo que hubiese deseado, han modificado el ritmo y dirección del trabajo fin de master. Sin embargo, ser capaz de reconocer estos factores y modificar los aspectos necesarios para convivir y sacar el trabajo ha sido enriquecedor y de un aprendizaje con mucho valor personal y emocional.

Una vez desarrollados todas las trayectorias e hitos que me acercan y construyen mis intereses por el sistema penitenciario y la realidad de las mujeres, en el siguiente apartado desarrollo la segundo etapa de este paso metafórico por prisión, y se corresponde con la estancia en el Centro Penitenciario de Albolote, y todo lo que esta experiencia me ha dicho sobre lo que significa ser mujer privada de libertad.

\subsection{Historias y vidas en la cárcel}

Una vez explicado mi proceso de vinculación e intereses de investigación con el ámbito penitenciario y las mujeres, es el momento de narrar aquellos aspectos y particularidades de la vida en prisión de las mujeres y que tuve la oportunidad de conocer durante mi estancia en el Centro Penitenciario de Albolote en el año 2013, cuyo análisis se ha visto enriquecido, tras mi paso por el master Gemma,

¿Qué me dice mi experiencia en prisión de la situación de las mujeres en el Sistema Penitenciario? ¿cuáles son algunas de las experiencias a las que tuve acceso? ¿cómo éstas se ven atravesadas por las desigualdades de género que imperan en nuestra sociedad? El inicio de este punto viene marcado por los interrogantes, únicamente soy capaz de cuestionarme y de cuestionar todo lo experimentado hasta ahora. Esa es mi única certeza, la interrogación. 
El trabajo aquí recogido ha sido fruto de mucho tiempo de reflexión y de decisiones sobre aspectos que aparecerían o no. Quiero decir que por motivos de extensión y por la naturaleza misma del Trabajo Fin de Máster me ha sido imposible dibujar la complejidad de la realidad penitenciaria en los módulos de mujeres, cada historia que me llega incorpora elementos y experiencias de vida que difícilmente puedo pasar por alto: trayectorias de violencias familiares, machistas, maternidades, consumos, abusos...que no quiero simplificar ni reducir. La realidad que aquí presento no muestra ni la mitad de la crudeza de lo que allí se vive.

He divido este punto en cuatro apartados, con la finalidad de estructurar de alguna forma la complejidad que supone para las mujeres la estancia en un centro penitenciario. En primer lugar, reflexiono sobre las claves que con sus relatos las mujeres me han dado para dar un paso atrás en la investigación y tomar conciencia sobre cómo son las vidas de las mujeres antes de su acceso a la prisión. En segundo lugar, me posiciono geográficamente en los módulos 9 y 10 del Centro Penitenciario de Albolote, los dos espacios destinados a las mujeres en esta prisión. Aquí desarrollo algunos de los aspectos que construyen estas desigualdades de género dentro de la cárcel, tales como el trabajo o la identidad sexual. En un apartado a parte, debido a la centralidad que supone en el día a día de las internas en esta prisión profundizo en cuestiones referentes a los permisos y los beneficios penitenciarios y la participación voluntaria en programas de intervención, además, desarrollo en mayor medida aspectos relacionados con identidades de género y transexualidad. Finalmente, cierro este punto reflexionando sobre la medicalización de los malestares de las mujeres durante el encierro.

Las historias y los fragmentos aquí escogidos, en la mayoría de las ocasiones han sido decisiones tomadas a partir de la evocación y el recuerdo de situaciones vividas con ellas y de información con la que ya contaba, repensándolas ahora en relación a algunas de las peculiaridades que tiene para ellas el paso por prisión. En otros casos, es información recogida de encuentros actuales. 
"Sin haber anotado una sola palabra, mi comadre ha estado escribiendo la

Menos mal que entré en la cárcel ¡le dí gracias a Dios! (Interna del Centro Penitenciario de Albolote). Son las palabras de una mujer, anónima, que recupero de mi diario de campo, el 23 de abril de 2014, mientras acudía a una entrevista para completar su historia social. ¿Anónima? No, no lo es, puedo nombrarla, pero cómo hacerlo si ni tan siquiera sabe que su historia forma parte ya de esta investigación, junto con la de Esperanza, Acuario, Leo, Thais, Ana, Manuela, Pedro...

La cárcel te quita tantas cosas buenas, lo pierdes todo, pero hoy en día estoy tan agradecida de entrar en prisión, hubiera acabado muy mal o muerta o con una enfermedad, no soy la misma persona, creo que mejor, tengo más conciencia... Pero ahora no tengo miedo, tengo ilusión. Me preocupa, no es una preocupación, pero el tener tu casa, llevarme a mi hijos, una siempre lo piensa, pero tengo mucha ilusión por tener una vida tranquila, normal...porque hay que tener en cuenta que he estado mucho tiempo fuera de la calle, es empezar de cero y tengo mucha ilusión, ganas, fuerzas para que todo salga bien...(Es uno de los fragmentos de la vida de Esperanza nombre ficticio -, entrevista realizada en el Centro Penitenciario de Albolote el 22 de mayo de 2014).

Yo he estado muy poquito tiempo presa eh...18 días nada más. Yo entré para 4 meses y medio pero cuando me dijeron que iba a estar solo 18 días me puse a llorar, te lo juro. Estaba mejor dentro que fuera...he tenido un montón de cosas pero normalmente me he librado...porque era menor de edad...o me ponían la condicional... (Acuario - nombre por el que elige ser llamada). Nosotras somos muy conscientes de todo lo que ha sucedido, y de cómo son las cosas. Actualmente tanto ella como yo, las dos tenemos en ese sentido...ella 
tiene su madre, tiene sus hijos, está bastante bien, ella tiene el "marío" preso y ya está. Yo con mi familia bien, con todo bien, y todo estupendo...(Leo nombre por el que elige ser llamada).

Los relatos de Leo y Acuario los recojo en el primer encuentro conjunto que hacemos las tres (11 de julio de 2016), en el despacho del Centro de Tratamiento Ambulatorio, en Granada, donde inicio mi trabajo de campo. Estos dos últimos relatos se siguen construyendo. Acuario y Leo, en cada encuentro, tienen algo que contarme, fragmentos de sus vidas que generosamente comparten conmigo.

Estas últimas palabras de Leo, son especialmente llamativas para mí, porque ese todo bien y todo estupendo tiene una fuerza que no sé cómo transmitir por escrito, con una historia del presente, que la atraviesa en estos mismos momentos muy difícil, pero que no la hace caer, y que sin embargo, a mí me derrumba en algún momento. Los miedos por la entrada en prisión de su hijo mayor afloran continuamente, la experiencia de una madre en este mismo lugar hace que ella sea consciente de la realidad y a la vez intente guiarlo desde su conocimiento en primera persona. Nuestra relación y vinculación aún están iniciándose, pero sus historias, con las pequeñas pinceladas de esas conversaciones que mantenemos mientras yo le sirvo un café, sin cuaderno, ya se adivinan, cuanto menos, de una vida de cárceles, consumos y superación. Y donde mi rol de investigadora no aparece, es decir, la mayoría de los encuentros entre nosotras han llegado en la cotidianeidad del centro, es decir, cuando yo era una más de las dinámicas que allí se establecían, estaba en cocina sirviendo el desayuno, acudía a lavandería a apuntarlas en los horarios o me sentaba con ellas en el salón. Pensando en ello, no consigo reconocer el factor que daba estas conversaciones, no sé si era yo la que me relajaba en mayor medida y me daba la oportunidad de llegar a sus historias y disfrutarlas, era ella a la que le impone la libreta o, posiblemente, todo convivía. Son palabras de aliento, de consuelo y hasta de agradecimiento, de muchas de estas mujeres al abrazo del sistema penitenciario. Me asaltan dudas acerca de dónde posicionarme. Quiero seguir conociendo sus historias para situarme más cerca del ángulo desde el que ellas miran y experimentan de esa forma al sistema penitenciario. 
La única conclusión a la que puedo llegar es que estas mujeres han aprendido a respetar, a sentir y vivir con todos las emociones/sentimientos, también los de culpa, estigma y arrepentimiento; sentimientos, todos, como regalos del vivir y de estar en el mundo.

Sin embargo, otras veces, este argumento no me basta, y me asaltan dudas sobre este mismo posicionamiento. Hay otro ángulo desde el que observar estas historias que me dice que la primera realidad a la que tenemos que hacer frente es, precisamente, conocer por qué muchas de estas mujeres agradecen su paso por prisión, a pesar de las desigualdades, de las desvinculaciones o de los sentimientos de culpa y rechazo. Me pregunto entonces, ¿Qué sucede en las vidas de estas mujeres para que encuentren en la cárcel la paz? ¿por qué es la cárcel la solución? ¿es realmente la solución? ¿qué vivían estas mujeres fuera para que les merezca la pena pagar el altísimo precio de la libertad? ¿cuáles son las herramientas por las que el sistema lo consigue? Y ¿por qué consigue esto, precisamente, en las mujeres? Resuenan en mí las palabras de Dolores Juliano sobre los delitos:

los cometen personas que tienen cuerpos y que actúan en tanto que seres sexuados y condicionados por su socialización de género. El cuerpo del delito, no es sólo la prueba material de la falta cometida, sino el cuerpo que delinque, el contexto físico de toda acción. Y claro está que este contexto tiene género (Juliano, 2002: 121).

Un contexto con género, en el que no podemos olvidar el cuerpo del castigo y el sistema que castiga. Toda una realidad atravesada por el patriarcado más severo. Pensar en ello podría darnos las claves para comprender en mayor medida estas afirmaciones de las mujeres en prisión, es decir, los roles y estereotipos de género que conviven en nuestra cultura traspasan también los muros de la prisión. En este sentido, las mujeres en la cárcel construyen, en muchas ocasiones, relatos inmaculados de sí mismas "como una estrategia para expiar su culpa y mostrar que ellas no son monstruos, sino mujeres correctas, madres abnegadas, buenas "muchachas" que cometieron errores" (Bello, 2013: 49). Como formas estratégicas de afirmar su disposición a la abnegación y su arrepentimiento por el delito, es una especie de apropiación del discurso de "rehabilitación" de la institución que exige de ellas el reconocimiento de la culpa, la sumisión, el arrepentimiento e incluso, en cierto modo, la vergüenza (Bello, 2013). 
Sin embargo, estos relatos de la cárcel como salvación, pueden verse de igual forma desde una óptica que refleja la capacidad de agencia de las mujeres como medio para gestionar el estigma que se les impone, desarrollando otras estrategias, es lo que Sassen (2007) denomina como "feminización de la supervivencia" (En, Bello, 2013: 50). No obstante, en cualquiera de los casos, es necesario volver un paso hacia atrás, antes de su entrada en prisión, para llegar a comprender en mayor medida la experiencia carcelaria para estas mujeres.

\section{b) Los módulos de mujeres: el 9 y el 10}

Releo la transcripción de la entrevistas de Thais y Esperanza, dos años después, y el efecto de la evocación me lleva a esos lugares del Centro Penitenciario de Albolote en el que compartimos espacio e historias por unas horas. Este centro es el llamado centro "tipo" de la provincia de Granada. Fue el segundo de Andalucía, construido en 1997, cuenta con una superficie de 304.216 m2. En la Provincia también podemos encontrar el Centro de Inserción Social “Matilde Cantos”.

Sus subjetividades y las mías están volcadas, en igualdad de condiciones, todo es tan real y contradictorio como la vida misma. Las historias que aquí se perfilan no tienen ni el más mínimo interés de ser lineales, unidireccionales y entendibles, el único fin es el de devenir en fragmentos de vidas y cuerpos narrados, de historias de encierro y libertades, de desconsuelo y esperanza, de castigo y agradecimiento.

Evocación que aprovecho para narrar y describir, quizás ya en un ejercicio más de ficción que de realidad - por tratarse de una información que se encuentra atravesada por todas mis subjetividades - , lo que en este momento es para mí el espacio que en esta prisión está reservado para las mujeres.

Este ejercicio no solo es de ficción, también es de suerte y azar porque cada una de ellas ocupaba uno de los dos módulos que este centro destina a las mujeres. Thais el módulo 9 y Esperanza el 10. 
El primer aspecto a tener cuenta lo recupero del relato de Thais:

El centro no se adapta ni a la de los hombres, se va a adaptar a la de las mujeres...tendría que haber clasificación más específica para mujeres también (26 mayo 2014).

La realidad es que se trata de un centro mixto, concebido como una ciudad, y presenta un diseño urbanístico octogonal, estando las zonas de residencia o módulos en los laterales y las de equipamiento en el centro, separados ambos por dos calles principales. En el interior se encuentran 17 módulos, repartidos en módulos de preventivos y penados, ordinarios o de respeto, además de enfermería, módulo de aislamiento y módulo terapéutico. Hay un pabellón socio cultural donde se realizan actividades deportivas, está la biblioteca, el colegio, espacios para la realización de talleres y el salón de actos. Por otro lado, la zona donde se ubica la cocina, lavandería, economato y los diferentes talleres formativos existentes. De los 17 módulos que había en su momento tan solo dos están destinados de forma específica a las mujeres, cuya localización geográfica ya es llamativa, pues se encuentran separados por unas vallas metálicas del resto de módulos de la prisión.

Recupero los datos recogidos en febrero de 2014, mediante consulta interna del material, y veo que el número de personas privadas de libertad en este centro ascendía a 1481, de las cuales 1296 eran hombres y 185 mujeres. La explicación de la existencia de tan solo dos módulos de mujeres vendría dada por su baja proporción en relación a los hombres. Sin embargo, las consecuencias no aparecen tan fácilmente en los documentos de la institución ni parecen tan claras. No obstante, al consultarles a ellas, Thais lo deja claro. El módulo 10 es de respeto ${ }^{12}$ y el módulo 9 es un módulo ordinario. Esto se traduce en una

\footnotetext{
12 Según la Secretaría General de Instituciones Penitenciarias un módulo de respeto es una unidad de separación interior dentro de un centro penitenciario, cuya finalidad es "lograr un clima de convivencia y máximo respeto entre los residentes del módulo. En ellos el interno deja de vivenciar el módulo y sus normas como "algo impuesto" para considerarlo como "algo propio". El factor fundamental es la participación del interno en la vida, las tareas y las decisiones del módulo, a través de grupos de trabajo y comisiones de
} 
clasificación únicamente binaria para los casos de mujeres. Quiero decir, las mujeres no tienen acceso al módulo terapéutico, ni a espacios diferenciados entre reincidentes o no, o consumidoras. Los llamados "perfiles" en femenino conviven únicamente en estos dos espacios. Por lo tanto, los servicios, programas y talleres quedan limitados y reducidos en comparación con los hombres:

Tú me llevas a un curso para decirme que las mujeres no somos menos que los hombres pero en el economato ponen a hombres... y no se lo digo a la subdirectora porque temo que me quiten los permisos ... ¿no me voy a callar...si tengo niños en la calle? Para las mujeres la vida en la cárcel es la peluquería, limpiar los bajos y los chabolos ${ }^{13}$... los hombres en la cárcel, trabajar, las mujeres no tenemos esos derechos.

Fragmento que recojo de la entrevista del 26 de mayo de 2014, con Thais, una de las mujeres que marcó mi estancia, por los lazos y las afectividades que no se pueden frenar, por las energías y las conexiones entre personas. Ella se definía como mujer de 27 años, soltera, mestiza y con dos hijos; y con orgullo reconocía que en su sentencia se la consideraba como cabecilla de banda organizada. Escucharlas a ellas es la gran revelación, acudir a mis documentos después de tiempo, a la vez que realizar entrevistas con otras mujeres nuevas me entusiasma, ellas son las que definen mejor que nadie su realidad, ellas son las que llenan de sentido y vida toda la teoría y las que en dos frases son capaces de resumir y explicar lo que yo no alcanzo a hacer.

Las palabras de Thais sacan a la luz, nombran y denuncian la realidad laboral y las oportunidades de acceso al trabajo de las mujeres en prisión, un aspecto en el que elijo detenerme. En el artículo 26 de la LOGP es definido como derecho y deber de las personas privadas de libertad, es decir, para hombres y para mujeres. La actividad laboral es considerada una de las principales actividades de la que la Administración penitenciaria dispone para el tratamiento de las y los condenados. Así se le atribuyen funciones tan importantes como la reinserción social, en dos sentidos: por un lado, por la capacitación profesional que supone 
para la persona en cuanto a aprender un oficio o profesión ; y, por otro lado, ayudaría a la modificación de la conducta, al tenerse que adquirir una serie de valores que se entiende muy beneficiosos para la convivencia en la sociedad. Aspecto también cargado de polémica esta concepción del trabajo como valor pues ¿son realmente buenos o beneficiosos los valores que se asocian comúnmente al trabajo?, ¿han podido ser estos valores impuestos por determinados modelos productivos que previamente los y las han excluido? (Daunis, 2016).

De acuerdo con el Programa de Acciones para la Igualdad entre Mujeres y Hombres en el Ámbito penitenciario (PAIMHAP) (2009), aparece un dato llamativo, las mujeres acceden al trabajo retribuido en mayor proporción (un 9,27\%) que la media del conjunto de la población penitenciaria (8,18\%). He traído aquí este dato por el interés que pudiera suscitar, o incluso, la contradicción. Hablando de desigualdades entre mujeres y hombres dentro de las cárceles y considerando el trabajo y los destinos ${ }^{14}$ como factores a tener en cuenta: ¿las estadísticas vienen a decirnos todo lo contrario? ¿o no?. Reside aquí el interés de estos datos, pues aunque efectivamente la incorporación de las mujeres al trabajo retribuido dentro de prisión llega a ser casi un punto superior a la media, ¿cuáles son estos trabajos de los que se habla? ¿qué rango representan? Casi tres cuartas partes de los empleos de mujeres en las cárceles se corresponden con servicios a la propia red. Del conjunto del empleo destinado a servicios al sistema, un 16,2\% se corresponde con empleos en cocina, un 4,2\% en servicios de panadería y un $11,7 \%$ en mantenimiento. El resto, un 67,9\%, desarrolla funciones auxiliares, en algunos casos indeterminadas, de baja cualificación, o en el economato ${ }^{15}$ interior, experiencia difícilmente acreditable para inserción laboral en el mercado de trabajo (PAIMHAP, 2009: 27).

Estas actividades laborales, en muchas ocasiones y como denuncia Thais en su relato, continúan siendo sexistas, centradas en los casos del módulo 9 y 10 en la

\footnotetext{
14 Como dentro de la prisión se denomina a los trabajos, los destinos pueden ser o no remunerados.

15 La Secretaría General de Instituciones Penitenciaria, en el Real Decreto 190/ 1996 (de 9 de febrero) define los economatos como un servicio prestado por la institución penitenciaria a los internos e internas que permite disponer de un sistema de adquisición de productos de naturaleza complementaria a los facilitados por la propia Administración penitenciaria, es decir, se trata de pequeños espacios reservados en cada módulo con características similares a un pequeño negocio de ultramarinos. En ellos, tanto las personas privadas de libertad como los/las trabajadorxs mediante una tarjeta-valor o más conocido como peculio, podrán adquirir aquello que necesiten - en el caso de los /las internxs de acuerdo siempre a otras normas tales como los objetos y alimentos que se pueden tener en la celda-. El peculio es la forma en que se llama al "dinero" o la forma de intercambio monetario dentro de una prisión, queda prohibido el uso de dinero "normal", para ello cada establecimiento penitenciario establece la obligatoriedad de efectuar las compras mediante tarjeta-valor, tarjeta magnética, tarjeta microchip u otro sistema análogo. Además, existe un máximo posible de gasto.
} 
costura, confección, peluquería o manualidades. Además, en su mayoría, acceden a los puestos de trabajo de limpieza, lavandería, es decir, en el interior de las prisiones se sigue reproduciendo la tendencia a la domesticidad de las mujeres, que se pone de manifiesto en esta formación y actividades ocupacionales (Almeda, 2002; Cervelló, 2006). Actividades que nada tienen que ver con los talleres que se le ofertan a los hombres, carpintería, carpintería metálica, construcción, diseño gráfico. El Defensor del Pueblo Andaluz en su informe de 2006 viene a denunciar esta situación, preguntándose sobre el por qué de mantener esta división de roles, y “¿por qué no abrir caminos a las mujeres en otro tipo de incorporación laboral?" (p.150). De nuevo la Institución Penitenciaria reproduce los roles y estereotipos asignados tradicionalmente a las mujeres. No solo es eso, también acaba generando modelos y perfiles de mujeres aptas para ser reinsertadas y para que la sociedad las considere como tal, cuestión sobre la que profundizaré en el apartado 4.3 de este análisis.

Esta misma reflexión de Thais, recogida dos páginas más arriba, me pone de nuevo a mitad de dos caminos, lo cual me sitúa lejos de las verdades absolutas y me relaja, porque deja espacio a la reflexividad y la crítica. Mientras que esta joven y experimentada mujer se empodera a sí misma reconociéndose como cabecilla, aparece el argumento de otra mujer, profesional de los servicios religiosos que acude a diario al centro y con la que mantengo una conversación que resume de manera muy sencilla esta otra realidad también:

Estoy convencida de que quienes están recluidos en los centros penitenciarios son los pobres entre los pobres. Y dentro del espectro de pobreza, las que más la sufren son las mujeres. No es solo ser mujer, sino el estigma de mujer que ha cometido un delito. El rol social de la mujer es incompatible con el delito. En el hombre se puede aceptar más, pero en la mujer resulta imperdonable. Son cuidadoras, entregadas, soporte de la familia, amantes y amadas. Pacientes, amables, perdonan y disculpan sin límites. Son madres, esposas, hermanas e hijas. Tiernas y cercanas. Confidentes y cómplices de las causas más difíciles. Nada que ver con un contexto como una prisión (16 de julio de 2016). 
Ambas realidades conviven, comienza a visualizarse lo invisible del encierro, la cárcel como un lugar de contradicciones y de algunas libertades, como un lugar que puede ser completamente diverso dependiendo del ángulo desde el que lo observes o te sitúes, ninguno más cierto que otro, todos experienciales. Aunque sí es cierto que hay espacios en los que la institución y sus discursos llegan fácilmente y otros en los que el hormigón hace una barrera infranqueable. Los brazos del sistema carcelario, aunque largos y diversos, encuentran vacío y obstáculo en algunas de nosotras.

Muy en sintonía con el discurso que daba la profesional, y la consideración de las mujeres que delinquen, está lo que Thais afirmaba que la sociedad esperaba de ella:

Que fuera una niña buena, por mi familia, mis amigos, que fuera una niña pija porque aunque mi padre es chusma su familia no, son gitanos muy bien vestidos. Que me casara con un pañuelo, los problemas no salieran de mi casa...y me divorcié, tengo dos niños uno de cada padre y soy bisexual, y lo digo con la boca llena (26 de mayo de 2014).

Thais se convirtió en una persona importante durante mi estancia allí, su carácter y habilidad para sacarte una sonrisa eran extraordinarios, al igual que sus energías para imaginar su vida después de prisión. Mi tutora también se volcó con este caso y la intervención que realizamos con ella fue de mayor profundidad, ya que siempre nos abría las puertas de sus experiencias y pensamientos.

Quiero recuperar aquí su identificación como bisexual. El compartir momentos más íntimos con otras mujeres era una realidad dentro del módulo. No quiero generalizar, simplemente narrar lo que yo percibí años atrás. Dialogar con ellas me permitió conocer una de las singularidades del espacio carcelario, la eliminación de ciertos tabúes sexuales y una mayor permeabilidad para la experimentación entre mujeres. Me explico, entre otras mujeres, Thais afirmaba que ella no se identificaba como lesbiana a pesar de que en ese momento se relacionaba con otra chica cuya familia, incluso, la estaba ayudando en la búsqueda de trabajo que la llevara a conseguir la libertad condicional. Reconocía que era una 
realidad y experiencia en prisión pero que en el exterior se relacionaría con hombres. Eran decisiones que ella parecía tener claras y así te las hacía llegar.

Tuve la oportunidad de dialogar con otras mujeres cuya experiencia las había llevado a construir una relación con otra mujer dentro de la prisión, habiendo mantenido anteriormente otras relaciones con hombres en el interior, con hijos en el exterior y redescubriendo sus placeres e identidades sexuales.

Es en este punto donde comienzan a nacer en mi preguntas que se adivinan aspectos en los que debo profundizar y desarrollar en la tesis doctoral, pues en este proyecto y su extensión resulta imposible detenerse de la manera en que desearía en todos los interrogantes fruto de estas interacciones: ¿de qué forma el contexto de privación de libertad física permite o facilita para las mujeres el desarrollo de su libertad sexual? ¿existe un cierto redescubrimiento de sus libertades?

Es habitual que en los análisis feministas ${ }^{16}$ sobre los sistemas carcelarios, las menciones a la sexualidad se hagan desde una perspectiva dominocéntrica que las lleva a no tomar en consideración la acción de las agentes y sus resistencias frente a las tecnologías disciplinarias del sexo y la sexualidad (Bello, 2013).

En cierto modo, se concibe la sexualidad en este contexto desde la imposición estatal, de nuevo como medio de castigo y como marginación de los géneros y las sexualidades normativas, es decir, "una sexualidad entendida como un dispositivo del sexo-capitalismo (Preciado, 2003)" (Bello, 2013: 181).

Sin lugar a duda, las prácticas de dominio patriarcal, sexual y de violencia se encuentran en la estructura de los sistemas carcelarios contemporáneos. Sin embargo, y como defiende la antropóloga Carole Vance (1989) es común que la sexualidad en prisión se represente parcialmente como una "zona peligrosa", de violencia e invisibilidad. Esto lleva en ocasiones a descuidar la otra "posibilidad creadora" de la sexualidad de la que esta investigadora habla, la potencialidad para la generación de lazos sociales, la afirmación vital y la creación de placeres y resistencias. En este sentido, Vance nos propone a todas llevar a cabo lecturas de esta realidad que enfaticen a las mujeres también como "agentes sexuales y no sólo como víctimas de los aparatos de dominación: ¿cómo significan sus experiencias sexuales las personas presas? ¿qué placeres, alegrías y frustraciones emergen en

16 Davis, 2003; Sudbury, 2005; Stanley, 2011. 
este contexto? (...) ¿qué cuerpos, qué vínculos y qué subjetividades emergen del entramado de relaciones sexuales que acaecen en la cárcel? ¿cómo se imbrican las relaciones de género con el eje de la sexualidad en la cárcel?” (Bello, 2013: 181).

\section{c) ¿Permisos y Beneficios Penitenciarios?}

Aunque anteriormente hablaba de algunas libertades, no podemos obviar los mecanismos de control, miedo y dominación como herramientas básicas del sistema penitenciario. Es de una valentía y una superación intachable el acto de habla, de expresión, lucha y resistencia que todas estas mujeres han llevado a cabo permitiendo que yo plasme por escrito sus vidas, historias, experiencias, denuncias y superaciones.

Claro que nos callamos, si tenemos niños en la calle ¿no nos vamos a callar?, pero Lorena esto que sirva, que salga, tú por lo menos eres una voz... afirmaba Thais ( 26 de mayo de 2014).

Es decir, no podemos olvidar que el sistema también juega sus cartas, entre sus ases más cotizados se encuentran los permisos de salida y los conocidos como beneficios penitenciarios. Ambos se cuelan en el día a día de los encuentros y entrevistas de los y las profesionales con las personas privadas de libertad, pues no dejan de ser su fin último.

Los permisos de salida ordinarios, según la Secretaría General de Instituciones Penitenciarias, son concebidos en la legislación penitenciaria como "un instrumento idóneo para la preparación a la vida en libertad. Facilitan la reinserción, reducen los efectos negativos del encarcelamiento prolongado, y favorecen los vínculos familiares y sociales. Son, por tanto, un elemento esencial del tratamiento penitenciario"17. Los internos y las internas clasificados en $2^{\text {o }}$ grado pueden llegar a disfrutar de un total de 36 días al año y los clasificados en $3^{\text {o }}$ grado de 48, siendo 7 días el tope máximo de duración de cada permiso. Los requisitos para su concesión están divididos en:

${ }_{17}$ En: http://www.institucionpenitenciaria.es/web/portal/laVidaEnPrision/salidasExterior/permisosOrd.html 
- Objetivos: estar clasificado en $2^{\circ}$ o $3^{\circ}$ grado de tratamiento; tener la cuarta parte de la condena cumplida; no observar mala conducta; informe preceptivo del Equipo Técnico en la Junta de Tratamiento (no vinculante) ${ }^{18}$.

- Subjetivos: que no resulte probable el quebrantamiento de condena; no sea previsible la comisión de nuevos delitos; el permiso pueda tener una repercusión negativa en el programa individualizado de tratamiento.

Adjunto en el Anexo I algunos de los materiales utilizados por los y las trabajadoras sociales del centro penitenciario para recabar la información necesaria con la que acudirán a la Junta de Tratamiento y se tomarán las decisiones correspondientes. Desde el Trabajo Social, disciplina a la que pertenezco se llevan a cabo actuaciones destinadas a conocer la situación sociofamiliar y laboral de los/as internas; participan en la elaboración de los programas individuales de tratamiento; atención al ingreso en prisión de la persona; atención a las personas durante la estancia en prisión; atención a familias de los y las internos/as; elaboración de informes sociales tanto para la Junta de Tratamiento como para el Juez de Vigilancia Penitenciaria; participación en los Equipos Técnicos y Juntas de Tratamiento, aportando la información social, para ello se entrevistan tanto con los y las internas como con los familiares o entidades públicas y/o privadas que fueran necesarias ${ }^{19}$. De acuerdo a la Circular I-1/12 por la que se regulan los Permisos de Salida y Salidas programadas, son dos los instrumentos utilizados por los profesionales para valorar la concesión o no de permisos de salida: la Tabla de Variables de Riesgo - que adjunto - y la Tabla de Concurrencia de Circunstancias Peculiares - a la que no he podido acceder-.

En cuanto a los beneficios penitenciarios, son definidos en el artículo $202 \mathrm{del}$ Reglamento Penitenciario como "aquellas medidas que permiten la reducción de la duración de la condena impuesta en sentencia firme o de la del tiempo efectivo de

\footnotetext{
${ }^{18}$ Los equipos técnicos son las unidades de estudio, propuesta y ejecución, en las que se divide la Junta de Tratamiento, presidida por el director del Centro Penitenciario, y compuesta por el Subdirector/a de Tratamiento, el Subdirector/a Médico/a, un/una profesional del Trabajo Social; un/a profesional de la Psicología, un/a educador/a, Jefe/a de Servicios.Podrán formar parte del equipo técnico: juristas, psicólogxs, pedagogxs, sociólogxs, médicxs, maestros, educadorxs, trabajadorxs sociales.

${ }^{19}$ Más información Anexo II.
} 
internamiento. Constituyen, por tanto, beneficios penitenciarios el adelantamiento de la libertad condicional y el indulto particular"20.

Estos marcan la forma de relacionarse - hablo en concreto de mi experiencia con las mujeres - y acercarse de las internas con el resto de personas que conviven en el módulo, es decir, funcionarios, trabajadora social, psicóloga, educadora, voluntarios y en mi caso como práctica. Qué mujeres acuden a los diversos programas que oferta el centro, por qué acuden y bajo qué preceptos.

Es decir, está en juego el mayor o menor tiempo de estancia en prisión, sus libertades y las apuestas que los y las profesionales puedan hacer por ellas. Esta vara de medida no las posiciona en igualdad respecto al sistema en sí, que es quien tiene en sus manos las decisiones más importantes que recaen sobre la vida de las personas que allí se encuentran.

Durante mi estancia en el Centro Penitenciario de Albolote, dentro de este sistema de beneficios penitenciarios, tuve la oportunidad de asistir y participar semanalmente en un proyecto de prevención de la violencia de género con mujeres privadas de libertad: "Ser Mujer.es". Consistía en una intervención conjunta entre dos trabajadoras sociales y una psicóloga del Centro. Este tipo de intervenciones no se encuentran de manera obligatoria entre las distintas funciones que desde el Trabajo Social y la Psicología se desarrollan en el centro sino que, de manera voluntaria, las profesionales se acogen o no a estos programas. Además, el diseño, cronograma, documentos y materiales con los que se trabajan vienen elaborados, previamente, desde la Dirección General de Instituciones Penitenciarias, es decir, las actividades, contenidos y desarrollo metodológico son iguales para todas las prisiones y, en este caso, grupos de mujeres.

Los y las profesionales únicamente se encargan de impartir las sesiones y seguir el cronograma propuesto en estas páginas. Entre tanto, no se tienen en cuenta las características concretas de las mujeres que participan y se pierde, en cierto modo, la especificidad de cada centro y de cada grupo, la realidad de cada prisión es diferente, así como el perfil de profesionales e internas.

Dadas estas características del programa, surge en mí un primer dilema, por un lado, soy consciente de la necesidad y de la importancia de la existencia de este

${ }^{20}$ En:http://www.institucionpenitenciaria.es/web/portal/documentos/normativa/ReglamentoPenitenciario/rd1901996.t8.html 
tipo de programas e intervenciones colectivas, sin embargo, su punto de partida sentí y viví que no eran las mujeres, ni sus demandas y necesidades.

Personalmente defiendo el trabajo grupal y, en concreto, esta intervención con mujeres, educativa, preventiva y social como una herramienta necesaria dentro del Sistema Penitenciario. Aparte de ser una ayuda para la promoción de estas mujeres, podría ser una alternativa para abordar el aislamiento y el malestar que producen las estancias en prisión. Además, creo que es necesario llevar a cabo intervenciones desde un enfoque de género y feminista que permita trabajar sobre la base del poderío y la sororidad de las mujeres.

Reflexionando desde la distancia veo aquel aula como un intercambio de percepciones, ideas y sentimientos. Como posibilidad, por un lado, para las profesionales de posicionarse ante estas mujeres en un espacio que les permitiera escuchar y acercarse a la situación social de las internas. Por otro lado, a las internas les brinda la oportunidad de sentirse comprendidas y apoyadas entre ellas, verse reflejadas en otras historias y sentirse partícipes de un proyecto común que repercute directamente en la concepción de sí mismas.

Sin embargo, desde mi situación actual, con las herramientas obtenidas con el master, entiendo que esto no se propició. Son numerosas las preguntas que me hago y ante las que claramente no puedo tener una respuesta. En realidades tan complejas como son las prisiones y donde las mujeres ocupan lugares de desigualdad terribles respecto a los hombres ¿cómo construir este espacio que anteriormente planteaba?. Viví situaciones difíciles, las cuales me siguen causando el mismo dolor. Qué importa el contenido de una sesión o una actividad o el programa en sí ante la muerte, por ejemplo, al final hay que transformar el espacio del aula en un espacio de diálogo, de duelo, de entendimiento y de desahogo.

Por otro lado, me pregunto cómo se construye un programa de prevención de violencia de género desde una institución que considero ejerce violencia simbólica sobre las mujeres y sobre sus cuerpos.

¿Qué pasa con las identidades sexuales en estos contextos de riesgo? ¿Qué está permitido en el interior de una prisión? ¿qué no? ¿qué cuerpos importan? ¿qué se escribe en esos cuerpos? ¿Permite el contexto de prisión, jaula y encierro, experimentar corporal y sexualmente otras formas por la seguridad de que la sociedad no va a conocer de qué se trata? ¿La no permeabilidad del sistema otorga 
esta "posibilidad"? Irremediablemente me siento obligada a traer aquí las manifestaciones y definiciones en torno a la categoría bisexual y todas las veces en que te decían que fuera eso no sería así.

Las amistades amorosas entre mujeres $i$ se corresponden con la necesidad que en muchas ocasiones sentimos como "mujeres" de ser amadas y amantes? ¿cómo fluyen y se desarrollan estas identidades?

No puedo dejar de pensar en la historia de dos personas que conocí en el módulo 9 de esta prisión. Sus nombres son ficciones: Pedro y Manuela.

Sé que a Pedro le hubiera gustado ser nombrado como deseaba y sentía, y que en el interior no todo el mundo lo hacía, pero no será posible, un cuerpo político y luchador al que la vida se le fue. Su muerte durante mi estancia allí fue una de las experiencias más duras, por lo que supone la muerte de una persona y por el desaliento y la rabia con las que dejó a muchas de sus compañeras.

Mi narrativa de estos acontecimientos, construida después de dos años de distancia, solo el tiempo me ha dado la fuerza para crearla y compartirla, antes no me sentí capaz. Contarlo expone mi ser más vulnerable y lo hago porque su historia merece ser pública desde el más fiel de los anonimatos, sin embargo, su lucha ya era política antes de que yo la sintiera, aquí, en la prisión, como diría Kate Millet lo personal también es político.

Ambos cuerpos e identidades, Pedro y Manuela, se encontraban en el módulo 9 de esta prisión, módulo para mujeres. Ambos resultaban incómodos al sistema, uno por tratarse de un hombre y la otra por su identidad trans rompían su estabilidad y representaban esa otredad que a veces no tiene que situarse geográficamente a kilómetros de distancia. Sin embargo, aunque compartían tanto, identidades no normativas, también eran paradigma de jerarquía, simplemente en la forma de querer ser nombrados puede verse que el nombre, masculino, "Pedro" frente a Manuela, rompía los esquemas y estructuras más férreas dentro de aquellas paredes. Es decir, estábamos hablando de una persona que se identificaba como hombre dentro del módulo de mujeres porque su documento de identidad no lo reconocía como tal. Esto es, a Manuela se le permitía nombrarse como tal porque en su documento de identidad así aparecía, a Pedro se le obligaba a nombrarse y situarse en la categoría mujer, aunque él no la sentía, porque su documento de identidad así lo establecía. 
A Pedro tuve la gran suerte de conocerlo, paradójicamente, en el programa de prevención de violencia de género - del que hablé anteriormente - Ser Mujer.es. Nuestro primer contacto, en mis primeros días allí, es posiblemente el encuentro que más veces me viene a la mente cuando pienso en mi experiencia con ellas y ellos entre aquellos muros. Fue mi primer día en el programa, el 21 de enero de 2014, llegué cuando ya estaba avanzado en algunas sesiones, por lo que había que ver cómo podía influir mi nueva presencia en el grupo y analizar si era beneficiosa - finalmente, formé parte del mismo -. Era el momento de una ronda de presentaciones, fue la última persona en hablar: Hola, soy Pedro, recuerdo sus palabras. ¿La respuesta de una profesional? No, no, di como te llamas por favor; Hola, soy María; esta segunda respuesta dejó más tranquilas a todas las profesionales. Estábamos en un programa de mujeres, no podía identificarse como un hombre, molestaría al grupo, me justificaron más adelante. El rostro de él casi ni cambió ante las reacciones. El mío, hoy lo siento como si palideciese, realmente no pude ver mi color ni recogí la sensación en aquel momento.

¿Cuerpo dócil o forma de resistencia pasiva ante el sistema? Al paso de las sesiones observé que él siempre dormía, permanecía tranquilo y calmado a la espera de las dos horas que duraba el programa semanalmente, los beneficios penitenciarios eran su motor de asistencia. Él no se sentía representado, al sistema poco le importaba su representación porque asistía regularmente y su nombre femenino nutría las listas exitosas de taller. Sus compañeras estaban acostumbradas a él, su pareja, con quien compartía chabolo (como llamaban ellas a las celdas) y vida lo aceptaba tal cual. ¿El problema? Lo tenía realmente el sistema, pero el diálogo parecía no ser la herramienta, funcionaba mejor la negación y la imposición.

Manuela, era - quizás - la mujer más llamativa del módulo. Con una vida dedicada a la prostitución, su cuerpo y su personalidad se hacían notar. Se nombraba mujer, tenía un "gran" pecho, vestía como tal y, lo más importante, su DNI, a ella sí la reconocía con la categoría mujer con la que se identificaba; ¿su historia y trayectoria? Respecto a sus identidades de género y sexuales no importaban. Podía pasar inadvertida dentro de la categoría mujer y, si no se removía mucho su historial, el sistema permanecía tranquilo. 
Anteriormente recogía el famoso lema feminista de lo personal es político, pero ¿qué es aquí lo personal? ¿cómo se inscriben estas identidades en la vida diaria y común de la prisión? ¿por qué Manuela sí puede adoptar una determinada identidad y Pedro no? ¿qué hacer cuando la vida me desborda y la política no me sirve? “¿Me enfado con la política porque no habla de mis problemas y mis problemas no se consideran políticos? ¿Me enfado con mi red, con quien vivo, porque los lazos son débiles, porque no me siento cubierta? ¿Me enfado conmigo porque mis elecciones no han sido las correctas?"21.

Uno de los profesionales que intervenían en este módulo con una asociación me describía así la situación de estas personas:

Al final dentro de la escala del género, pues si...eres mujer estás en un escalón por debajo del hombre y si eres transexual estás un escalón por debajo de la mujer. Si eres transexual de hombre a mujer desciendes, si te cambias de mujer a hombre como que asciendes en la escala, porque antes eras mujer $y$ ahora eres hombre, asciendes en la jerarquía de poder del género. Pero al ser al contrario, si tú te cambias de hombre a mujer, has estado en una figura de hombre con más poder y ahora bajas porque te cambias a mujer-Entonces, allí dentro, es una discriminación dentro de la discriminación de por sí que ya tienen las mujeres. Entonces suele ser complicado por el trato que se le da, ¿por que? Porque es más visible normalmente, se suele notar antes una mujer trans que un hombre trans, entonces las discriminación se hace más fuerte porque se sabe quiénes son las mujeres trans y quiénes no, quiénes son las personas transgénero o las personas que cambian de identidad pero no cambian de sexo, entonces es complicado. Tienen una discriminación fuerte dentro, al igual que si eres mujer y extranjera tienes otra, o mujer $y$ gitana...imagínate ya si eres trans, vas bajando en la escala de las jerarquías y los privilegios de género que también se dan dentro de la cárcel, es complicado y es difícil para ellas (Conversación con Profesional I, 29 de julio de 2016).

${ }^{21}$ En: https://www.diagonalperiodico.net/blogs/vidas-precarias/aterrizando-lo-personal-es-politico.html 
El sistema penitenciario, al igual que muchos otros sectores y ámbitos de la sociedad continúan adheridos a la polaridad hombre/mujer o masculino/femenino, estos lugares impiden que las vidas de estas personas, sus identidades y lo que ellas nos dicen tengan sentido alguno para el sistema. Es necesario situarnos entre (Parrini, 2007)- Pedro es hombre y mujer, femenino y masculino; "no porque los mezcle, sino porque altera cada polaridad en su propio cuerpo y se sitúa en su flujo antes que en las unidades" (Parrini, 2007: 18).

Las respuestas de las profesionales de negación ante su identificación no solo se producían en el contexto del taller, también en el día a día dentro del módulo, cada vez que se pronunciaba su nombre, aunque únicamente por parte de la institución. Es decir, el resto de compañeras lo identificaban como él deseaba y otros profesionales del tercer sector que accedían desde fuera y realizaban intervenciones en el módulo también lo hacían. Desde el sistema penitenciario de nuevo imperan representaciones sociales, construidas y asentadas en el exterior sobre la "normatividad" humana, automatizando respuestas tanto discursivas como actitudinales que se reflejan en prácticas institucionales de negación, como esta que he presentado (Mendoza, 2016).

No deja de ser un problema de exclusión de lo diverso. Las personas que se identifican como trans o las que simplemente se sitúan en identidades fluidas desafían tanto en el interior de la prisión como fuera los patrones establecidos y los transgreden, en este sentido puede decirse que representan cuerpos estratégicos (Mendoza, 2016: 221) que cuestionan el sistema heterosexista binario impuesto en nuestra sociedad occidental. Finalmente, estas conductas sexuales consideradas como anormales o desviadas son perseguidas y marginadas a través de los aparatos judiciales, psiquiátricos, generando una dimensión punitiva como seña Gale Rubin (1989) dentro de nuestro sistema sexual, es decir, se produce una hetero-punición:

Las sanciones no formales del sistema sexo/género y la heterosexualidad obligatoria, se conjugan con la criminalización de las estrategias de supervivencia que estas personas construyen en las calles, como punto final de esta cadena incorporada de violencias, el Estado carcelario penaliza su abyección y su precariedad económica y social, al ponerlos tras las rejas (Bello, 2013: 74).

Sin embargo, deseo cerrar este apartado pensando en las resistencias que también emergen dentro de estos módulos, mujeres y hombres que son capaces de 
transgredir el orden heterosexual y adaptarse a él al mismo tiempo. Capaces de vivir su cotidianeidad identificándose con la masculinidad y responder al sistema cuando lo identifican con la feminidad sin generar ningún tipo de respuesta agresiva, a veces simplemente manifestándose como pasivas o pasivos. Consiguiendo poner en marcha una resistencia que se adapta y además es performativa en el sentido en que se engendra desde el cuerpo "entendido no sólo como un lugar de disciplinamiento, sino como posibilidad de desafío e insumisión contra el castigo generizante estatal" (Bello, 2013: 147).

\section{d) Anestesiando los dolores: medicinas y drogas}

Mi estancia en el centro de reducción del daño y los encuentros con Leo y Acuario allí me recuerdan algo que, aunque no había olvidado, tampoco lo había situado en el centro de la investigación, y es que la realidad del consumo de drogas forma parte de la estancia en prisión de las mujeres.

Hace que broten en mí sensaciones y recuerdos respecto a esto que tuve la oportunidad de manifestar en mi Trabajo Fin de Grado en el que desarrollé de una manera más amplia dicho aspecto. Releyendo lo escrito entiendo que es imposible aproximarse a la cárcel y a la criminalización de las mujeres sin tener en cuenta trayectorias de consumo, metadona ${ }^{22}$ y la forma en que todos sus malestares, también los más personales, se medicalizan:

En el modulo 9 creo que las mujeres tienen muchos problemas con el consumo de drogas, problemas de autoestima, problemas relacionales, etc. Sobre todo el consumo de estupefacientes hace que sea complicado el trabajo en el módulo (Conversación con Profesional II, 19 de julio de 2016).

Soy consciente de que analizar este aspecto en la medida en que la droga forma parte de la realidad penitenciaria necesitaría de otro proyecto. Es por ello que mi meta aquí es simplemente dibujar un panorama general de las trayectorias

\footnotetext{
22 De acuerdo con el Centro para el Control y la prevención de enfermedades (2003:1) la metadona "es un agente sintético que funciona "ocupando" los receptores del cerebro afectados por la heroína y otros opiáceos” (En: http://www.cdc.gov/spanish/udi/substanceabuse/methadone.pdf)
} 
de estas mujeres. Comenzar con un esbozo que retomaré y profundizaré en mi tesis doctoral.

Antes de continuar avanzando, quisiera distinguir -aunque finalmente resulta imposible porque todas las experiencias resultan entrelazadas- entre tres trayectorias en las mujeres: consumo de drogas, delitos contra la salud pública y dependencia a los psicofármacos. Es este último aspecto el que elijo desarrollar en este apartado. Las razones, más allá de las limitaciones de extensión del documento, están en la cotidianeidad con la que los psicofármacos aparecían en las conversaciones con ellas y las dependencias. A pesar de ello y de su centralidad, durante mi proyecto fin de grado no los tengo en cuenta.

Aún recuerdo la primera vez que bajé al módulo de mujeres, era enero de 2014. En uno de los primeros encuentros entre la trabajadora social y una de las mujeres este mismo día ya emergía esta realidad y, a la vez, mi desconocimiento más profundo sobre la misma. La mujer estaba recién ingresada al centro, dialogaba con la profesional sobre la posibilidad de hablar con el médico para que le recetase "benzos", así lo llamaba ella. Mi torpeza y mi inexperiencia me impedían incluso reconocer de qué estaban hablando. Ahora sé que se trataba de benzodiacepinas (BZD), definidas por el Servicio Andaluz de Salud (2014) como fármacos que actúan sobre el sistema nervioso central ejerciendo efectos sedantes, hipnóticos, ansiolíticos, anticonvulsivantes y miorrelajantes. Sus principales indicaciones son como hipnóticos y ansiolíticos.

Después de este encuentro mi tutora me explicó de qué se trataba y comenzó a darme las primeas pinceladas de una realidad que, poco a poco, yo misma iría descubriendo en su cotidianeidad. El consumo de psicofármacos, sus dependencias y "trapicheos", como ellas llaman al intercambio de pastillas y otras sustancias, estaban en el día a día del módulo 9 de mujeres.

Al final, los procesos de consumo, dependencia e intercambio de estos medicamentos parecieran ir por los mismos cauces que lo hacen las sustancias ilegales. La única diferencia es que se trata de drogas legales y prescritas, cuyo consumo está avalado moralmente por el sistema médico y de salud, su consumo no representa un desafío a la norma y no se percibe como arriesgado (Farapi, 2009). Sus malestares contaban con recetas. Como establece Mabel Burin (1990) 
una tranquilidad recetada que también se produce en la intimidad, cotidianeidad y privacidad de los muros de la prisión.

En una conversación con Leo le preguntaba sobre esta cuestión:

¿Te daban muchas pastillas?

¿El médico allí? Ese lo único que hacía era darme más medicación, yo salí con más medicación de la que entré...me daba las pastillas y las vendía, para qué te voy a engañar (Leo, 11 de julio de 2016).

Thais en muchas ocasiones reconocía y asumía su dependencia con la medicación. Realmente me conmueve recordar algunos episodios al respecto, verla gritar, llorar cuando el médico le retiró las pastillas de un día para otro. Esta historia es una más de las muchas todas las que allí viví, pero la relación que entablé con esta mujer me lleva a recordarla en mayor medida. Sin embargo, en el día a día pude ver como la culpa, el arrepentimiento, el encierro, generaban malestares tremendos a estas mujeres, episodios de agresividad en los despachos y muchas situaciones que realmente no puedo olvidar.

En este punto me pregunto por la responsabilidad de los profesionales, que en muchas ocasiones, la traspasan a las internas. Quisiera explicarme respecto a esto, son los y las profesionales de la medicina los que recetan este tipo medicaciones por diversas razones. En ocasiones, la relación de dependencia entre los psicofármacos y estas mujeres ya la mantenían en el exterior, sin embargo, en otros momentos se inicia en prisión. Sea cual fuere la circunstancia lo importante y esencial es que la necesidad de consumo ya está presente. Los profesionales conocen el procedimiento de actuación que siguen estos fármacos y es por ello que una vez recetados y extendido su consumo en el tiempo, la responsabilidad de la dependencia no puede recaer solamente en las mujeres, también deben ser conscientes los que propiciaron que estas pudieran tomar Diazepan, Valium o cualquier otra sustancias durante todo el tiempo.

Por otro lado, la existencia de la realidad de "trapicheo" e intercambio de sustancias entre las mujeres no es nueva para ninguna de las personas que trabajaban allí. Aunque en este trabajo no he incorporado a los y las trabajadoras 
de la institución, dos de los voluntarios que se han interesado por la investigación y han participado narraban así su día a día:

Lo que se lleva allí es el tema del trapicheo, la mayoría de las mujeres allí, como ya sabes, son drogodependientes, entonces tienen una medicación fuerte que mezcladas unas con otras pues les puede hacer el mismo efecto que si consumen...aunque yo de eso no entiendo mucho, médico no soy hasta ahora jajaja eso es lo que me han contado. Eso el tema del trapicheo...En cuanto al tema de las pastillas, muchas veces no sabemos si están drogadas, porque como sabes hay mucha droga en la cárcel, o del mismo hecho de las pastillas como son drogas también...tú piensa que un tranquimazin te deja hecho mistos, entonces muchas veces llegan a los talleres y no sabía si estaban drogadas por alguna droga ilegal o estaban drogadas por alguna droga legal. Mezclan unas pastillas con otras, se las intercambian por favores o por cosas, o porque deben o porque tal, entonces también hacen un efecto más grande, entonces es complicado. Sí que te digo que eso que como general así, como la mayoría han sido toxicómanas o tienen problemas depresivos por estar en la cárcel al ser un medio cerrado y todo lo que ello conlleva pues la mayoría...por no decir todas, toman antidepresivos...la mayoría...pero ya te digo que sobre todo por el tema del trapicheo y del intercambio hacen que los efectos sean mayores (Conversación Profesional II, 19 de julio de 2016)

El tema de la medicación...pues...es una problemática bastante grande porque a nivel general en toda la cárcel hay bastante medicación, pero sobre todo en los módulos como el módulo 9 que es un módulo tradicional, ordinario o conflictivo, como quieras llamarle pues hay mucha más medicación, y ya no solamente que haya más medicación, también que se negocia con ella entonces... a hacer ese cambio de pastillas se utiliza eh...como una droga, aunque realmente es una droga legal... pero qué ocurre, que al cambiar la medicación unas con otras y mezclarla con otras pastillas y otras sustancias suele ser un problema bastante grande porque al final lo que lo utilizan no es para lo que se le haya recetado el personal médico sino para coger un colocón y al final pasar el día u olvidarse de algo. Hoy en día se está utilizando mucho 
la medicación en la cárcel...lo cual es un problema porque la droga no hay que meterla desde fuera, pero la medicina al ser una droga legal es más complicada de erradicar porque está allí día a día dándole las pastillas o tratamientos a las personas. Se ve mucho en mujeres y en personas que están en enfermería, personas con problemas de salud mental, con algún tipo de dependencia, drogadicción, las tienen un poco más ...que le dan más pastillas, y es un problema bastante grande (Conversación profesional I, 29 de julio de 2016).

Siguiendo a José María Gallego (2011) un 57\% de mujeres en prisión consumen estas sustancias, la incidencia entre estas destaca por ser un patrón de consumo que se repite.

¿La culpa? Cada día que me levanto... no tendría que haberlo hecho así, pero ya está hecho, a pagarlo! (Thais, 26 de mayo de 2014).

En muchas ocasiones como medio para tratar la culpa y la depresión en las mujeres estas sustancias toman especial protagonismo, como medio para facilitar la adaptación a la prisión y evitación del sufrimiento (Gallego, 2011). Además, los estereotipos de género asociados a la construcción de una imagen de la mujer como débil, pasiva y dependiente también se encuentran entre los profesionales sanitarios. Todo ello hace que ante situaciones inespecíficas de malestar expresadas por las mujeres, y no tan inespecíficas, porque en este caso están derivadas de la estancia en prisión, médicos y médicas tiendan a prescribir psicofármacos (Farapi, 2009). En este sentido, no solo son respuesta a malestares inespecíficos también son una vía para evitar el levantamiento, luchas y reivindicaciones de estas mujeres en prisión.

\subsection{Los "oasis" de la reinserción}

Este último apartado del análisis se corresponde dentro del paso por prisión metafórico del que vengo hablando desde el inicio del análisis, con el último eslabón de la cadena, es decir, la salida de los Centros Ordinarios de Cumplimiento 
y el inicio de la vida en semi-libertad o libertad. Tras el inicio de mi trabajo de campo, en este apartado me pregunto sobre ¿qué he aprendido del propio sistema carcelario a raíz de querer investigar sobre reinserción de mujeres? ¿de qué forma afecta de manera diferenciada a hombres y a mujeres? ¿el Sistema Penitenciario puede ser espacio de rehabilitación y transformación?

De acuerdo al artículo 25.2 de la Constitución española, el fin último de las penas privativas de libertad y de las medidas de seguridad son la reeducación y la reinserción social. Sin embargo, el Sistema Penitenciario no logra ser espacio de rehabilitación y transformación:

¿Que si creo en la reinserción? Noooo...en la que te dan en la cárcel no! Creo en la reinserción que te da tu familia, que porque tú estudies aquí un cursillo de peluquería no sales siendo peluquera. ¿Y todo el tiempo que he estado presa sin mis niños? No ayuda en verdad...porque si a tus hijos les falta de comer y no te dan trabajo porque vienes de la cárcel? Lo volvería a hacer para te voy a decir que no... (Thais, 26 de mayo de 2014).

¿Qué reinserción? Eso no existe...Yo estoy trabajando, estoy ocultando mi pasado, mintiendo todo el día y punto, esa es mi realidad (Ana, 5 de julio de 2016).

El sistema penitenciario tiene un motor enfermo que no puede producir reinserción porque la materia prima que utiliza, el castigo, difícilmente puede ser transformada en otro producto que no sea más castigo, del pasado que siempre regresa, del instante presente que ya es pasado y culpa y del futuro que de incierto tiene tan poco porque el estigma lo ha abrazado, incluso antes de su llegada.

Si acudimos al símil metafórico de la enfermedad, son tres los síntomas principales de los procesos de salida del sistema penitenciario que el inicio de mi trabajo de campo y las dificultades de acceso al mismo me dan a conocer. Han sido casi dos meses de contactos con profesionales, entrevistas, correos electrónicos, presentaciones de la investigación, llamadas telefónicas; meses en los que no he accedido a las mujeres que se encuentran ya en libertad o cumpliendo la última parte de su condena en medio abierto porque la estructura del sistema no me lo permitido. Con todas las dificultades encontradas, me veo "obligada" a desarrollar 
este apartado como medio para reflexionar sobre las presencias y las ausencias encontradas en este camino.

\section{a) El acceso a través de las y los profesionales}

Me ha resultado especialmente característico y complejo entablar relaciones de manera directa con mujeres que quisieran en participar en el proyecto. El objetivo de entablar estas relaciones era doble, por un lado, dar respuesta al TFM, por otro, comenzar la investigación para el doctorado. Las vías de acceso de las que he hecho uso han sido diversas. He procedido a presentar el proyecto de investigación a la Institución Penitenciaria para solicitar el acceso al Centro de Inserción Social Matilde Cantos, la respuesta afirmativa me ha llegado recientemente.

A este centro llegué en mayo de 2016 a través de un compañero, que se ha vuelto figura clave de esta investigación por tratarse del punto de partida y nexo conector con la mayoría de los contactos iniciales. Es a través de él que consigo contactar con la directora de programas y que sorprendentemente se interesa e involucra con mi trabajo de manera excepcional, a pesar de mi poca esperanza puesta en ello, pues me encontraba en un momento débil de la investigación, por la dificultad de acceso al campo y las limitaciones continuadas que aparecían para iniciar el mismo, además, mis propios prejuicios me hacían desconfiar de la institución como facilitadora de la investigación.

Casi dos meses después, a finales de julio, consigo el permiso de acceso por seis meses, bajo la figura de investigadora doctoranda, previa cumplimentación de una solicitud en la que tuve que desarrollar mis objetivos y metodologías de investigación, en el marco de mi proyecto de tesis doctoral. En la actualidad me encuentro negociando mis condiciones de acceso, previo contacto con la subdirectora de tratamiento, a la espera de que el director se manifieste al respecto y acordar si es necesario desarrollar alguna actividad paralela en relación a talleres o encuentros en el Centro, como contraprestación de la ayuda y el espacio cedido en el CIS. 
Por otro lado, he contactado con asociaciones y organizaciones que trabajaban con mujeres en diversos lugares de la península, esto daría respuesta a objetivos más a largo plazo respecto a la posibilidad de diseñar mapas geográficos y rutas que emprenden las mujeres al salir de los Centros Penitenciarios Ordinarios. Además, he iniciado mi trabajo de campo en un centro de reducción del daño en la provincia de Granada, como medio de contacto con algunas de estas mujeres que hacen uso de servicios de este tipo y que previamente han vivido la realidad penitenciaria. Por otro lado, mantengo varios encuentros con miembros de la pastoral penitenciaria, consiguiendo finalmente la posibilidad de colaborar en el piso de acogida para mujeres en prisión que tienen en Granada. Finalmente, quedo a la espera de comenzar en septiembre mi trabajo como voluntaria en la Asociación PIDES dentro de Centro Penitenciario de Albolote. Todo este proceso ha requerido de casi cuatro meses de diálogo, paciencia y cabezonería para ser escuchada.

En la introducción de este apartado hablaba de la sensación de un sistema enfermo que presentaba tres síntomas que me hacían pensarlo. Este sería el primero de ellos, la dificultad de investigar el encierro - incluso ya en libertad - de las mujeres debido a la barrera que supone el acceso directo a ellas. En muchas ocasiones, estas mujeres no pueden elegir libremente participar de ciertas actividades, en este caso una investigación, ya que tuve que pasar antes por un/a profesional que diera el "visto bueno". La primera decisión de participación debe llegar de ellos, después le darán la posibilidad a ellas.

El control del sistema penitenciario sobrepasa los muros de las prisiones y llega hasta las instituciones y agentes sociales que prestan servicios al margen de la cárcel al colectivo de mujeres que se encuentran en libertad o semi-libertad.

De ninguna manera puedo generalizar, ni hacer extensible estas circunstancias a todos/as los/las profesionales con los que me he relacionado durante este tiempo. Sin embargo, ha sido importante para mí reflexionar sobre este hecho y sobre cuál es el papel que las disciplinas de lo social, tanto el Trabajo Social, como la Sociología, Antropología, Educación Social, tienen respecto a la reproducción social y/o atenuación de las contradicciones y desigualdades generadas por la sociedad capitalista y neoliberal de nuestros tiempos. De acuerdo con Sergio García (2013: 31), profesor de Trabajo Social en la Universidad Complutense de 
Madrid, este sistema neoliberal cuenta con su propia política social, la cual se apropia de las estructuras del Estado de Bienestar dotándolas de un nuevo uso, es decir, "tanto los dispositivos de atención como los individuos objeto de la intervención serán gestionados de acuerdo a la forma social del mercado". Y los profesionales se regirán como agentes disciplinarios y de control, la intervención social finalmente se vuelve intervención estatal en una sociedad disciplinaria. Las trabajadoras sociales, entre otras profesionales, se vuelven transmisoras de las normas morales:

El Estado del Bienestar, como auge de la sociedad disciplinaria, fue la mejor forma de controlar normativamente a la población más empobrecida y afectada por el desempleo, esto es, excluida de los otros dispositivos disciplinarios. La normalización era para toda la sociedad, pero la vigilancia sobre su cumplimiento se aplicaba principalmente sobre una población concreta, la más empobrecida y deslegitimada (García, 2013: 35).

Esta forma de intervenir y estas dificultades encontradas en mi relación con los profesionales están conectadas con la lógica disciplinaria y de castigo de poblaciones empobrecidas que Wacquant (2010, 2012) y Garland (2015), entre otros y otras investigadoras, defienden y a la que hice mención en el primer apartado del marco teórico.

Desde esta lógica, y antes de continuar avanzando, quisiera aclarar que en este punto soy consciente de que en la mayoría de las ocasiones las actuaciones de y decisiones de estos profesionales no se han debido a decisiones personales sino que hay que ubicarlas y enmarcarlas en dinámicas generales y políticas más amplias de actuación.

Buscando entender cuáles han sido los motores y las lógicas que han imperado en mis dificultades de acceso a estas mujeres, comienzo a vislumbrar algunas de las dinámicas complejas que se desarrollan dentro de las intervenciones sociales, de corte más neoliberal en general, y pensando en particular en esta población. En muchas ocasiones estos profesionales actúan como elementos de detección y contención de los posibles puntos de inestabilidad que podrían llevar a fenómenos disruptivos e incluso "peligros" para la sociedad (Ávila, 2010), donde la población penitenciaria puede verse como el máximo exponente. 
Para concluir, acudiendo de nuevo al símil médico, la antropóloga Débora Ávila (2010) nos invita metafóricamente a pensar que, al igual que desde la medicina el enfoque de las epidemias no trata tanto de curar a todos sino de acotar la enfermedad para que no se contagie más, en la intervención social neoliberal no se trataría de eliminar los puntos o poblaciones inestables o resolver el problema, como de localizarlo, evitar su extensión y mantenerlo dentro de los límites de "tolerabilidad". En este sentido podría explicarse el componente de hermetismo, dificultad de acceso, falta de investigaciones respecto algunos colectivos para los que se busca el máximo aislamiento que permita el control del problema, sin contagio ni reivindicaciones del colectivo.

\section{b) Malas mujeres que se redimen}

En segundo lugar, de acuerdo a los síntomas de un sistema de reinserción penitenciario enfermo a los que me refería, aparece la "invisibilidad" y el nomadismo de las mujeres que han estado privadas de libertad, en comparación con los hombres, en la última etapa de cumplimiento de la condena y la posterior libertad.

Es decir, como afirmaba en uno de los encuentros una de las profesionales del Centro de Inserción Social, tras la puesta en libertad las mujeres toman trayectorias diversas tras finalizar sus estancias en los Centros Ordinarios, se dispersan y su llegada y permanencia en los Centros de Inserción Social es menor que la de los hombres. Debido a la forma en que impera en este contexto el reparto de roles de acuerdo al género las mujeres disfrutan de manera más habitual del proceso de semi- libertad y libertad condicional ejerciendo labores de cuidados y atención a las familias. Esto es así porque, según la profesional, en cierto modo el sistema "beneficia" a las mujeres por su papel de madres y cuidadoras. Existe una naturalización de la función de apego y cuidados de estas mujeres por parte de la administración a la hora de asignar o valorar la modalidad de cumplimiento de la última parte de la condena, primándose la modalidad de dispositivos telemáticos. Durante la última consulta en el mes de junio en el Centro de Inserción Social de Granada había ocho mujeres mientras el número de hombres superaba la centena. 
Según me explica esta profesional, las mujeres que mantienen su rol y deber de cuidadoras tienen más posibilidades de cumplir la última parte de la condena en libertad condicional, mediante el uso de la pulsera telemática ${ }^{23}$. Sin embargo, lo que ella me nombra como algo beneficioso para las mujeres, a mí me lleva de nuevo a cuestionarlo. No considero que sea arbitrario premiar el rol de cuidadora y madre de estas mujeres, en las cuales el sentimiento de culpa, por no ser lo que la sociedad espera de ellas, aflora diariamente. Estos beneficios están diseñados para seguir generando y controlando un perfil de mujer adecuada y a medida para estar en la sociedad, sustentando el sistema. Este premio al cuidado es a la vez exigencia. Contradictoriamente, estas mujeres privadas de libertad podrían verlo como tal, sin embargo, una vez fuera siguen siendo las más perjudicadas. Y ¿qué pasa entonces con las que no son madres o no adquieren el rol de cuidadoras?

Antes de su entrada en prisión y durante, una mujer madre es triplemente criminalizada, social, personal y penal (como he desarrollado en el marco teórico), sin embargo, a su vez queda beneficiada. Podría estar generándose entonces un modelo ideal de mujer reinsertada: madre, cuidadora, esposa, que decide olvidar su pasado y se muestra arrepentida y culpable. ¿Qué intereses ocultos hay detrás? ¿qué mecanismos activan las instituciones? Se trataría de una reinserción que es la que el sistema quiere, con los roles que él decide perpetuar, y los mecanismos y herramientas que le aseguran su continuidad:

Sé que ahora tengo a mi familia porque antes pensaba que pasaban de mí, soy consciente de la falta que me hacen mis niños, yo eso antes no lo miraba (Thais, 26 de mayo de 2014).

Hay continuas menciones a la familia y los hijos... una mujer reinsertada tiene que culpabilizarse, tomar conciencia de que es madre, jamás perder ese rol,

\footnotetext{
${ }^{23}$ Las pulseras telemáticas son unas de las medidas de control telemático. Estos medios son un conjunto de sistemas electrónicos que Instituciones Penitenciarias utiliza para el control de presencia a distancia de personas que se encuentran en el ámbito de sus competencias. El art. 86.4 del vigente Reglamento Penitenciario posibilita una forma específica de cumplir condena en régimen abierto, sustituyendo el tiempo de estancia mínimo obligatorio en el establecimiento por medios telemáticos u otros sistemas adecuados de control (Secretaría General de Instituciones Penitenciarias en: http://www.institucionpenitenciaria.es/web/portal/cumplimientoMedioAbierto/controlTelematico.html )
} 
siempre recuperarlo, y recuperar el tiempo perdido para que se olvide la etiqueta de mala madre.

Al inicio del apartado hablé de mi experiencia en Copenhague en relación a un chico que tuve la oportunidad de conocer en una de las salidas del curso al que allí asistía. Se trataba de un chico joven, danés aunque de procedencia musulmana, que había entrado en prisión por problemas relacionados con robos y tráfico de drogas. Durante su condena estudió Trabajo Social y a su salida montó una asociación para ayudar a menores con dificultades sociales. Hombre malo deviene en hombre bueno y decide ayudar al prójimo, sería el mito del hombre reinsertado, que tuvo problemas en el pasado, consiguió solucionarlos y su vida está libre de "pecado" en el presente.

Trayectorias como estas, sin desmerecer los éxitos alcanzados, son orgullosamente presentadas por el sistema. De nuevo generan modelos ideales, en este caso, de hombres reinsertados: hombre, joven, no extranjero o extranjero muy adaptado, arrepentido y que ha eliminado de su vida cualquier tipo de problema. Todo lo que se salga de estas trayectorias, por no irnos a los casos más extremos, nos harán saber que es culpa de la persona y que el sistema hizo todo cuanto estuvo en sus manos por ayudarla.

Finalmente, en el caso de las mujeres el castigo penitenciario genera programas de reinserción-rehabilitación feminizantes, como ya hemos dicho, estas mujeres son percibidas tanto por el Estado como por la sociedad como transgresoras de los roles de género. De esta forma la prisión en su forma sexista las adoctrina en pasividad, dependencia, sumisión y obediencia y, a la vez, se traduce en reproche y abandono social. Aparece la culpa como compañera de camino, debido al abandono de las funciones de cuidado y maternales (Bello, 2013). Todo ello lo que provoca es que estas mujeres cuando finalmente cumplen la condena material intenten por todos los medios librarse de la culpa, asumiendo los roles más tradicionales y supliendo las funciones que ellas piensan que no han podido ejercer durante su estancia en prisión. Así en muchas ocasiones buscan eliminar todo rastro de su estancia en prisión, haciendo como que dicha realidad nunca existiera:

Yo estoy trabajando...estoy ocultando mi pasado, mintiendo to el día y punto...es es mi realidad (Ana, 5 de julio de 2016). 


\section{c) Donde lo colectivo está atravesado por el estigma}

La invisibilidad y el nomadismo que caracterizan a las mujeres que han estado privadas de libertad desarrolladas en el apartado anterior, están muy relacionadas con el tercer síntoma sobre el que me hacen reflexionar las dificultades encontradas para acceder al campo, es acerca de la ausencia de asociaciones o agrupaciones de personas presas, en concreto de mujeres. En este punto me pregunto ¿Quiénes se agrupan? ¿qué hace falta para verse reconocido en otras personas? ¿qué personas permite el sistema que se agrupen?

Pienso, sin embargo, en la cantidad de colectivos que hay de personas en situación de dependencia, personas mayores, educación. ¿Qué mecanismos funcionan para activar la "lástima"? ¿Lástima Vs. Estigma? ¿a quién es moral ayudar? El sistema continúa haciendo uso de la caridad con un componente cristiano, mesiánico y salvador (origen del Trabajo Social), que de manera renovada sigue imperando en nuestra sociedad: estigma, olvido, no organizaciónagrupación.

¿Hay colectivos más óptimos para ser ayudados al igual que saberes tradicionalmente mejor valorados? Estas ausencias y presencias hablan también en términos de dominación y poder de determinados conocimientos sobre otros. Si entendemos la violencia epistémica (Spivak, 1998) como una forma de invisibilizar a la otra (mujer, privada de libertad), es una forma de expropiar y de interponerse a la posibilidad de su propia representación. La representación, a su vez, se relaciona con el poder: quien tiene poder puede representarse y manejar las formas en que se le representa. Poder entendido como habla, diálogo, discusión, es decir, una sujeta tiene poder "cuando logra separar su palabra del cuerpo y hacerla que circule y que impacte" (Lombardelli, 2008). Estas mujeres difícilmente lo consiguen, qué ocurre para aquellas que la palabra o el grito no son una opción y sus discursos quedan secuestrados por el sistema penitenciario, profesionales de lo social o investigaciones cuantitativas.

Es común que las personas de la tercera edad, la infancia o los colectivos dependientes en general suelan ser vistos como grupos que merecen apoyo y 
ayuda. Sin embargo, hay otros grupos tales como mujeres que ejercen la prostitución, personas en situación de drogodependencia o las que aquí nos ocupan, aquellas privadas de libertad, a los que se les atribuye la responsabilidad de su situación "y de los cuales se espera que se modifiquen a sí mismos para poder ser reinsertados en la vida social" (Juliano, 2004: 38). Siguiendo a Dolores Juliano (2004) estos colectivos no son objeto de intervenciones sociales reparadoras, sino de soluciones disciplinarias. Todo ello es finalmente un eslabón roto más en la cadena que llevaría a las mujeres que han estado privadas de libertad al auto-reconocimiento, asociacionismo y reconocimiento en las situaciones de las demás, haciendo que la estrategia de control social global continúe viva y manteniendo a estas mujeres segregadas. Esto evita a la vez la posibilidad de que puedan emprender luchas conjuntas por sus derechos y opciones vitales.

La fuerza del rechazo social y el fuerte estigma al que las mujeres privadas de libertad tienen que hacer frente las desalienta y aísla, dificultando así su organización y lesionando su autoestima (Juliano, 2004). Todo ello se materializaría en estas estrategias de ocultamiento de su pasado como medio de mantener a salvo sus vidas de esta estigmatización.

Sin embargo, esta falta de asociacionismo me lleva también a pensar el silencio y la ocultación de las mujeres privadas de libertad en una doble dirección. Por un lado, efectivamente como ausencia y estigma. Por otro lado, y volviendo a la luz del enfoque de las resistencias podría verse como acto de autocuidado y estrategia de resiliencia que ellas escogen para hacerse y asentarse en una sociedad que las rechaza. Sin embargo, existe siempre esta tensión entre lo que produce compasión y lo que produce temor e inseguridad y que a la vez se traduce en una forma represión (Fassin, 2014).

Quisiera finalizar este apartado, que a la vez es cierre del punto central de análisis de este trabajo, pensando en las palabras de aliento de Garzón (2007) al invitarnos a reflexionar sobre la performatividad del silencio de estos grupos. Es verdad que el silencio actúa como estrategia disciplinaria pero también debe ayudarnos a pensar nuevas estrategias de lucha y resistencia. 


\section{EL ENCIERRO NO SE PUEDE CERRAR Y OTRAS FORMAS DE CONCLUIR}

Estar escribiendo estas líneas comienza a producirme más incertidumbres, vértigos y cuestionamientos que grandes certezas, algunas verdades y muchas respuestas. Desde pequeña he oído que para concluir con algo o con alguien había que cerrar la puerta y poner el candado más grande, para que así el pasado no te invada continuamente y deje espacio a nuevas construcciones. Siempre me ha agobiado enormemente esta idea. Sin embargo, me tranquilizaban diciendo que aunque esa puerta se cerrase, una ventana se abriría. Yo la imaginaba amplia, de madera y de dos hojas, por la que entraba mucha luz y dando al campo. Era la inocencia y la imaginación de una niña. Hoy, y llegada a este punto, me pregunto que pasaría si al abrirla te encuentras con unas rejas y la puerta de hierro más pesada y resistente acompañada de un cerrojo se acaba de cerrar a tus espaldas, si ese tuviera que ser tu espacio durante un periodo de tiempo que a poco que parezca ya te ha robado instantes de vida. Concluir entonces se hace difícil.

¿Cómo se construyen entre sí los procesos de castigo, criminalización y encarcelamiento en las mujeres? Este proyecto gira en torno a rejas, puertas de hierro, muros de hormigón y roles de género, pero también, sobre las libertades que emergen en las esquinas de las celdas, las formas de habitar la cárcel desde la categoría mujer y las formas en las que la cárcel habita en las mujeres. Desde un posicionamiento abolicionista, feminista y parcial y la óptica del Trabajo Social, la etnografía, la auto-etnografía y la reflexividad. Estos ejes lo han nutrido, guiado y, finalmente, construido.

Me permito a mí misma comenzar por el Trabajo Social, pues ha sido esta, mi disciplina, la que me acercó al sistema penitenciario y me contagió de su rabia y ganas de luchar. Me ha permitido un comprensión profunda y holística de la realidad de las cárceles, entender que se puede llegar a conocer a una sociedad justamente desde los márgenes, acercándose a lo que excluye, estigmatiza y finalmente, encierra.

Pensar en las intervenciones que se llevan a cabo desde la profesión, y que yo realicé en el Centro Penitenciario de Albolote años atrás, y analizarlas desde el proceso etnográfico que ello supuso me obliga a reflexionar sobre las 
vinculaciones y semejanzas que puedan tener estas intervenciones y el propio proceso etnográfico, realmente ¿dónde empieza y terminan unas y otro? ¿cuándo empezó y cuándo terminará mi trabajo de campo?

Siguiendo a Alcázar-Campos y Espinosa (2014) efectivamente he podido entender que las principales características del método etnográfico, entender la perspectiva de las sujetas y la manera en que la gente otorga sentido a su vida son útiles y enriquecedoras para hacer investigación e intervención desde el Trabajo Social, ya que estamos siempre vinculadas a la sociedad, sus problemas, sus gentes y sus vidas. Y viceversa, se puede hacer etnografía de una intervención social y una estancia en el medio sin que el fin inicial fuera, efectivamente, hacer investigación.

Por otro lado, la perspectiva feminista me ha permitido estudiar y analizar el encarcelamiento de las mujeres bajo las matrices interseccionales de opresión, para tender cómo se articulan las diferencias de género, raza, clase y sexualidad, entre otras, en estos procesos. Los feminismos me llevan a conceptualizar y entender la cárcel como una compleja red de poderes que sobrepasan los propios muros de la prisión, es decir, en la medida en que el castigo es visto como "una institución inseparable del capitalismo global, el racismo, el sexismo y el heterosexismo" (Bello, 2013: 2).

Así mismo, me han acercado al enfoque abolicionista, que no tiene por qué ser feminista, sin embargo, he llegado por este. Además, me han nutrido de las herramientas para continuar construyendo este proyecto (que inicio con el Trabajo Fin de Master y se extiende hasta el doctorado) desde el interés por los conocimientos, saberes y agencias de las mujeres en prisión en contextos "localizados y específicos de criminalización, castigo y resistencia" (Sudbury, 2005: 17).

Quisiera concluir en tres sentidos, al igual que lo hice anteriormente en el desarrollo de mi análisis. Por un lado, la decisión de narrarme a mí misma en el documento - de incluir mis pensamientos, mis circunstancias personales y mi trayectoria y vinculación con el ámbito penitenciario - y de llevar a cabo el ejercicio de memoria que he realizado, me ha permitido redescubrir y valorar saberes, conocimientos y situaciones que inconscientemente había pasado por alto. Experiencias de mi estancia en prisión y de mi acceso al campo que, reconozco, había subestimado en un principio. Y, sin embargo, me han dado claves 
más importantes y son los cimientos más férreos para la construcción de mi tesis doctoral.

Thais, Esperanza, Paco, Leo, Acuario, Ana, Manuela... y todas las demás que compartisteis comentarios, experiencias y entrevistas conmigo, vuestras historias, esas reales, de carne y hueso, verdaderas y encarnadas, conforman mis conclusiones subjetivas, interpretadas, posicionadas y parciales.

Me habéis dado la clave para entender que estudiar la realidad de la cárcel requiere antes dar un paso atrás y preguntarse sobre cuáles son las circunstancias que os han llevado hasta allí y de qué formas. Es decir, con vuestros relatos me alertasteis de que no podía dejar mudas vuestras palabras de agradecimiento a la prisión. Además, me habéis presentado y permitido conocer la realidad de los módulos 9 y 10 de la prisión, su cotidianeidad y vuestras demandas. Reconocer que el sistema punitivo también es heterosexual y que se incomoda ante las identidades sexuales que deciden no ubicarse donde les mandan. Sin embargo, también me habéis llevado a reflexionar sobre vuestras experimentaciones y formas de romper ese binarismo sexual. Por otro lado, me habéis orientado y alertado de que el consumo de drogas ilegales, efectivamente, es una realidad en las prisiones pero que estaba pasando por alto las dependencias y dolores que acallaban las drogas legales. Los psicofármacos y efectos en vuestros malestares, la culpa, el arrepentimiento.

Una vez acabada la condena en el Centro Penitenciario Ordinario, cuando he querido contactar con vosotras desde la semi-libertad o libertad, mucho antes de que pudiésemos hablar, cuando los profesionales han decidido por vosotras y he encontrado mil dificultades para generar puntos de encuentro entre nosotras, me habéis advertido de la longitud de los brazos del sistema penitenciario y punitivo, y de la figura de contención y barrera que en muchas ocasiones podemos suponer los y las trabajadoras de lo social para impedir permear a los colectivos "peligros". Además, me habéis permitido encontrar vuestras rutas en libertad, de forma paradójica, porque son las de la dispersión y nomadismo en busca, en muchas ocasiones, de los cuidados y la atención de vuestras familias, "premiadas" por el sistema al ser mujer, madre, hija, esposa... Finalmente, me alarmasteis, con vuestra falta o nula representación y asociacionismo, de que sois un colectivo peligroso, la 
cárcel y sus experiencias no merecen estos espacios, la lástima y el estigma siguen caminos distintos.

Ante todo lo anteriormente desarrollado mi posicionamiento "situado" y mi propuesta de acción están permeados e inspirados por la perspectiva abolicionista a la que hacía mención anteriormente (Davis, 2014; Subdury, 2005; Bello, 2013). Este enfoque teórico y político pone en cuestión la figura de la cárcel y del castigo como las únicas herramientas que la justicia utiliza para resolver los conflictos sociales. Así, las prisiones se han convertido en dispositivos de exclusión de poblaciones marginadas y de encarcelamiento de sectores empobrecidos. El enfoque abolicionista propone entonces trabajar en dos sentidos. Por un lado, llevar a cabo reformas para que las personas encarceladas en todo el mundo dejen de experimentar violaciones de derechos humanos. Por otro lado, dar un paso más allá de la reforma, no se trataría de construir "más y mejores cárceles", sino de superar las políticas racistas, sexistas, capitalistas que sustentan las prácticas del encarcelamiento. La propuesta es un proceso positivo de recuperación y construcción de las instituciones, prácticas y formas de relacionarnos que nutran la movilización social, lo común y la autodeterminación (Bello, 2013).

Creer en la resiliencias, resistencias, poderío, sororidad y agencia de las mujeres privadas de libertad y no imaginar una alternativa constructiva a su situación carecería de sentido personal para mí. La opción de imaginar un mundo mejor siempre está, el componente utópico podría ser su motor, erguida sobre unas ruedas que siempre estuviesen en contacto con la tierra fértil y con los pies en el suelo. Eso sí, los obstáculos a esquivar en este camino serán muchos y diversos. Debiéramos de estar atentas para no arrollar a nadie durante nuestra andadura:

Cada vez que insistimos en un sistema de salud accesible y abierto, educación de calidad, empleo significativo y seguro, relaciones amorosas y curativas, $y$ clamamos por ser nosotras mismas, estamos haciendo abolición. La abolición se refiere a romper cosas que oprimen y construir cosas que nutren. La abolición 
es la práctica de transformación en el aqui y el ahora y para siempre24.

\section{BIBLIOGRAFÍA}

Aguilera, Marga. "Mujeres presas: la doble condena". En Políticas Sociales para abolir la prisión, de César Manzanos Bilbao, 9-21. Victoria-Gasteiz: Ikusbide, 2011.

Alcázar-Campos, Ana y Espinosa Spínola, María. “¿Por qué es importante la etnografía para el Trabajo Social? Algunas reflexiones para el debate". Humanismo y Trabajo Social, no 13-14, pp. 335-347, 2014.

Almeda Samaranch, Elisabet. Corregir y castigar: el ayer y hoy de las cárceles de mujeres. Barcelona: Edicions Bellaterra, 2002.

Almeda Samaranch, Elisabeth. Mujeres Encarceladas. Barcelona: Ariel S.A., 2003.

Almeda Samaranch, Elisabet y Bodelón González, Encarna (coord.). Mujeres y Castigo: un enfoque socio-jurídico y de género. Madrid: Edit. Dykinson, 2007.

Ávila Cantos, Débora, y Marta Malo de Molina. "Manos invisibles: de la lógica neoliberal de lo social". Trabajo Social Hoy, no 59, 2010.

Ávila-Fuenmayor, Francisco. "El concepto de poder en Michel Foucault". Telos 8: 215-234, 2006.

Azaola, Elena. "Mujeres en el sistema de justicia penal y la antropología a la que adhiero". Cuadernos de Antropología Social No 22, pp. 11-26, 2005.

Behar, Ruth. Cuéntame algo aunque sea una mentira: las historias de la comadre Esperanza. Fondo de Cultura Económica, 2009.

${ }^{24}$ Sudbury, 2011: 313, en Bello, 2013: 8. 
Bello Ramírez, Jeisson. Cuerpo encerrados, vidas criminalizadas. Interseccionalidad, control carcelario y gobierno de las diferencias (Tesis doctoral). Universidad Nacional de Colombia. Bogotá. 2013

Benzodiazepina: riesgos y estrategias para su retirada. "Boletín terapéutico Andaluz". Centro Andaluz de Documentacion e Información de Medicamentos. 2014. En: http://dx.doi.org/10.11119/BTA2014-29-02.

Bernstein, Elisabeth. “Las políticas carcelarias representan la justicia de género? La trata de mujeres y los circuitos neoliberales del crimen, el sexo y los derechos". Debate Feminista, 25 (50) pp. 280-320, 2014.

Bodelón González, Encarna en: Mujeres en prisión: los alcances del castigo / compilado por CELS, Ministerio Público de la Defensa de la Nación, Procuración Penitenciaria de la Nación. - 1a ed. - Buenos Aires: Siglo Veintiuno Editores, 2011.

Borges, Jorge Luis. "El etnógrafo" en: Borges, Jorge Luis. Elogio de la sombra. (pp. 57-61) Buenos Aires/Barcelona: Emecé. 1969.

Burin, Mabel, Esther Moncarz, y Susana Velázquez. El malestar de las mujeres. La tranquilidad recetada. Buenos Aires: Paidós, 1990.

Cazorla, Jose Manuel. "Funciones de los trabajadores sociales en Prisión". Blog de Trabajo Social Penitenciario (Comentario enviado el 26 de abril de 2013). En: $\quad$ http://trabajosocialpenitenciario.blogspot.com.es/2013/04/ante-laavalancha-de-futurasos.html

Cerri, Chiara. "Dilemas éticos y metodológicos en el trabajo de campo. Reflexiones de una antropóloga". Revista de Antropología Experimental. no 11, 2011.

Cervelló Donderis, Vicenta. "Las prisiones de mujeres desde una perspectiva de género". Revista General de Derecho Penal. № 5, 2006. 
Circular I-1/12, de 2 de abril de 2012, por la que se regulan los Permisos de salida y salidas programadas (Secretaría General de Instituciones Penitenciarias).

Cordelier, Benoit. “Cómo hacer organización sin palabras: performatividad y silencio". Revista Académica de la Federación Latinoamericana de Facultades de Comunicación social. 2012.

Daunis Rodríguez, Alberto. Ejecución de penas en España: la reinserción social en retirada. Granada: Comares, 2016.

Davis, Angela Y., entrevista de Amy Goodman. «Ángela Davis habla de la abolición de la cárcel, la guerra contra las drogas y los movimientos sociales .» Democracy Now. (6 de marzo de 2014). En: http://www.democracynow.org/es/2014/3/6/angela_davis_habla_de_la_abolicio $\mathrm{n}$

Davis, Angela Y. Democracia de la Abolición: Prisiones, Racismos y Violencia. Edici ón e introducción de Eduardo Mendieta. Traducido por Irene Fortea . Madrid: Editorial Trotta, 2016.

De Miguel Calvo, Estibaliz. "Relaciones amorosas de pareja en las trayectorias vitales de las mujeres encarceladas". Tesis doctoral de Sociología: Universidad del País Vasco, 2012.

Defensor del Pueblo Andaluz. Mujeres privadas de libertad en centros penitenciarios de Andalucía. Sevilla: Defensor del Pueblo Andaluz, 2006. Disponible en

línea: http://www.defensorand.es/informes_y_publicaciones/informes_estudios_y_resol uciones/informes_especiales/informe_0002/informe_0002.html

Del Valle, Teresa. "Metodología para la elaboración de la autobiografía”. En C. Sanz Rueda, Invisibilidad y presencia. Seminario internacional "Género y trayectoria profesional del profesorado universitario". Madrid: Instituto de Investigaciones Feministas de la Universidad Complutense de Madrid, pp. 281-289, 
1995.

Del Valle, Teresa. "Interpretaciones de ciertos mecanismos del recuerdo" Ankulegi: gizarte antropologia aldizkaria , 347X, №. 10, pp. 11-18, 2006.

“Drogas y Género”. Farapi S.L. 48, 2009.

Erving, Goffman. Estigma: la identidad deteriorada. Buenos Aires: Amorrortu, 1998.

Fassin, Didier. La fuerza del orden: una etnografía del accionar policial en las periferias urbanas. Edición en español. Traducido por Andrea Sosa Varrotti. Barcelona: Siglo XXI, 2016.

Foucault, Michel. Vigilar y Castigar. Nacimiento de la prisión. 2009. Madrid: Siglo XXI, 1979.

Gallego, Jose María. "Nuevos controles sociales ante un caso de exclusión social extremo: el control de la población drogodependiente en prisión". Revista de Estudios Sociales y Sociología, no 161, pp.115-132, 2011.

García-Bores Espí, Josep María. "El impacto carcelario". En: Bergalli, Roberto (coord.). Sistema penal y problemas sociales, págs. 395-425, 2003.

García España, Elisa. "Las otras poblaciones presas: mujeres y extranjeros". Revista de Derecho Penal y Criminología 3, no 7, 2012.

García García, Sergio. "Lógicas y perfiles profesionales en la intervención social: un análisis centrado en los Servicios Sociales de Madrid". Plaza Púlblica: Revista de Trabajo Social 8, no 9, pp. 30-49, 2013.

García Vita, Ma del Mar. 2015. "Redes de apoyo y entornos sociofamiliares en mujeres reclusas: análisis de las relaciones con las drogas, el acompañamiento en prisión y los procesos hacia la reinserción social”. Tesis doctoral de Ciencias de la Educación: Universidad de Granada. 
Garland, David. La cultura del control. Crimen y orden social en la sociedad contemporánea. Traducción de Máximo Sozzo. Barcelona: Gedisa, 2015.

Garzón Martínez, María Teresa. “Proyectos corporales. Errores subversivos: hacia una performatividad decolonial del silencio". Nómadas (Col), pp. 154-165, 2007.

Gimeno Martín, Juan Carlos. Poniendo la antropología en valor. Revista Nuevas Tendencias en Antropología, №. 2, 147-179, 2011.

Gregorio Gil, Carmen. "Contribuciones feministas a problemas epistemológicos de la disciplina antropológica: representación y relaciones de poder", Revista de Antropología Iberoamericana, Ed. Electrónica nำ1, pp. 22-39, 2006.

Guerrero Muñoz, Joaquín. "El valor de la auto-etnografía como fuente para la investigación social: del método a la narrativa". Azarbe: Revista Internacional de Trabajo Social y Bienestar, nํㅜ, pp 237-242, 2014.

Haraway, Donna. J. Conocimiento situado. En Ciencia, cyborg y mujeres: la reinvención de la naturaleza. Haraway, Donna J. Madrid: Cátedra, 1995.

Jefatura del Estado «BOE» núm. 281, de 24 de noviembre de 1995 Referencia: BOE-A-1995-25444 Ley Orgánica 10/1995, de 23 de noviembre, del Código Penal TEXTO CONSOLIDADO: Última modificación: 28 de abril de 2015

Jiménez Bautista, Francisco; Jiménez Aguilar, Francisco. "Foucault, cárcel y mujer: el conflicto de la reincidencia". Revisa de Humanidades, 20, pp. 83-104. 2013.

Jiménez-Bautista, Francisco, “Criminalidad y violencia en América Latina: el caso de las mujeres colombianas en las prisiones de España", Respuestas, vol. 20, no. 2 , pp. 105-118, 2015.

Jimeno Santoyo, Miriam; Murillo, Sandra Liliana y Martínez Julián, Marco, Etnografías contemporáneas. Trabajo de campo. Bogotá: Universidad Nacional de Colombia, 2012.

Juliano, Dolores. Excluidas y Marginales. Feminismos. Madrid: Cátedra, 
2004

Juliano, Dolores. "Delito y Pecado. La transgresión en femenino". Política y Sociedad, vol.46, nำ1, pp. 79-95, 2009.

Juliano, Dolores; et al. Encarceladas: invisibilizadas, transgresoras y estigmatizadas. Pamplona: Emakume Internazionalistak , 2010.

Juliano, Dolores. Presunción de inocencia: Riesgo, delito y pecado en femenino. San Sebastián: Edit. Garkoa, 2011.

Langle de Paz, Teresa. "A Golden Lever for Politics: Feminist Emotion and Women`s Agency”. Hypatia 31, no 1, pp. 187-203, 2016.

Lombardelli, $\quad$ Martha (2008)

http://lombardellimarthalicia.blogspot.com.es/2008/12/violencia-epistmica.html

López Castro, Leticia. "El tratamiento penitenciario. Evolución histórica desde el s. XVII hasta la actualidad con perspectiva de igualdad de género". Cuestiones pedagógicas: Revista de ciencias de la educación, №. 24, pp. 89-102, 2015.

Makowski Muchnik, Sara. "Formas de resistencias y acción colectiva en cárceles de mujeres". FERMENTUM. Mérida-Venezuela, pp.68-77, 1997.

Mallicoat, Stancy L. "The incarceration of Women". En Women and Crime: a text/reader, de Stancy L. Mallicoat, editado por California State University, pp. 461511. California: SAGE Publications, 2011.

Manzanos Bilbao, César. Cárcel y Marginación social. Contribución crítica e investigación aplicada a la sociedad vasca. Donostia: Hirugarren Prentsa, S.A., 1992.

Mapelli Caffarena, Borja, y Myriam Herrara Moreno. "La exclusión de las excluídas. ¿Atiende el Sistema Penitenciario a las necesidades de género?: una visión andaluza". Estudios Penales y Criminológicos XXXIII, pp: 59-95, 2013.

Marina, Sandra. “Cuerpos, resistencia y performatividad, un análisis de los ciertos mecanismos de acción colectiva en una cárcel de mujeres". I Jornadas de 
Sociología. Facultad de Ciencias Sociales, Universidad de Buenos Aires, Buenos Aires, 2015.

Markez, Iñaki; Póo, Mónica (Coord.). Drogodependencias: Reducción de Daños y Riesgos. Euskadi: Observatorio Vasco de Drogodependencias, 2000.

Martínez, Luz María. “Preguntarse sobre el 'Sentido': Trazos de una indefinición necesaria". Athenea Digital: revista de pensamiento e investigación social, 10, pp. 77-89, 2006.

Martos i García, Daniel; Devís Devís, José. “Un día cualquiera en la cárcel: la etnografía-ficción como representación de una investigación”. AIBR: Revista de Antropología Iberoamericana, Vol. 10, №.3, 2015.

McCall, Leslie. "The Complexity of Intersectionality". En Journal of Women in Culture and Society, 30 (3). Chicago: The University of Chicago. 2005.

Medina Dómenech, Rosa María. "Sentir la Historia. Propuestas para una agenda de investigación feminista en la historia de las emociones". Arenal. Revista de historia de las mujeres 19, no 1, pp. 161-199, 2012.

Mendoza Eskola, Gladys, y Catalina Mendoza Eskola. “"Ella, por favor". La victimización de la "diferencia sexual": percepciones, representacionesy decisiones desde la cárcel y el hospital. Un caso de Exclusión". En Sexualidades. Represión, resistencia y cotidianidades, de José Mํㅡ Valcuende del Río y Piedad (coord) Vásquez Andrade, editado por Acongagua. Sevilla, 2016.

Miranda López, Ma Jesus. “Cárceles, ¿para qué?”. Política y Sociedad 39, no 2, pp.377-397, 2002.

Mohanty, Chandra. "De vuelta a "Bajo los ojos de Occidente" la solidaridad feminista a través de las luchas anticapitalistas". En Descolonizando el feminismo: teorías y prácticas desde los márgenes, de Liliana Suárez Navaz y Rosalva (edit.) Hernández Castillo. Madrid: Editorial Cátedra, 2008.

Nari, Marcela; Andrea Fabre et al. Encierro y resistencia en las cárceles de mujeres en Argentina. Editado por Universidad de Buenos Aire. Buenos Aires, 2000. 
Parrini Roses, Rodrigo. "Panópticos y laberintos: subjetivación, deseo y corporalidad en una cárcel de hombres". México D.F: El Colegio de México, Centro de Estudios Sociológicos, Programa Interdisciplinario de Estudios de la Mujer. 2007.

Pascual Gil, Ana. "La reinserción social de mujeres". XVII Premio SIEM de Investigación Feminista "Concepción Gimeno de Flaquer".

Piña, Carlos. Sobre las historias de vida y su campo de validez en las ciencias sociales. Santiago, Chile: FLACSO. 1986

Poó Puerto, Candela. "Qué puede un cuerpo (impaciente). Reflexiones autoetnográficas sobre el cuerpo y la enfermedad". Athenea Digital. Revista de Pensamiento e Investigación Social, pp. 149-168, 2009.

Programa de acciones para la Igualdad entre mujeres y hombres en el ámbito penitenciario. España, Abril de 2009. Disponible en línea http://www.mir.es/INSTPEN/INSTPENI/Programas/Plan_de_Igualdad_en_el_amb ito_penitenciario.pdf

Real Decreto 190/1996, de 9 de febrero, por el que se aprueba el Reglamento Penitenciario (BOE no 40).

Romero Mendoza, Marta. “¿Por qué delinquen las mujeres? Parte II. Vertientes analíticas desde una perspectiva de género". Salud Mental 26, no 1, pp. 32-41, 2003.

Samayoa Herrara, Claudia María. "Vigilar y castigar: Nacimiento de la prisión”. Revista Policía y Seguridad Pública, [S.l.], p. 343-351, nov. 2014.

Sandbeck, Sune."Towards an Understanding of Carceral Feminism as Neoliberal Biopower". Canadian Political Science Association. 2012.

Secretaría General De Instituciones Penitenciarias. Consultada en: http://www.institucionpenitenciaria.es/web/portal/index.html 
Silva-Segovia, Jimena. "The Face of a Mother Deprived of Liberty: Imprisionent, Guilt and Stigma in the Norte Grande, Chile". Affilia, no 31, pp. 98$111,2016$.

Spivak, Gayatri. “¿Puede hablar el sujeto subalterno?” Orbis Tertius, 3 (6), pp.175-235. 1998. En Memoria Académica. Disponible en: http://www.fuentesmemoria.fahce.unlp.edu.ar/art_revistas/pr.2732/pr.2732.pdf

Sudbury, Julia. Global Lockdown. Race, Gender and the Prison-Industrial Complex. Routledge:New York. 2005.

Tratamiento de Mantenimiento con Metadona. Centro para el Control y la Prevención de Enfermedades, 2003. http://www.cdc.gov/spanish/udi/substanceabuse/methadone.pdf

Vartabedian, Julieta. “Mujeres en Prisión: El cuerpo como medio de expresión". Centro Regional de Estudios Interdisciplinarios sobre el delito, 2001. En: http://www.cereid.org.ar/2012/04/investigacion-transferencia-deresultados/\#more-175.

Vidal Fernández, Fernando (coord.). Pan y Rosas: Fundamentos de exclusión social y empoderamiento. Cáritas Española y Fundación FOESSA, 2009.

Villaverde Maza, Noemí. "Angela Davis, mujeres y cárcel”. Mito / Revista Cultural, nํ‥30, 2016.

Wacquant, Loïc. Castigar a los pobres. El gobierno neoliberal de la inseguridad social. Traducido por Margarita Polo. Barcelona: Gedisa, S.A., 2010.

- b) Las dos caras de un gueto. Ensayos sobre marginalización y penalización. Buenos Aires: Siglo XXI, 2010.

Wacquant, Loic. "El matrimonio entre el workfare y el prisonfare en el siglo XXI”. Revista Astrolabio, Nro. 9. Buenos Aires, Argentina, pp.184-205, 2012. 
Walmsley, Roy. World Prison Population List (eleventh edition). 2016. Recuperado de: http://www.prisonstudies.org/sites/default/files/resources/downloads/world_p rison_population_list_11th_edition.pdf

- (2015). World female imprisonment list (third edition). Recuperado de: http://www.prisonstudies.org/sites/default/files/resources/downloads/w orld_fe male_imprisonment_list_third_edition_0.pdf

Yagüe Olmos, Concepción. "Mujeres en prisión. Intervención basada en sus características, necesidades y demandas". Revista Española de Investigación Criminológica, $\quad \mathrm{n}$-5,pp. $1-24, \quad 2007.2$ En: http://www.criminologia.net/pdf/reic/ano5-2007/a52007art4.pdf . 


\section{ANEXOS}

\section{ANEXO I}

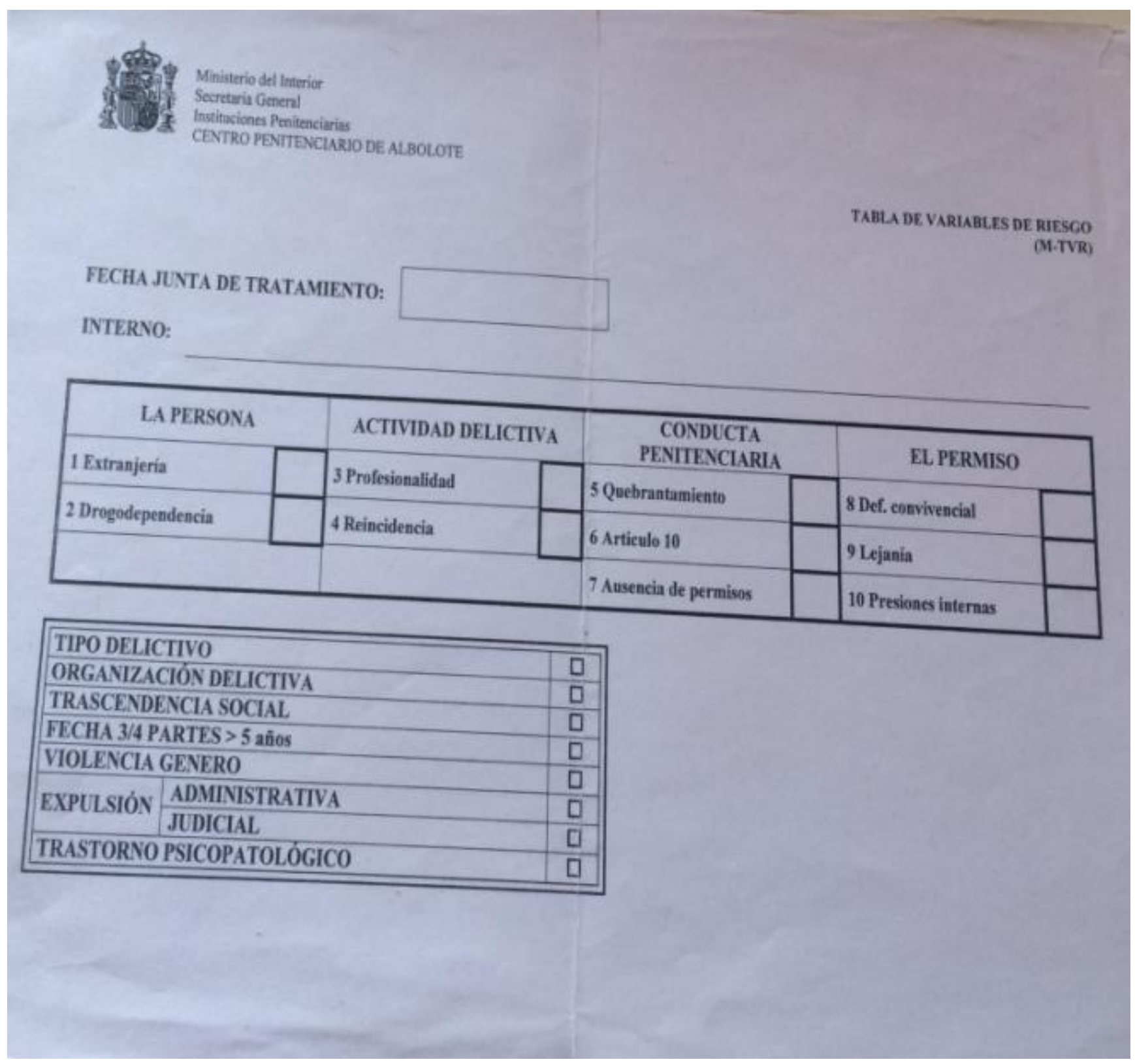

Imagen I: Tabla de Variables de Riesgo M-TVR a cumplimentar para el estudio de la concesión de permisos de salida.

La suma de todas las variables dará un porcentaje de la posibilidad de quebrantamiento del permiso. Aunque esta suma no condiciona el voto favorable o no de cada profesional en la Junta de Tratamiento. 


\section{Imagen II: Definición de las Variables de Riesgo de la Tabla de Variables de}

Riesgo

Esta tabla se rellena y estudia durante la reunión del equipo técnico, previa a la Junta de Tratamiento. Cada variable está asignada a un área y profesional: Trabajadxr Social, Psicólogx, Educadxr de módulo, Jurista.

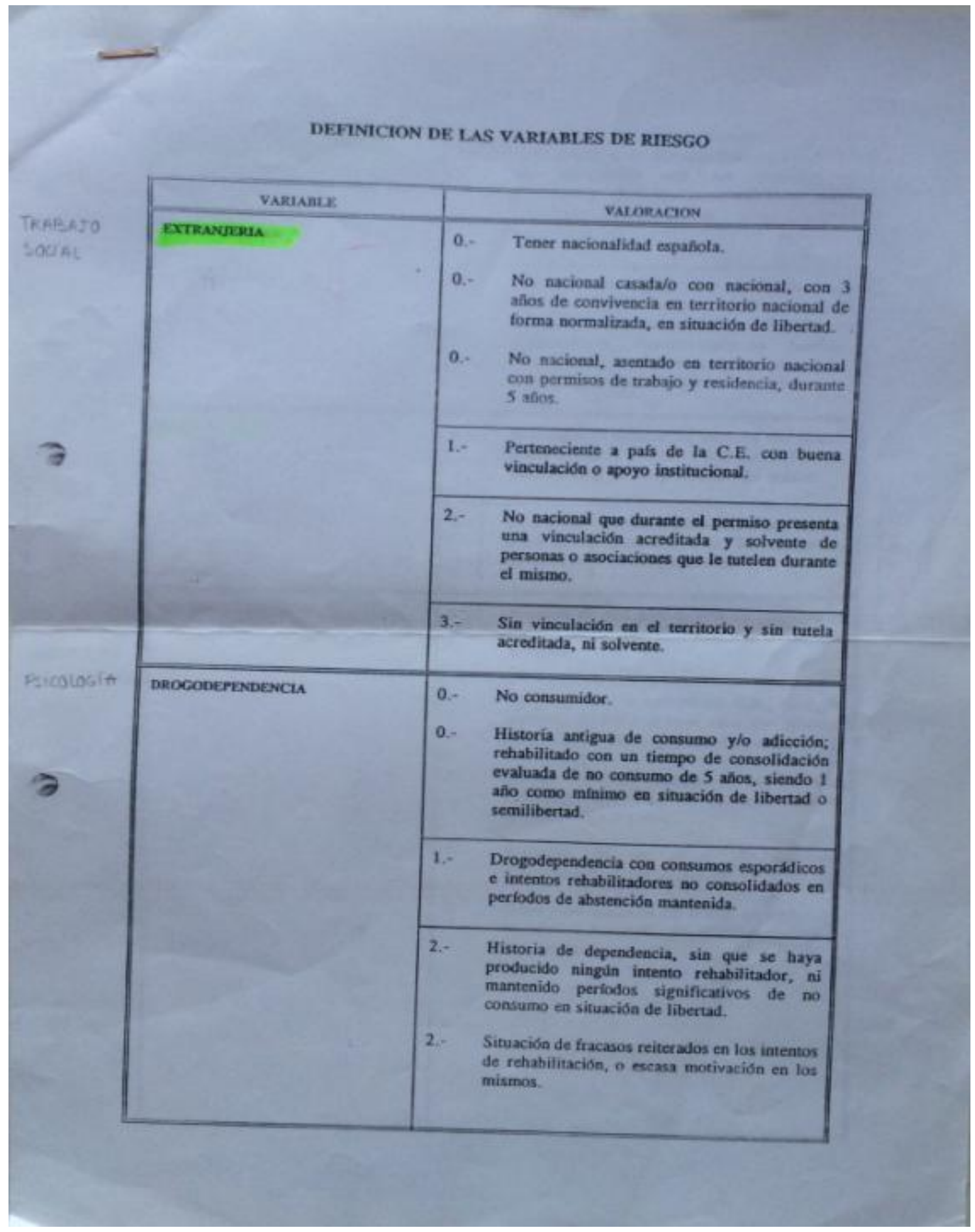




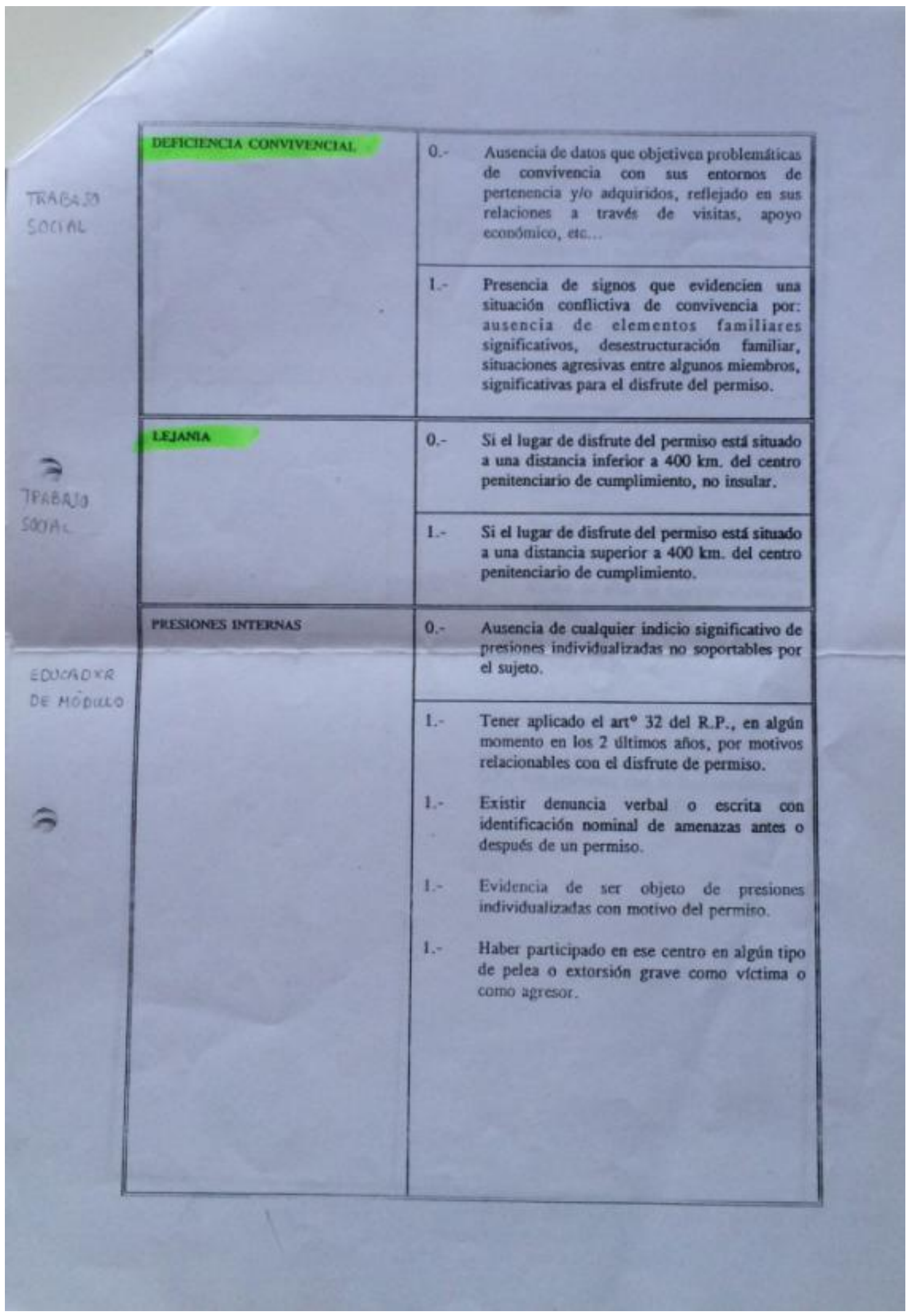




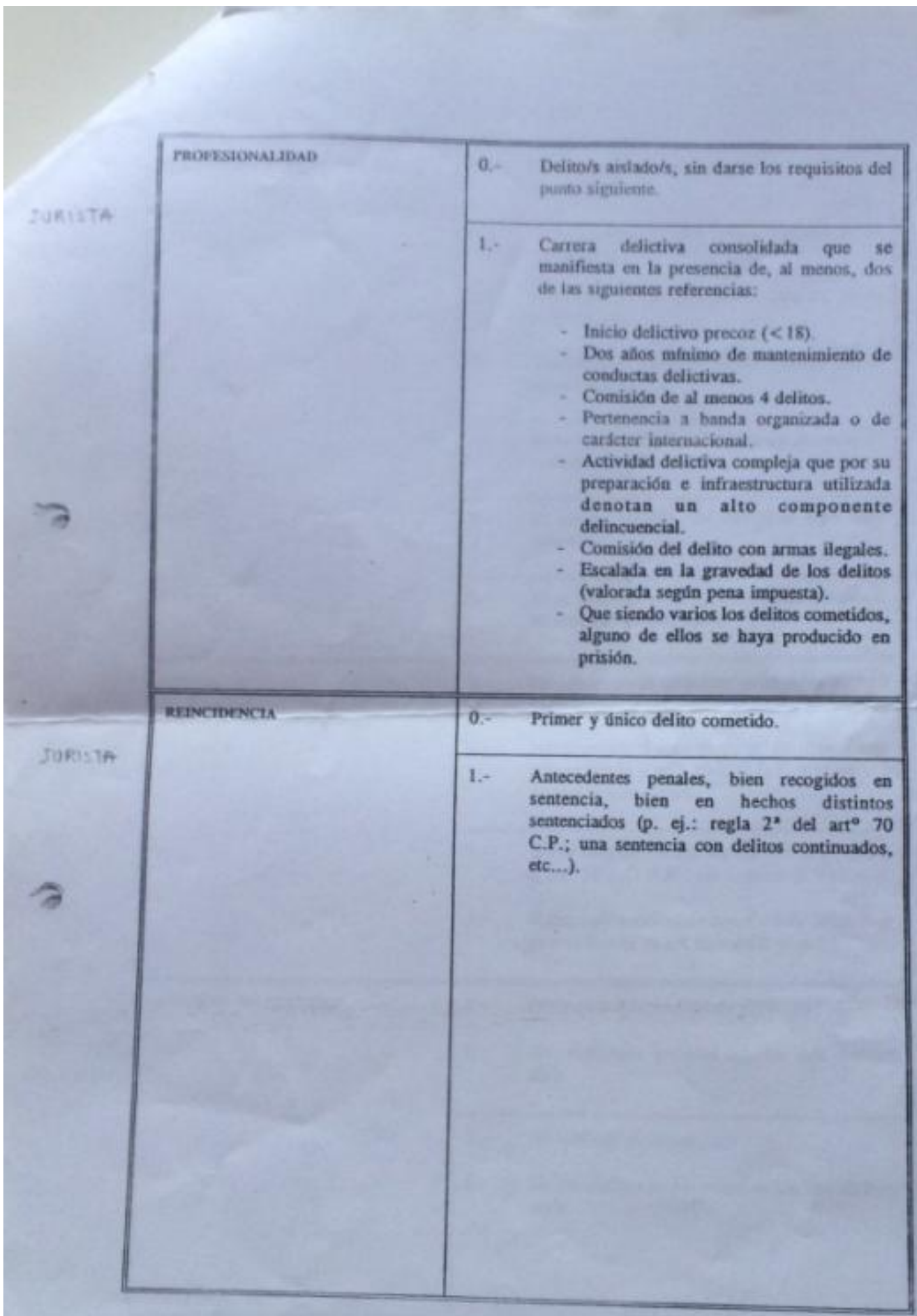




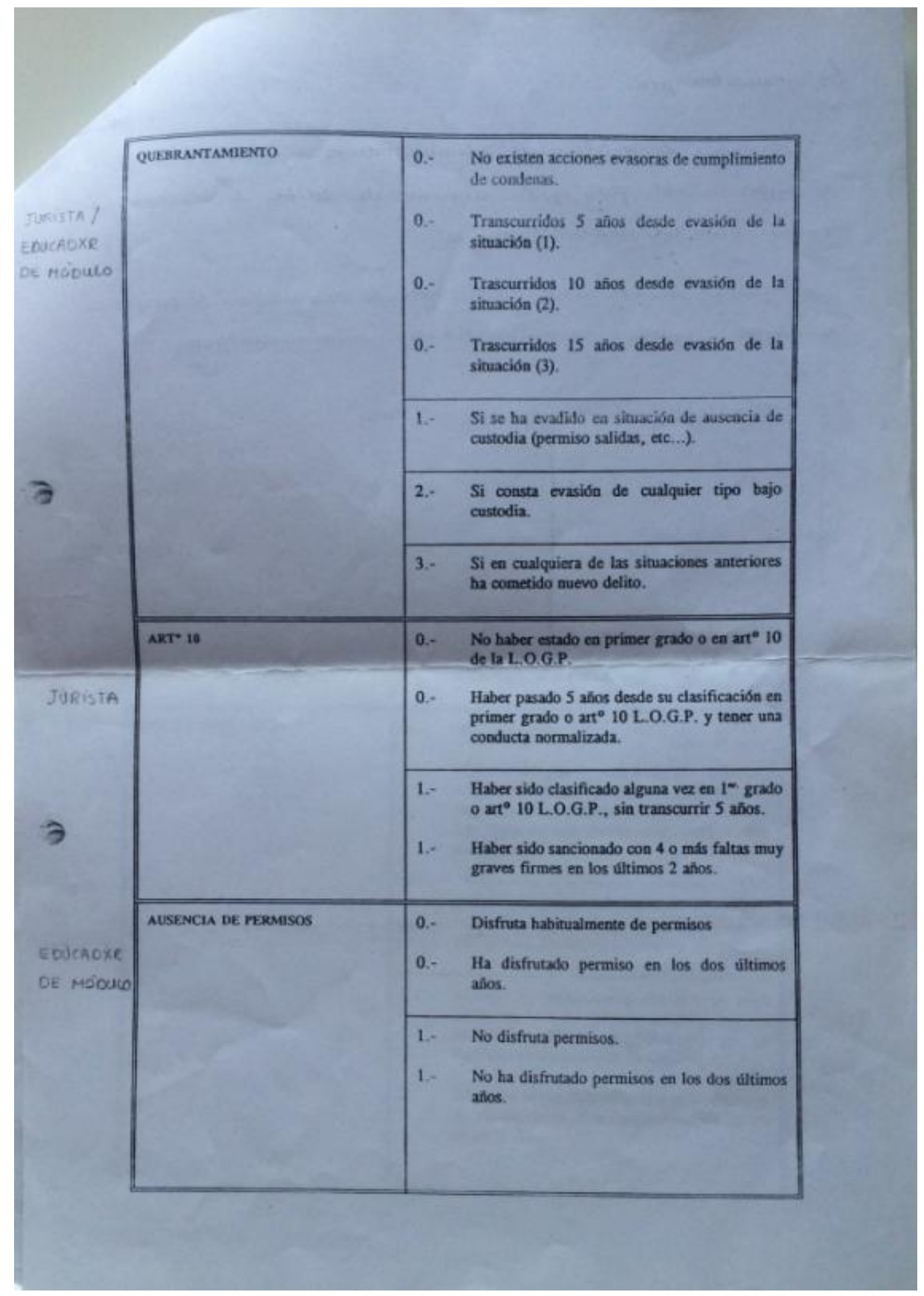




\section{ANEXO II}

\section{Imagen III: Principales categorías de demandas que llegan al departamento de Trabajo Social}

\begin{tabular}{|c|c|}
\hline \multicolumn{2}{|c|}{$\begin{array}{l}\text { PRINCIPALES CATEGORIAS DE DEMANDAS QUE LLEGAN AL } \\
\text { DEPARTAMENTO DE TRABAO SOCIAL: }\end{array}$} \\
\hline DE LOS INTERMOS & OE LAS FAMTLIAS \\
\hline 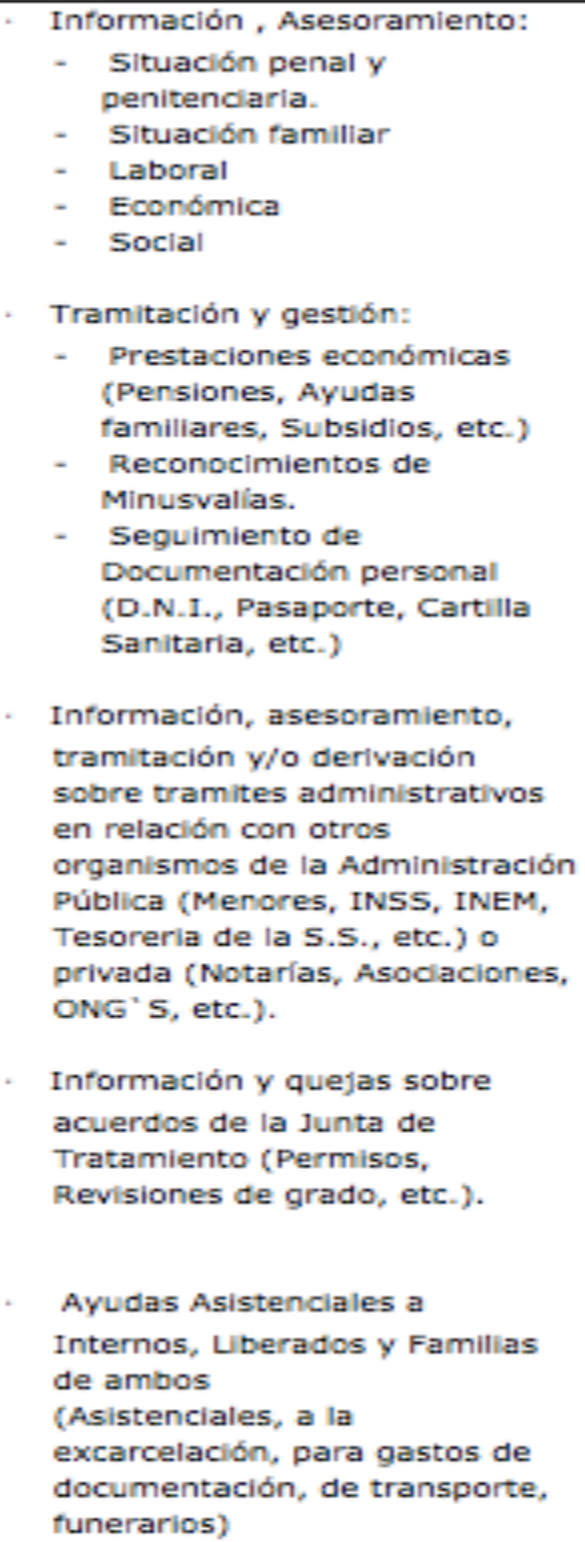 &  \\
\hline
\end{tabular}

Fuente: Cazorla, Jose Manuel. “Funciones de los trabajadores sociales en Prisión”. Blog de Trabajo Social Penitenciario (Comentario enviado el 26 de abril de 2013). En: http://trabajosocialpenitenciario.blogspot.com.es/2013/04/ante-la-avalancha-de-futurasos.html 
Imagen IV: Documento de consentimiento informado entregado a las mujeres.


\section{CONSTRUYENDO UN ESPACIO PARA SENTIRNOS COMMDAS}

Y te preguntarás quién soy yo ... Me presento ...

Querida compañera, buenos días, tardes, noches... me llamo Lorena Valenzuela Vela, tengo 24 años y soy trabajadora social o lo que muchas veces se conoce como asistenta social. Estoy estudiando un máster sobre estudios de las mujeres y de género en la Universidad de Granada y también estoy realizando mi doctorado dentro del Programa Oficial de Doctorado de Estudios de las Mujeres, Discursos y Práctica de Género, en esta misma universidad.

Me gustaría acercarme a ti y conocerte porque estoy llevando a cabo una investigación sobre reinserción de las mujeres que han estado privadas de libertad, con la finalidad de conocer, reconocer, pensar, repensar, plasmar... la diversidad de trayectorias que elegis durante este proceso y las capacidades y habilidades para tomar decisiones y sobreponerse día a día que todas vosotras desarrolláis. Considero muy importante conocer todo esto para poder desarrollar futuras medidas, servicios, recursos y profesionales que conozcan vuestras fortalezas y diseñen intervenciones que se asemejen a vuestras necesidades y demandas.

Me interesa este tema desde que hice mis prácticas de la carrera en el Centro Penitenciario de Albolote y tuve la oportunidad de conocer a muchas de las mujeres que se encontraban allí en ese momento.

Creo que es importante que lleguemos a algunos acuerdos si decides participar para que podamos sentirnos cómodas.

El trabajo que hasta ahora he venido desarrollando de forma individual me gustaría que se convirtiera en un trabajo conjunto contigo y con todas aquellas compañeras que como tú decidan sumarse a esta investigación. Me gustaría que juntas construyéramos otra forma de mirar el proceso de reinserción y el paso por prisión desde vuestras capacidades de acción y decisión. Este sería el objetivo de partida del trabajo, sin embargo, todo va a depender de aquello que vosotras queráis contar, compartir y decidáis que aparezca en el documento final.

Para todo ello, mi intención es mantener, contigo y con las otras mujeres que decidan participar, una serie de conversaciones a partir de una guía de preguntas 
que he elaborado, aunque esto es algo abierto, dinámico y que podemos ir modificando durante todo el proceso, es decir, puedes cambiar preguntas, evitar responderlas o incluir otras nuevas.

Me gustaría que el trabajo fuese colaborativo, por ello si en algún momento deseas o necesitas que yo comparta algo de mi vida, de mi experiencia, de mi forma de pensar, sentir o de las prisiones que todas nosotras guardamos dentro, no dudes en decirme o preguntarme.

Mi propósito es que aprendamos juntas de este proceso, compartamos ideas, sueños, metas, preocupaciones e ilusiones y construyamos algo que a todas nos beneficie. Partiendo siempre del respeto, el reconocimiento, la sinceridad y la confidencialidad de todo lo que se diga, se sienta, se sueñe o se experimente durante este proceso.

Yo me comprometo a tratar de manera respetuosa, sensible y confidencial toda la información. Tendrás la libertad de elegir qué parte de todo lo que hablemos durante el proceso quieres que se plasme en el documento final y qué parte quieres que se quede entre nosotras.

Quiero que sepas que tu participación es voluntaria y que por ello eres libre de abandonar en cualquier momento y sin necesidad de dar explicaciones.

Finalmente, me gustaría elegir contigo el lugar en el que ambas nos sintamos cómodas para conversar, y resaltar que si en algún momento no nos sentimos así, en confianza o con ánimo podemos parar la conversación, despejarnos o hablar sobre otra tema. También podrás decidir si quieres que nuestras conversaciones se recojan con una grabadora de voz o haga uso de mi libreta para tomar algunas anotaciones.

Estas últimas líneas son para tus propuestas y para que plasmes otros acuerdos que consideres necesarios y que nos puedan hacer sentir más cómodas:

Fdo:

\&

En , a de 